\title{
INFLUENCE OF POLYETHYLENE FIBER AND SUPER PLASTICIZER ON THE PROPERTIES OF FIBER REINFORCED CONCRETE
}

\author{
by \\ Iqbal Wahed \\ B.Sc. Engineering Civil, Military Institute of Science and Technology,
}

Dhaka, 2003

A project presented to Ryerson University

\author{
In partial fulfillment of the \\ Requirements of the degree of \\ Master of Engineering \\ In the Program of \\ Civil Engineering
}

Toronto, Ontario, Canada, 2016

(C)Iqbal Wahed, 2016 


\section{AUTHOR'S DECLARATION}

I hereby declare that I am the sole author of this thesis. This is a true copy of the thesis, including any required final revisions, as accepted by my examiners.

I authorize Ryerson University to lend this thesis to other institutions or individuals for the purpose of scholarly research.

I further authorize Ryerson University to reproduce this thesis by photocopying or by other means, in total or in part, at the request of other institutions or individuals for the purpose of scholarly research.

I understand that my thesis may be made electronically available to the public. 


\title{
INFLUENCE OF POLYETHYLENE FIBER AND SUPER PLASTICIZER ON THE PROPERTIES OF FIBER REINFORCED CONCRETE
}

\author{
Iqbal Wahed, Master of Engineering, 2016 \\ Department of Civil Engineering \\ Ryerson University, Toronto
}

\begin{abstract}
This research concentrated on high strength Fiber Reinforced Concrete (FRC) with polyethylene fibers. Four different FRC mixtures having different dosage of superplasticizer and fiber contents were investigated for fresh state (flowability and temperature development/setting time), mechanical properties (compressive/flexural strength, modulus of elasticity and fracture energy), durability characteristics (rapid chloride permeability) and microstructure (using scanning electron microscopy 'SEM'). All FRCS showed high strength development with low ductility (or strain hardening behavior). Increase of fiber content increased the tensile strength and fracture energy of FRCs. The SEM confirmed dense concrete matrix with stronger interfacial transition zone. No significant influence of superplasticizer (at the specified range of dosages) on the properties of FRCs was observed. The use shorter fiber compared to longer ones (18 mm used in this study) at lower dosages could improve ductility and flowability of the FRCs.
\end{abstract}




\section{ACKNOWLEDGEMENTS}

I would like to take this opportunity to express my sincere and deepest gratitude to my supervisor Dr. Khandaker M. Anwar Hossain for his dedication, guidance, support and patience during the development of this project. This project is the result of the belief and encouragement of my supervisor that made this project possible. I would like to thank Dr. Anwar Hossain for his kind words and always willingness to help, that pulled me through this project.

I would like to thank Ryerson's Civil Engineering Technicians - especially Min Yao and Nadal Jaalouk, for always being there and their prompt help with laboratory equipment's and procedures.

Finally, special gratitude goes to my family. Without their constant love, support and sacrifices my success would not be possible. 


\title{
Dedication
}

\author{
To My Family
}

\&

To My Teacher who Guide me on my Path 


\section{TABLE OF CONTENTS}

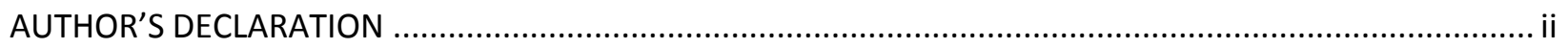

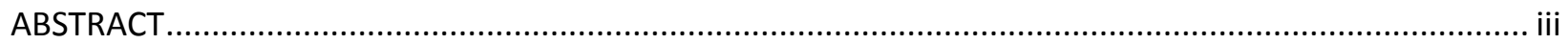

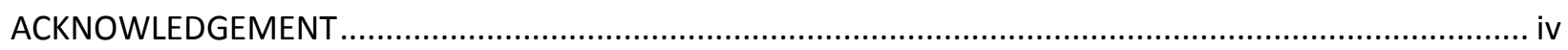

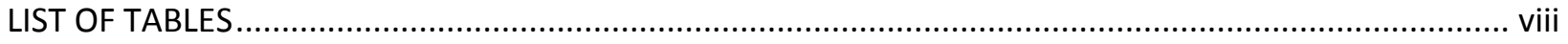

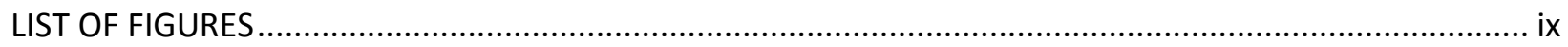

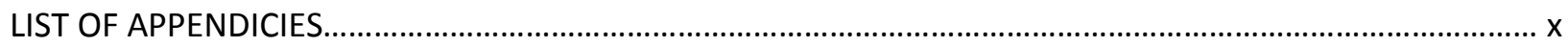

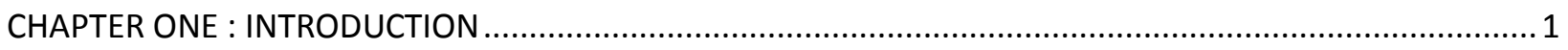

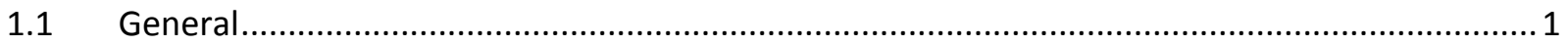

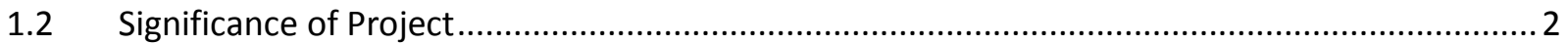

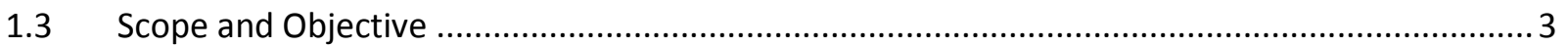

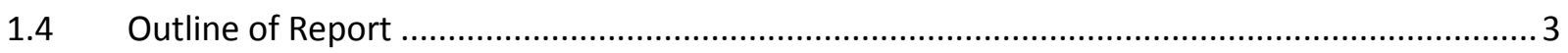

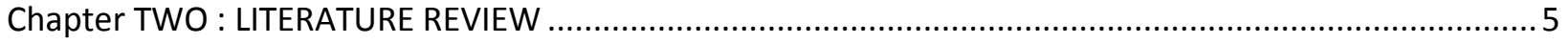

2.3 Fiber Reinforced Concrete - Applications, Research, Types and Properties............................. 6

2.3.1 Steel Fiber Reinforced Concrete (SFRC) …................................................................. 9

2.3.2 Plastic Fiber Reinforced Concrete (PFRC) ........................................................... 11

2.3.3 Synthetic Fiber Reinforced Concrete ........................................................................ 16

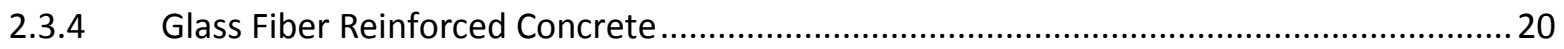

2.3.5 Carbon Fiber Reinforced Concrete............................................................................ 21

2.3.6 Natural Fiber Reinforced Concrete ........................................................................ 22

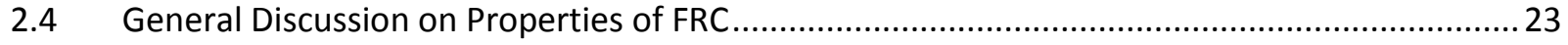

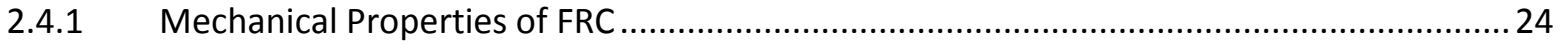

2.4.2 Durability Properties, Rapid Chloride Permeability Test (RCPT) ................................... 24

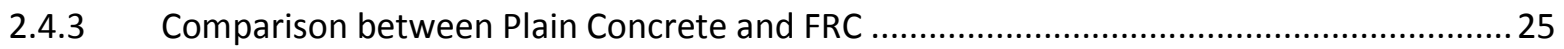

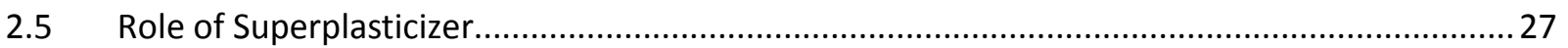

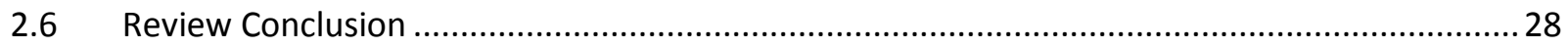

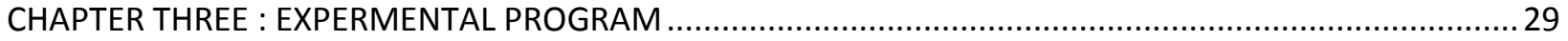

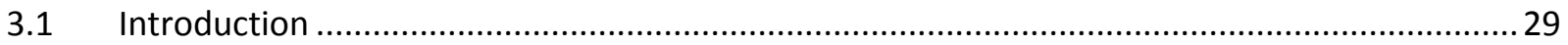




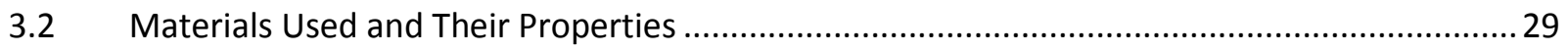

3.3 Mixture Design, Preparation and Mixing Procedures........................................................... 32

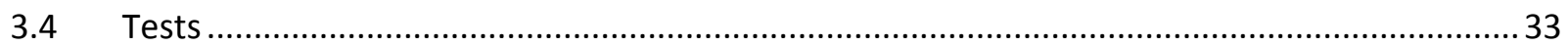

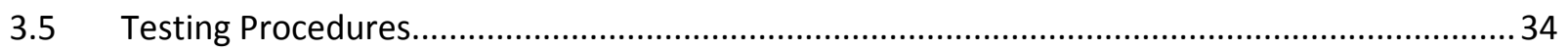

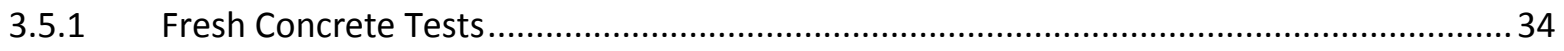

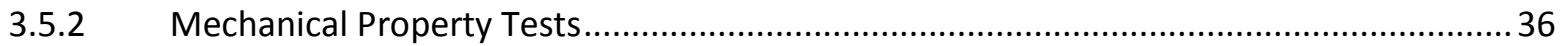

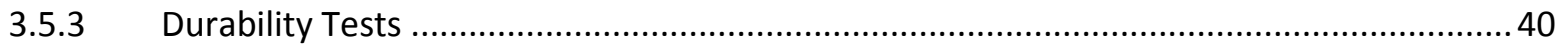

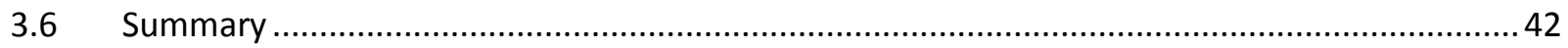

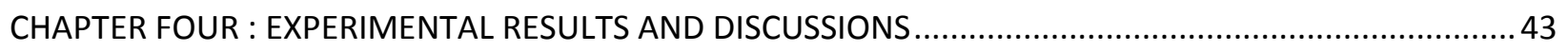

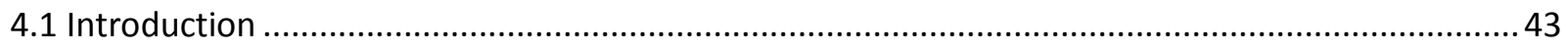

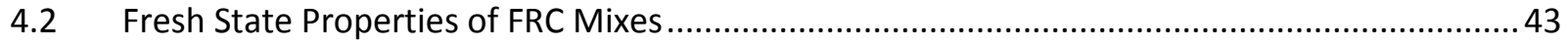

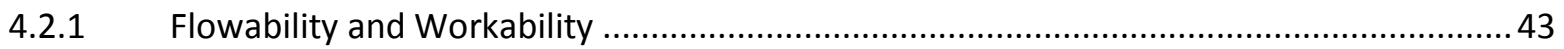

4.2.2 Time -Temperature Response and Setting Time ....................................................... 43

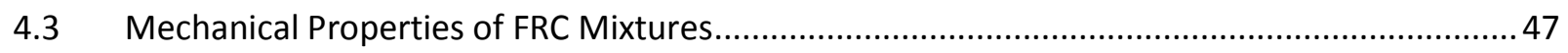

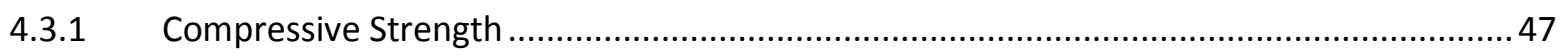

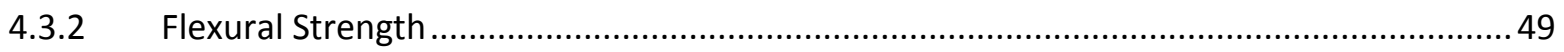

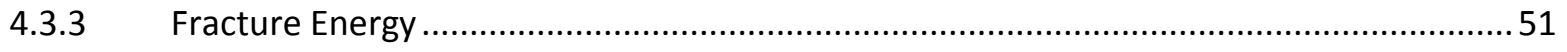

4.3.4 Modules of Elasticity and Stress-Strain Characteristics ................................................. 53

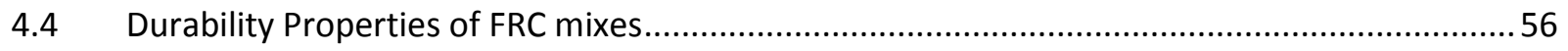

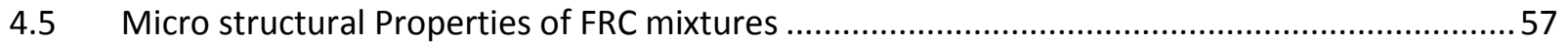

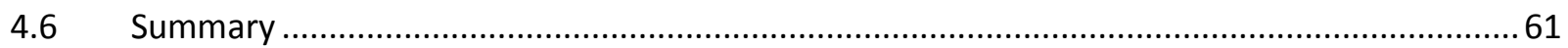

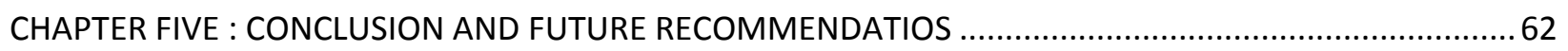

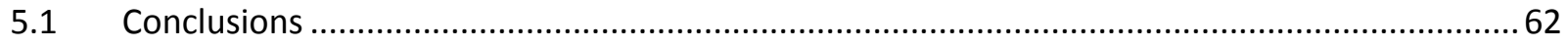

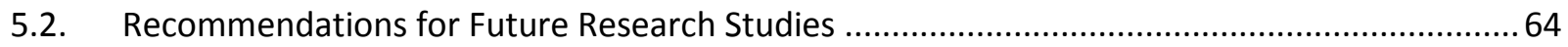

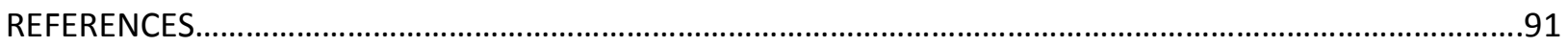




\section{LIST of TABLES}

Table 2.1 : Comarison of Different Types of Fibers used in FRC ........................................... 8

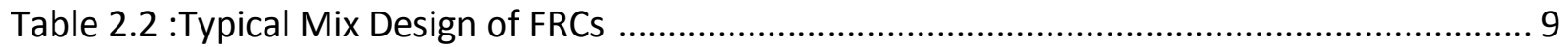

Table 3.1: Chemical and Physical Properties of Portland Cement ........................................ 29

Table 3.2 : Chemical and Physical Properties of Silica Fume ................................................ 30

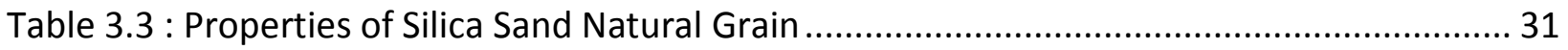

Table 3.4 : Geometry and Mechanical /Physical Properties of PE Fiber ................................. 32

Table 3.5 : Mix Design of FRC Mixtures ............................................................................... 32

Table 4.1: Summary of Temperature-Time Evolution and Setting Time ................................ 46

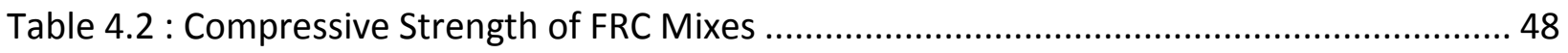

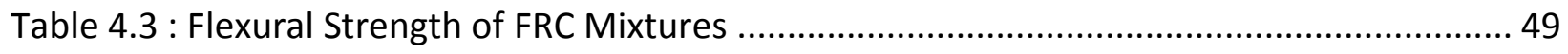

Table 4.4 : RCP Test Summary of FRC Mixes..................................................................... 56

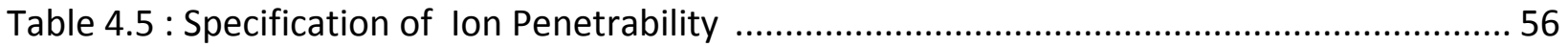

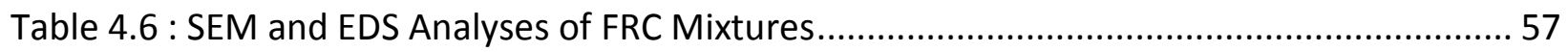




\section{LIST OF FIGURES}

Figure 2.1: Glass Fiber Reinforced Concrete Building Project at California,USA........................ 7

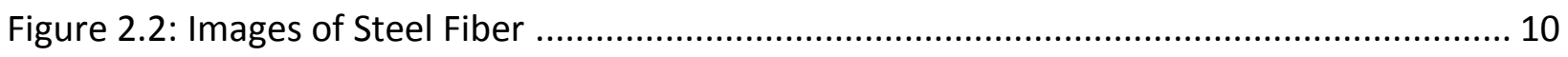

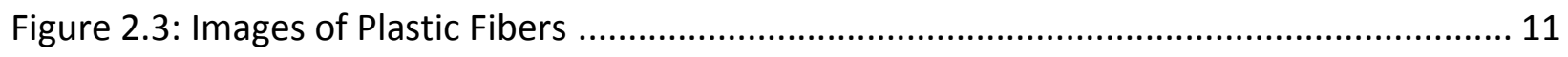

Figure 2.4: Images of Polyethylene Fiber..................................................................... 12

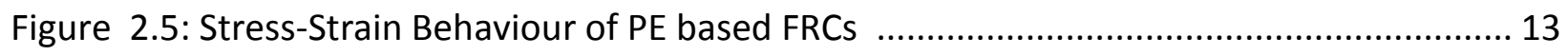

Figure 2.6: Comparison of Flexural and Deflection Capacities FRC Composites ..................... 15

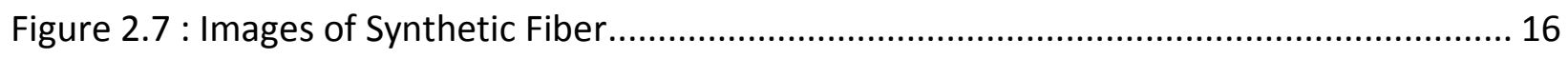

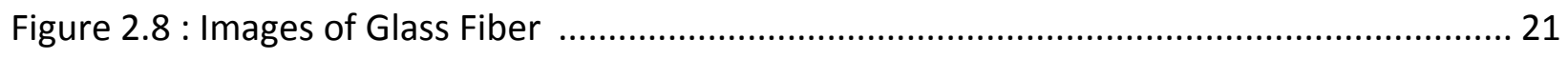

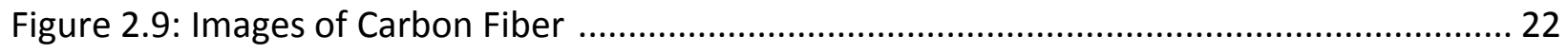

Figure 2.10: Images of Natural Fibers: Coconut ,Elephant grass and Wood ........................... 23

Figure 2.11: Tensile Load-Deformation Responses of Plain Concrete without Fiber and FRC .... 25

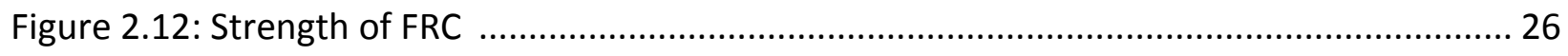

Figure 2.13 : Effect of Superplasticizer use in Flowable Concrete ....................................... 27

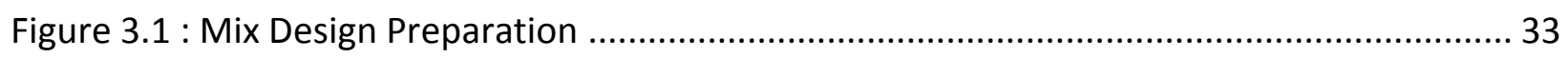

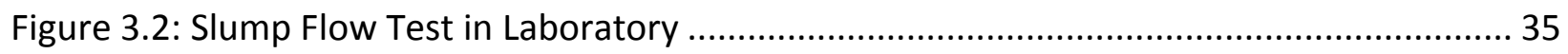

Figure 3.3 : Sample and Set up of Time-Temperature Curve Test ........................................ 36

Figure 3.4 : Compressive Strength Test on Cylinder and Cube Sample as per ASTM Standard ... 37

Figure 3.5 : Beam Sample for Flexural Strength ............................................................ 38

Figure 3.6 : Flexural Strength Set Up and Beam Sample Under Four Point Loading.................. 38 
Figure 3.7 : Notched Beam and Test Setup for Fracture Energy 39

Figure 3.8 : Fracture Energy Test Setup and Failed Notched Beam Specimen ........................ 40

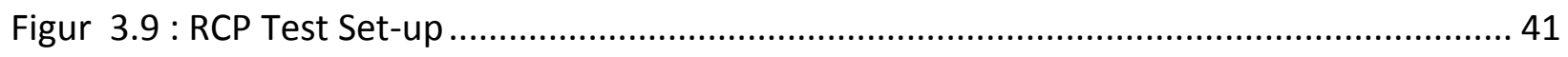

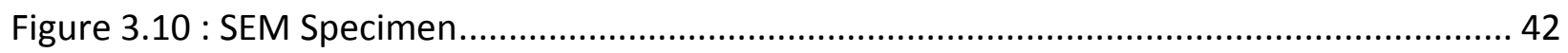

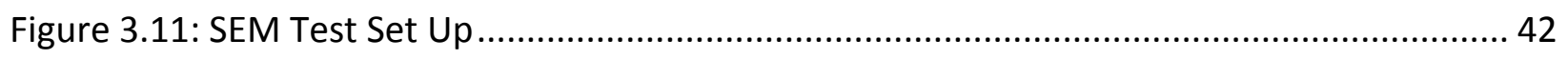

Figure 4.1 : Time vs.Temperature Graph for FRC Mix P19 S26 .......................................... 44

Figure 4.2: Time vs.Temperature Graph for FRC Mix P19 S26 .......................................... 44

Figure 4.3: Time vs. temperature Graph for P10 S26 .................................................... 45

Figure 4.4 : Comparison of Time vs. Temperature Responses of FRC Mixes ......................... 45

Figure 4.5: Evolution of Cube Compressive Strength with Age ....................................... 48

Figure 4.6 : Flexural Load-Displacement Responses of FRC Mixtures ................................... 50

Figure 4.7 : Efeects of Short Fiber on Micro-Cracking and Long Fiber on Macro-Cracking ......... 51

Figure 4.8: Load -Displacement Responses of FRC Mistures from Fracture Energy Tests .......... 52

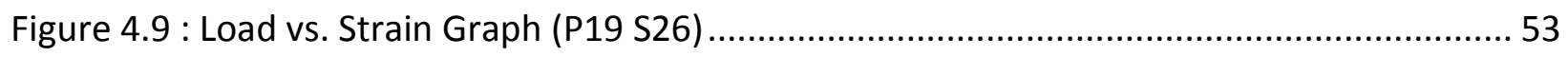

Figure 4.10 : Load vs.Strain Graph ( P10 S26) .................................................................. 53

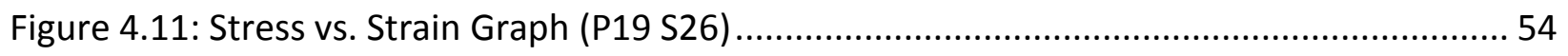

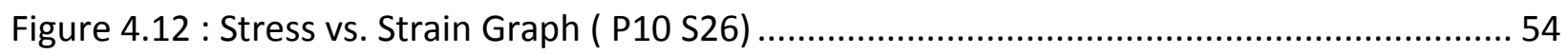

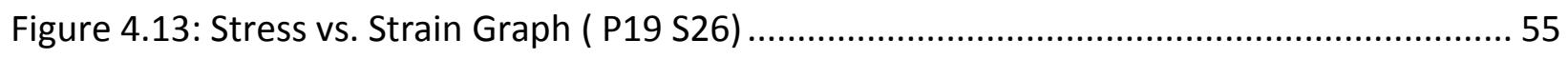

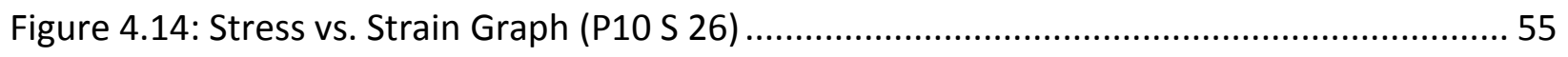

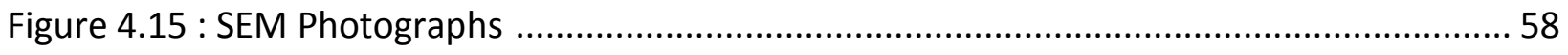

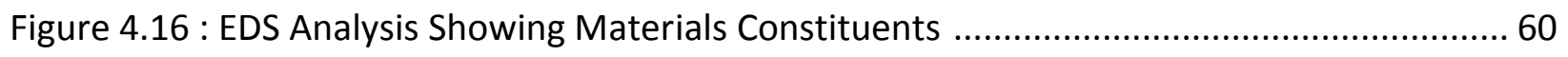




\section{LIST OF APPENDICES}

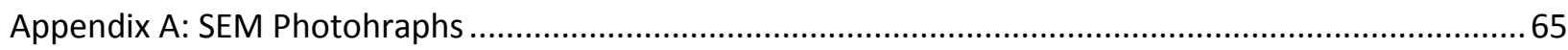

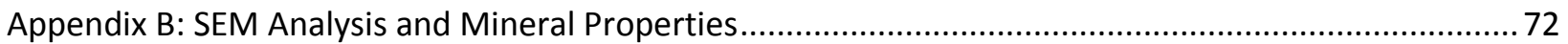




\section{NOTATION AND ABBREBIATIONS}

\begin{tabular}{|c|c|}
\hline CSW & Coupled Shear Wall \\
\hline DSCWs & Double Skin Composite Walls \\
\hline $\mathrm{E}$ & Modules of Elasticity \\
\hline ECC & Engineered Cementitious Composite \\
\hline EDS & Energy Dispersive Spectroscopy \\
\hline FRC & Fiber Reinforced Concrete \\
\hline FRSCC & Fiber Reinforced Self Compacting Concrete \\
\hline GU & General Use \\
\hline HPC & High Performance Concrete \\
\hline HPFRCC & High Performance Fiber Reinforced Cementitious Composites \\
\hline HMPE & High Modulus Polyethylene \\
\hline HPPE & High Performance Polyethylene Fiber \\
\hline HSHDC & High Strength high ductility concrete \\
\hline ITZ & Interfacial Transition Zone \\
\hline Le & Embedment Length \\
\hline PE & Polyethylene fiber \\
\hline PVA & Polyvinyl Alcohol \\
\hline RCPT & Rapid Chloride Permeability Test \\
\hline SEM & Scanning Electronic Microscope \\
\hline
\end{tabular}


$t_{500} \quad$ Time to reach $500 \mathrm{~mm}$ slump flow

UHMWPE Ultra High Molecular Weight Polyethylene

ULFRC Ultra-Lightweight Fiber Reinforced Concrete

VHSC Very High Strength Concrete

VMA Viscosity Modifying Admixture

$\sigma$

Bond Stress 


\section{CHAPTER ONE}

\section{INTRODUCTION}

\subsection{General}

Fiber Reinforced Concrete (FRC) is getting very popular in today's construction world. Extensive research has been conducted this field and still; there are a lot of scopes to do development on FRC technology. Steel fiber was most commonly used in FRC for the last decades. However, other fibers (natural and artificial) like polyvinyl alcohol (PVA), glass, polyethylene (PE), plastic, nylon, waste rubber, jute, bamboo etc. are also found very useful in FRC.

Over the last decades new classes of FRC were developed. FRCs at the frontiers of these classes includes Very High Strength Concrete (VHSC) with compressive strength of 200MPa and Engineered Cementitious Composite (ECC) with tensile ductility of 3-6\% and multi-cracking characteristics. The development of these two classes of FRCs was based on two different design philosophies that targeted two different structural performances. VHSC and similar high strength concretes were designed to achieve size efficiency for very large structures and to provide additional strength margin for strategically critical and protective structures. On the other hand, ECC and similar High Performance Fiber Reinforced Cementitious Composite were developed to ensure ductility of structural elements and massive energy absorption in the face of extreme load /displacement events such as earthquakes. A combination of high strength and high ductility in one concrete material is highly desirable to ensure resiliency of critical structures under extraordinary loads/displacements which is the motivation for this research project. 
In this research project, a detailed study was carried out on FRC mixtures with polyethylene fiber in an attempt to achieve high strength, ductility and energy absorbing capacity. For proportioning of high strength FRC, an ultra-high strength FRC mix developed at Ryerson University was used as a basis to come with optimized mix design to produce high strength, ductility, energy absorbing capacity and durability performance.

\subsection{Significance of Project}

The performance of FRC with steel fibers with traditional mix design was the subject matter of numerous research studies. The primary function of FRC is to provide high tensile ductility and strain capacity while maintaining self-controlled tight micro-crack widths (Sahmaran et al., 2007; Li et al., 2011; Afefy and Mahmoud, 2014). Cost-effective highly flow able green ductile ECCs made of locally available materials were developed recently at Ryerson University (Hossain 2014; Sherir et al., 2014). ECC with high strain capacity (300 to 500 times greater than normal concrete) while maintaining low crack widths (less than $60 \mu \mathrm{m}$ ) could resolve many problems and improving constructability (faster construction and better concrete) as well as enhancing ductility and durability (Hossain and Vinay, 2012).

Extensive research has been conducted on FRC using different types and combination of fibers particularly steel fibers. However, the role of different types of fibers on fresh, mechanical and durability properties still needs to be investigated. The synergy between fibers and superplasticizers in the production of high strength and high ductility FRC is still unknown for many kinds of fibers. This research makes an effort to study fresh state, mechanical and durability properties of high strength polyethylene FRC based on range of tests including scanning electron microscopy (SEM). The combined influence of polyethylene fiber and superplasticizer dosage on FRC properties is studied and results of this research will contribute to the existing high strength FRC technology. 


\subsection{Scope and Objective}

Four fiber reinforced concrete (FRC) mixtures with different amount of polyethylene (PE) fiber and superplasticizer were investigated. The main scope of this research aim was to study the influence of dosages of superplasticizer and PE fiber on the properties of four chosen FRC mixtures. The detailed objectives of this research are to:

- Investigate fresh state properties such as: flowability, temperature evolution with time and setting time.

- Investigate mechanical properties such as compressive/flexural strength, modulus of elasticity and fracture energy at different ages

- Determine durability properties in terms of rapid chloride permeability 'RCP'.

- Carry out micro structural characteristics through scanning electron microscopy (SEM) and Energy Dispersive Spectroscopy (EDS). The main aim was to study the influence of dosages of superplasticizer and PE fiber on the properties of FRC mixtures.

- Make recommendations for the production of high strength FRC mixtures with PE fibers and suggest how to achieve high ductility and strain hardening behavior.

\subsection{Outline of Report}

This report consists of five 5 chapters which can be outlined as follows:

Chapter One provides a brief introduction about the fiber reinforced concrete, the significance of this research followed by the objectives of this study. 
Chapter Two presents a literature review on the development of fiber reinforced concrete and its different properties. In addition, recent investigations on FRC made of different types of fibers are presented based on previous research studies

Chapter Three provides a brief description of the experimental program including properties of materials, tests and testing procedures.

Chapter Four describes experimental results and the influence of fiber and superplasticizer dosages on fresh, mechanical and durability properties as well as micro structural characteristics of FRC mixes.

Chapter Five presents the main conclusions and recommendations for future research studies. 


\section{Chapter TWO}

\section{LITERATURE REVIEW}

\subsection{Introduction}

Fiber reinforced concrete (FRC) is getting popularity for its high strength and high ductility behavior. In this chapter, the development and recent investigations on FRC made of different types of fibers are presented based on previous research studies.

\subsection{Development of Fiber Reinforced Concrete (FRC)}

The development of FRC material has undergone a number of phases. In the 1960's, research demonstrated the effectiveness of short steel fibers in reducing the brittleness of concrete (Romauldi and Mandel, 1964). This development has continued with expansion to a variety of other fibers, such as glass, carbon, synthetics and natural fibers (Vandewalle et al., 2003).

Beginning as early as the 1980's, interest in creating a fiber reinforced concrete material with tensile ductility has been gaining popularity. Within FRC, the toughness of the materials increased, but no change in ductility is attained.

Attempts in achieving tensile ductility in concrete material have been made (Aveston et al., 1971), and later by Krenchel and Stang (1989), who demonstrated that with continuous aligned fibers, high tensile ductility hundreds of times that of normal concrete can be attained. Naaman and Reinhardt (2003) classified such material as High Performance Fiber Reinforced Cementitious Composites (HPFRCC).

In recent years, two new classes of HPFRCC have emerged. Ultra-high strength concrete (UHSC) which has high tensile strength of $12 \mathrm{MPa}$ and a ductility of $0.02-0.06 \%$ (Chanvillard and Rigaud, 
2003), and Engineered cementitious composite (ECC) originally developed at the University of Michigan, with a typical moderate tensile strength of 4-6MPa and a higher ductility of 3-5\% (Li, 1993; Fischer et al., 2003,2006).

Ranade (2013) developed fiber reinforced, high strength high ductility concrete (HSHDC) which possess a rare combination of very high compressive strength $166 \mathrm{MPa}$ and a very high tensile ductility of $3.4 \%$ strain capacity. The unique performance of HSHDC was achieved through deliberate selection of fiber; matrix and their interface, guided by the micromechanics based design principles for engineered cementitious composites.

\subsection{Fiber Reinforced Concrete - Applications, Research, Types and Properties}

Concrete is relatively brittle, and its tensile strength is typically only about one tenths of its compressive strength. Regular concrete is therefore normally reinforced with steel reinforcing bars. For many applications, it is becoming increasingly popular to reinforce the concrete with small, randomly distributed fibers. Their main purpose is to increase the energy absorption capacity and toughness of the material, but also increase tensile and flexural strength of concrete.

Concrete containing a hydraulic cement, water, fine or fine and coarse aggregate and discontinuous discrete fibers is called fiber-reinforced concrete (FRC). It may also contain pozzolans and other admixtures commonly used in conventional concrete. Fibers of various shapes and sizes produced from steel, plastic, glass, and natural materials are being used.

However, for most structural and nonstructural purposes, steel fiber is the most commonly used of all the fibers.

The areas of application of FRC are listed but are not limited to; thin sheets, shingles, roof tiles, pipes, prefabricated shapes, panels, short Crete, curtain walls, slabs on grade, precast 
elements, composite decks, vaults, safes, impact resisting structures. Figure 2.1 shows a building made of glass fiber reinforced concrete in California, USA.

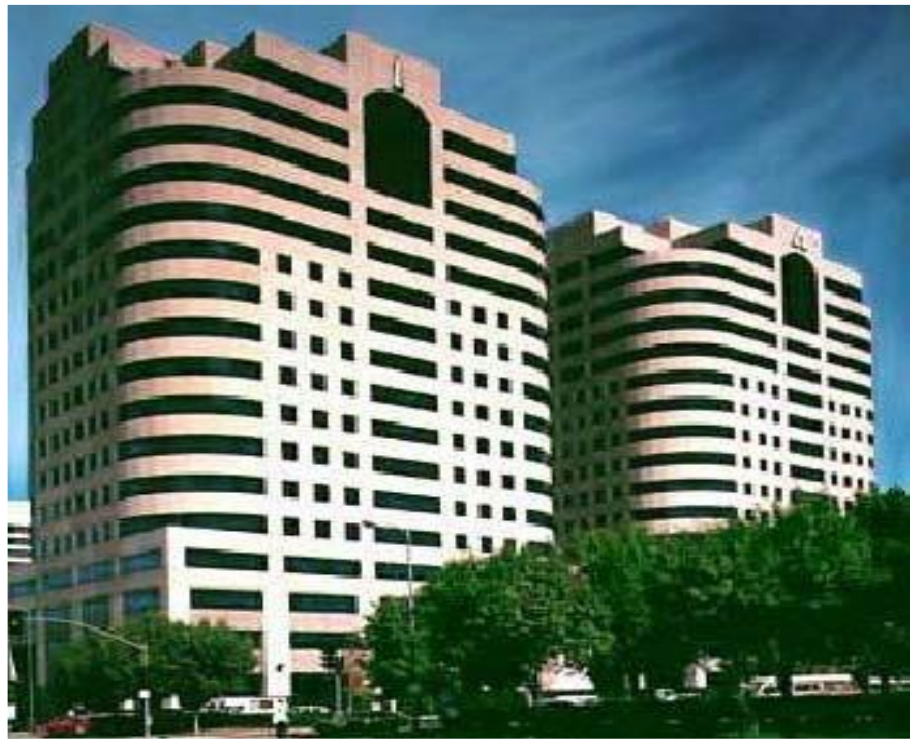

Figure 2.1: Glass Fiber Reinforced Concrete Building Project at Trillium Building Woodland Hills, California (Nemati, 2005)

The different fibers used in FRC have different characteristics and performance. A comparison of fiber types and properties used in FRCs is shown at table 2.1. Types of Fibers Include:

- Steel

- Plastic (Polyester, Polypropylene, Polyethylene, Agamid)

- Synthetic ( Polyvinyl alcohol)

- Glass

- Carbon

- Natural Materials (Wood Cellulose, Bamboo, Jute, Elephant grass). 
Table 2.1: Comparison of Different Types of Fibers used in FRC (Nemati, 2005)

\begin{tabular}{|c|c|c|c|c|c|}
\hline \multirow[t]{2}{*}{ Fiber Types } & \multicolumn{5}{|c|}{ Geometric dimensions and materials properties } \\
\hline & $\begin{array}{c}\text { Diameter, } \\
\mathrm{mm}\end{array}$ & $\begin{array}{l}\text { Specific } \\
\text { Gravity }\end{array}$ & $\begin{array}{c}\text { Modulus of } \\
\text { Elasticity, } \\
\text { GPa }\end{array}$ & $\begin{array}{c}\text { Tensile } \\
\text { Strength, } \\
\mathrm{MPa}\end{array}$ & $\begin{array}{l}\text { Strain at } \\
\text { Failure\% }\end{array}$ \\
\hline High Tensile Steel & 0.2 & 7.8 & 200 & $5-25$ & 3.5 \\
\hline Glass & $0.1-.127$ & $2.5-2.7$ & $71-74$ & $7-50$ & $3.6-4.8$ \\
\hline \multicolumn{6}{|l|}{ Polymeric } \\
\hline Polypropylene & $0.50-1.4$ & 0.9 & 3.4 & $15-20$ & 8 \\
\hline Polyethylene & $0.25-0.41$ & 0.96 & $13-25$ & $6-60$ & $3-80$ \\
\hline Polyester & $0.1-0.76$ & 1.38 & $9-10$ & $15-32$ & $10-50$ \\
\hline Polyvinyl Alcohol & & 1.3 & & $32-65$ & \\
\hline Carbon & 0.9 & 1.9 & $23-55$ & $50-370$ & $0.5-1.5$ \\
\hline \multicolumn{6}{|l|}{ Natural } \\
\hline Wood Cellulose & 3 & 1.5 & $9-15$ & $9-25$ & - \\
\hline Bamboo & $1.2-2.5$ & 1.5 & $33-34$ & $10-14$ & - \\
\hline Jute & $2.5-4.5$ & $1.02-1.04$ & $37-38$ & $7-10$ & $1.5-1.9$ \\
\hline Elephant Grass & 10 & - & 5 & 5 & 3.6 \\
\hline
\end{tabular}

Typical mix designs of few FRC mixtures are presented in table 2.2 from previous research studies (Hillerborg, 1983; Li, 2013; Wang, 2003; ChandramouliK, 2010). 
Table 2.2: Typical Mix Design of FRCs (Hillerborg, 1983; Li, 2013; Wang, 2003; Chandramoulik, 2010)

\begin{tabular}{|c|c|c|c|c|c|}
\hline Property & $\begin{array}{l}\text { Synthetic } \\
\text { fiber FRC } \\
\left(\mathrm{kg} / \mathrm{m}^{3}\right)\end{array}$ & $\begin{array}{c}\text { Plastic fiber } \\
\text { FRC (ratio by } \\
\text { weight) }\end{array}$ & $\begin{array}{l}\text { PVA Fiber } \\
\text { FRC } \\
\left(\mathrm{kg} / \mathrm{m}^{3}\right)\end{array}$ & $\begin{array}{c}\text { Glass fiber } \\
\text { FRC } \\
\left(\mathrm{kg} / \mathrm{m}^{3}\right)\end{array}$ & $\begin{array}{c}\text { Carbon fiber } \\
\text { FRC } \\
\left(\mathrm{kg} / \mathrm{m}^{3}\right)\end{array}$ \\
\hline Cement & $446-559$ & 1 & 583 & 318 & 546 \\
\hline Sand & $1438-1679$ & & 467 & 666 & 694 \\
\hline Aggregate & & & & 732 & 1050 \\
\hline Fly Ash & & & 700 & & \\
\hline Fiber & $35-157$ & 0.0234 & 26 & 0.55 & 32 \\
\hline $\mathrm{w} / \mathrm{c}$ ratio & $0.40-0.45$ & & & 178 & \\
\hline Silica Sand & & 0.967 & & & \\
\hline Superplasticizer & & 0.0153 & 19 & & 8.19 \\
\hline Water & & 0.208 & 298 & 1118 & 169 \\
\hline
\end{tabular}

\subsubsection{Steel Fiber Reinforced Concrete (SFRC)}

It is well established that one of the important properties of steel fiber reinforced concrete (SFRC) is its superior resistance to cracking and crack propagation. As a result of this ability to arrest cracks, steel fiber composites possess increased extensibility and tensile strength, both at first crack and at ultimate age, particular under flexural loading, In addition, the fibers are also able to hold the matrix together even after extensive cracking. Images of steel fiber of different configurations are shown in figure 2.2. 


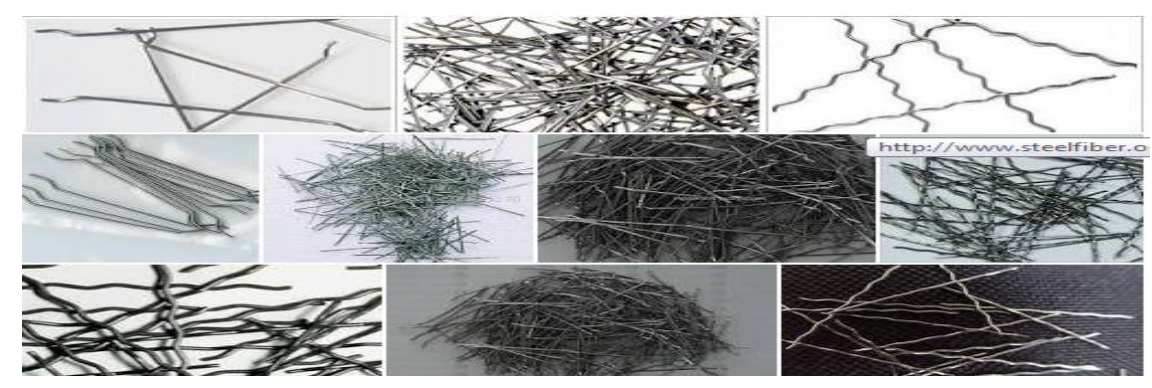

Figure 2.2: Images of Steel Fiber (Johnson, 2001)

Li $(2012,2001)$ studied the influence of the fiber orientation $\left(0^{\circ}, 30^{\circ}\right.$ and $\left.60^{\circ}\right)$, as well as the embedded length $(10,20$ and $30 \mathrm{~mm})$ on the fiber pullout behavior for SFRC. In general, maximum pullout load had an almost linear increase with the embedded length for both hooked and straight fibers. However, this increase was more significant on the straight fibers, since the pullout response of hooked fibers, regard less the fiber embedded length, is predominantly influenced by the mobilization and straightening of the fiber hooked-end. Regarding the effect of the fiber orientation angle, the maximum pullout load increased up to an inclination angle of $30^{\circ}$ and then decreased for a $60^{\circ}$ inclination angle. For both hooked and straight fibers the highest maximum pullout load was observed for an inclination angle of $30^{\circ}$

Wille (2010) focused on the pull-out behavior of high strength straight smooth steel fibers embedded in ultra-high performance concretes (UHPC). These fibers are generally brass-coated and widely used in research studies and applications of UHPC and FRCs. The UHPCs used had a compressive strength ranging from $194 \mathrm{MPa}$ to $240 \mathrm{MPa}$, achieved by paste optimization and particle packing without resorting to heat, pressure or other special treatments. The fibers used in all the pull-out tests were brass-coated was with a diameter of $0.2 \mathrm{~mm}$.

Hossain et al. $(2012,2013)$ developed fibre-reinforced self-consolidating concrete mixtures by incorporating different volumes of polyvinyl alcohol (PVA) and metallic fibres to a maximum of $0.3 \%$ by volume. Fresh, mechanical and durability (in terms of chloride penetration resistance) properties of all fiber reinforced self-compacting concrete (FRSCC) mixtures were evaluated. 
The influence of fibre type/size/dosage and combination (used in hybrid mixes) on fresh properties (slump flow, L-box passing ability, V-funnel flow time and segregation index) and hardened properties (fracture energy and compressive/flexural/splitting tensile strength) were critically analyzed to study the performance of the FRSCC mixtures. The fibres -metallic ones in particular were more effective in increasing the fracture energy of FRSCC than in increasing its compressive/splitting tensile/flexural strength. A substantial fracture energy gain of about $507 \%$ was observed compared to a $10 \%$ increase in compressive strength, a $39 \%$ gain in splitting tensile strength and a $124 \%$ increase in flexural strength. The improved strength and fracture energy of such FRSCC mixtures can significantly reduce the amount of tensile reinforcement required and substantially increase the energy absorbing capacity of concrete structures.

\subsubsection{Plastic Fiber Reinforced Concrete (PFRC)}

Wang (1983) found that the plastic fibers form a very strong bond with the cement matrix but polyester fibers form relatively low bond strength. The bond strength varied with age in cementitious composite because the fiber surfaces were attacked by the cement alkalis and were roughened. Images of plastic fibers if different types and configurations are shown in figure 2.3.The various types of plastic fibers are polyester, polypropylene, polyethylene, aramid and etc.

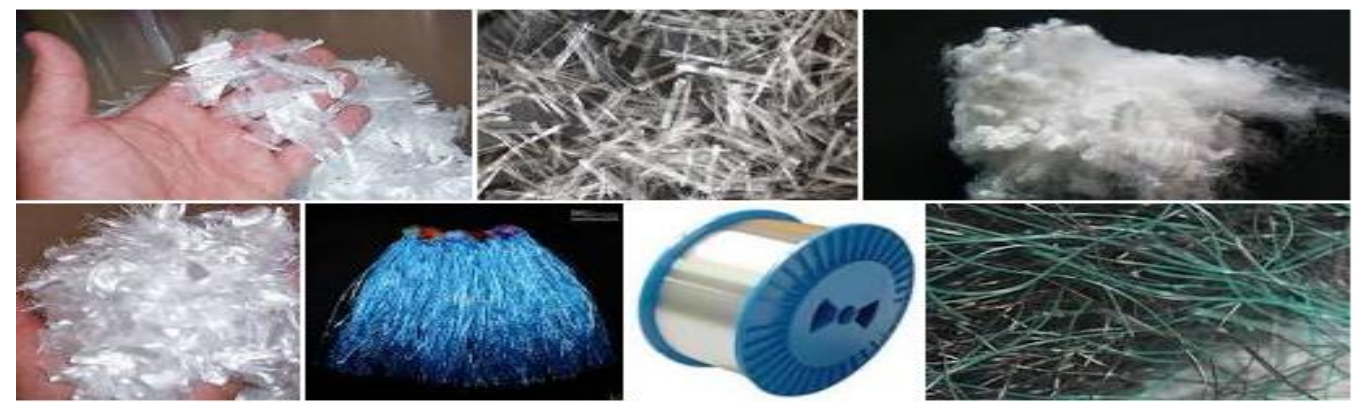

Figure 2.3: Images of Plastic Fibers (Wang, 1983) 
Stanley (1988) carried out experimental investigation on various FRC mixtures made of different polyethylene (PE) fibers (images of different polyethylene fiber are shown in figure 2.4). The ultra-high-molecular-weight polyethylene (UHMWPE, UHMW) is a subset the thermoplastic polyethylene. This is also known as high-modulus polyethylene (HMPE), or high-performance polyethylene (HPPE). This fiber has extremely long chains, with molecular mass usually between 2 and 6 million. Stanley (1998) found the longer chain serves to transfer load more effectively to the polymer backbone by strengthening intermolecular interactions.

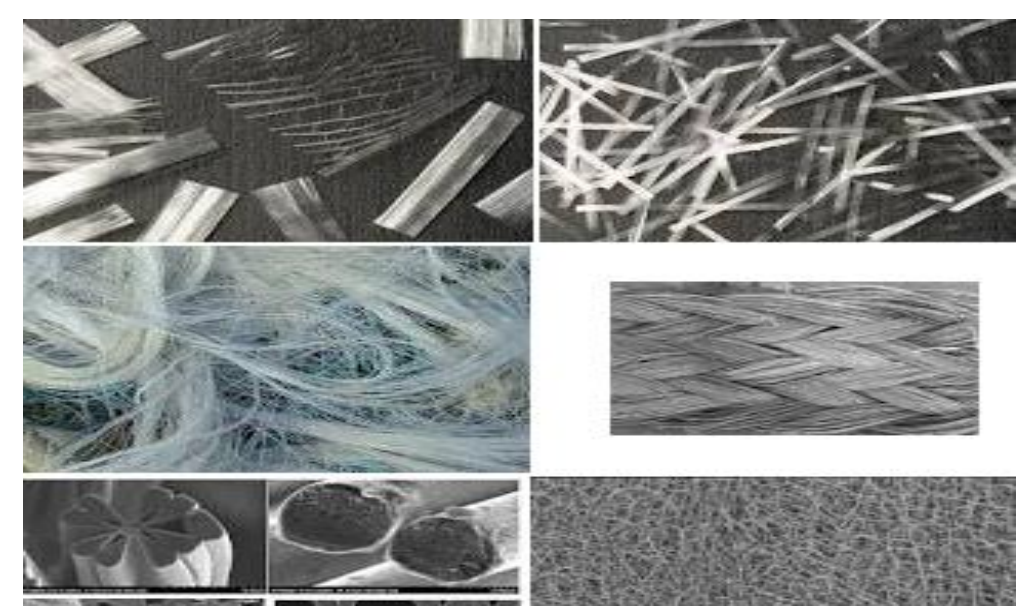

Figure 2.4: Images of Polyethylene Fiber

Comprehensive researches have been conducted on polyethylene based fiber reinforced concrete over the last decades. For examples, a few research studies are highlighted in the following paragraphs.

Ranade (2011) developed FRCs with polyethylene fiber having a compressive strength of 160 MPa and average strain capacity of 3.5\%.The ultimate tensile stress capacity such FRCs was governed by the minimum of the peak bridging capacities at various cracks, which is further dependent on the interfacial bond and fiber dispersion. The stress-strain curve is almost linear 
elastic until the stress reaches the first crack strength of the matrix. Figure 2.5 (for four different FRCs indicated by 1, 2, 3 and 4) shows that the crack stress drops at the point signifying crack formation at the largest flaw and after that steady state propagation of cracks through the matrix. The modulus of elasticity of these FRCs was found to be around $53 \mathrm{GPa}$.

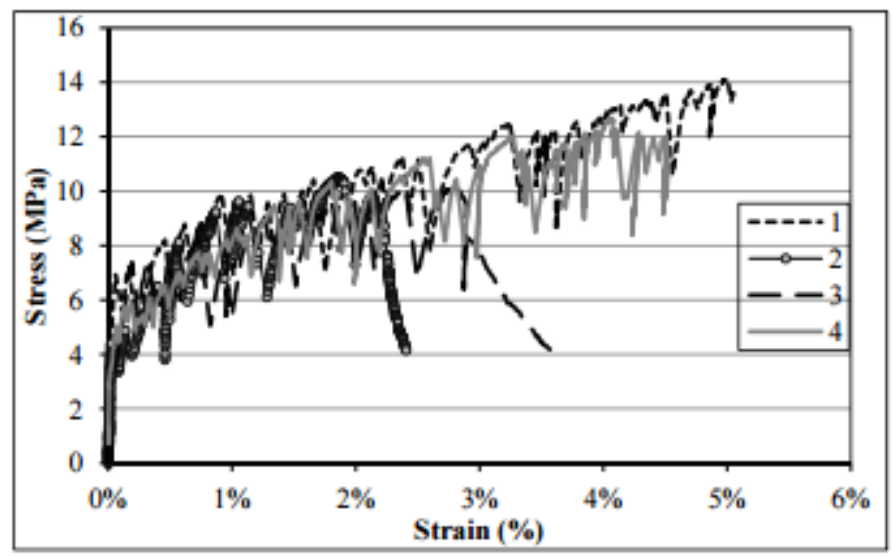

Figure 2.5: Stress-Strain Behaviour of PE based FRCs (Ranade, 2011)

Roel (2011) investigated that ultra-strong polyethylene fibers can be made by gel-spinning of Ultra High Molecular Weight Polyethylene (UHMWPE).Such fibers exhibit extraordinary properties. They show very high tensile strength and stiffness and low density. On the other hand, the axial and transverse compression strength is low. Polyethylene fiber show large difference with other advanced fibers like glass and carbon fibers.

Backer (1990) explained that FRCs with polyethylene fiber having $2 \%$ in volume needs superplasticizer to improve the workability. Superplasticizer Daracem-100 was used in this research. It was found that increase in fiber content increase the tensile properties of FRCs but it depends on uniformity of fiber dispersion. It is to be noted that Daracem- 100 is the first highrange water reducer specially formulated for extended slump life (Grace, 2015).

Ranade (2015) explained the mix designs and properties of High Strength-High Ductility Concrete (HSHDC) developed at the University of Michigan in collaboration with the Engineer 
Research and Development Center (ERDC) of the US Army Corps of Engineers. HSHDC exhibited a unique combination of ultra-high compressive strength (greater than $150 \mathrm{MPa}$ ) and ultra-high tensile ductility (greater than 3\% under direct tension).Such properties pointed toward the potential of utilizing HSHDC in structures subjected to high-energy dynamic loadings, such as impacts, blasts, hurricanes, and earthquakes. Such applications require an understanding of HSHDC's dynamic behavior at high strain rates. Ranade (2015) experimentally investigated the effects of strain rate from $0.0001 / \mathrm{s}$ to $0.01 / \mathrm{s}$ on the composite tensile properties and the micro-scale fiber/matrix interaction properties of HSHDC. Due to the unique interactions between the polyethylene fibers and densely packed ultra-high strength matrix of HSHDC this achievement was possible. It was found that as the strain rate increased from $0.0001 / \mathrm{s}$ to $0.01 / \mathrm{s}$, average crack strength and average ultimate tensile strength of HSHDC increased by about $53 \%$ and $42 \%$, respectively.

Ranade (2013) explained fiber pull-out behavior of polyethylene based FRCs. FRCs with $12.7 \mathrm{~mm}$ long fiber behaved like ductile material and showed very high tensile ductility with $3.4 \%$ average tensile strain capacity under direct tension loading. It was also revealed that in spite of a higher matrix toughness, FRC maintained tensile ductility by enhanced fiber bridging with a strong interfacial frictional bond and fiber length.

Ahmed (2007) worked with FRC composites containing different hybrid combinations of steel and polyethylene fibers. The results of experimental investigation on the strain-hardening behavior of hybrid steel-PE fiber composites under four-point bending were described. Comparison with hybrid steel-PVA (polyvinyl alcohol) fiber composites is presented in figure 2.6. Hybrid steel-PE fiber composites showed lower ultimate strength but higher deflection capacity at the peak load than that of hybrid steel-PVA fiber composites. Strain-hardening behavior accompanied by multiple cracking was achieved in all hybrid steel-PE fiber composites in this study. Hybrid combination of $1.5 \%$ steel and 1.0\% PVA exhibited best performance in terms of highest flexural strength while $0.5 \%$ steel and $2.0 \%$ PE exhibited highest deflection and 
energy absorption capacities. Rate of strength loss after peak load in hybrid steel-PE composites was found to be lower than that of steel-PVA hybrid composites.
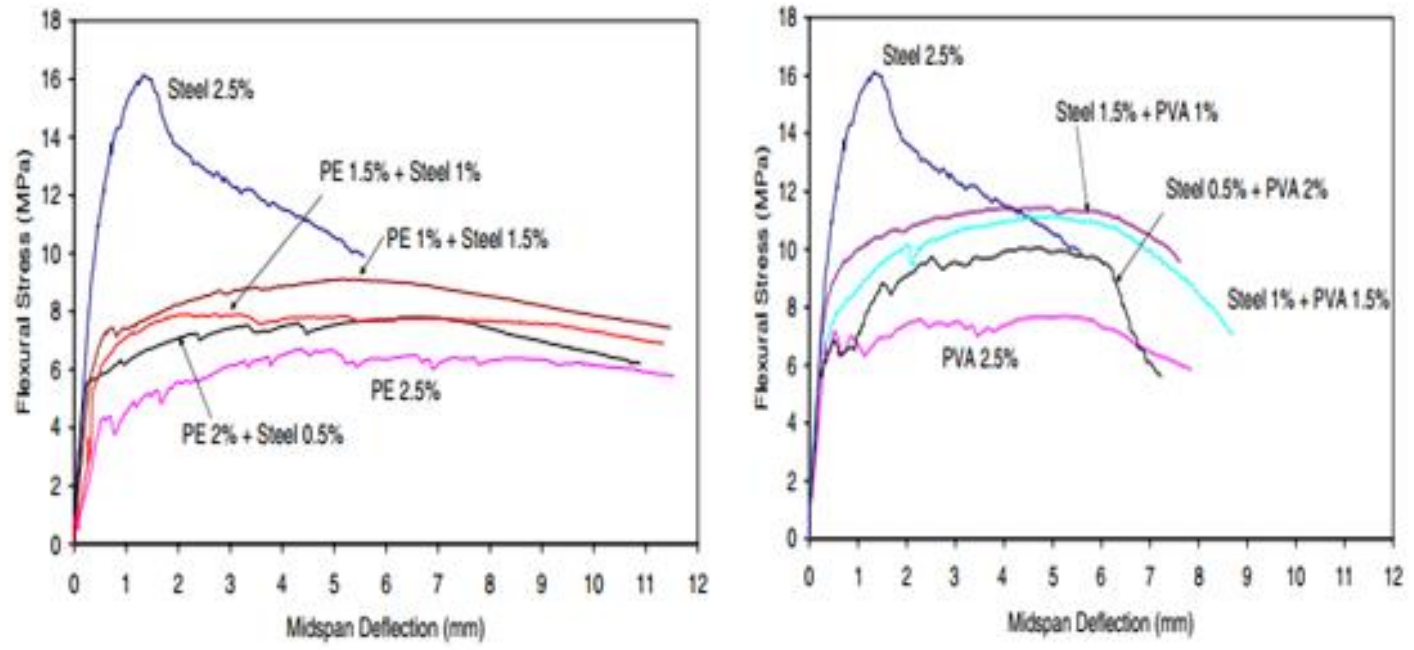

Figure 2.6: Comparison of Flexural and Deflection Capacities FRC Composites with Steel and Hybrid Fibers (Ahmed, 2007)

Yun (2013) investigated the influence of rapid freezing and thawing actions on mechanical properties of hybrid fiber reinforced strain-hardening cement based composites which exhibited multiple cracking and strain-hardening behavior in direct tension. The mixtures exposed to freezing and thawing were incorporating hybrid polyvinyl alcohol (PVA) and ultrahigh molecular weight polyethylene fibers at $1.5 \%$ volume fraction. Rapid freeze-thaw cycles had little effect on the compressive and tensile strength whereas freeze-thaw cycles had a negative effect on multiple cracking behavior and deformation capacity under direct tensile and flexural loadings.

Comprehensive research has been conducted to develop ultra-high performance concrete (UHPC) with steel fiber having a compressive strength of over $140 \mathrm{MPa}$. Fresh, mechanical and durability properties including bond strength of developed UHPC have been investigated (Mak, 2011). Research has been conducted at Ryerson University in collaboration with Ministry of Transportation Ontario (MTO), to develop competitive UHPC materials. The developed UHPC 
materials have been used to study the bond strength of glass fiber reinforced polymer (GFRP) bars using by pullout/beam specimens. The splice length of GFRP bars embedded in UHPC simulating bridge deck construction joints subjected to monotonic/cyclic loading. Recommendations for the bond strength and splice length of GFRP bars embedded in UHPC were made (Hossain et al., 2010, 2012).

\subsubsection{Synthetic Fiber Reinforced Concrete}

Polyvinyl alcohol (PVA) fiber is considered as one of the most suitable synthetic polymeric fibers to be used as the reinforcement of engineered cementitious composites (ECC) because of the unique microstructure characteristics (Wang, 2003). Image of PVA fibers are shown in figure 2.7 .

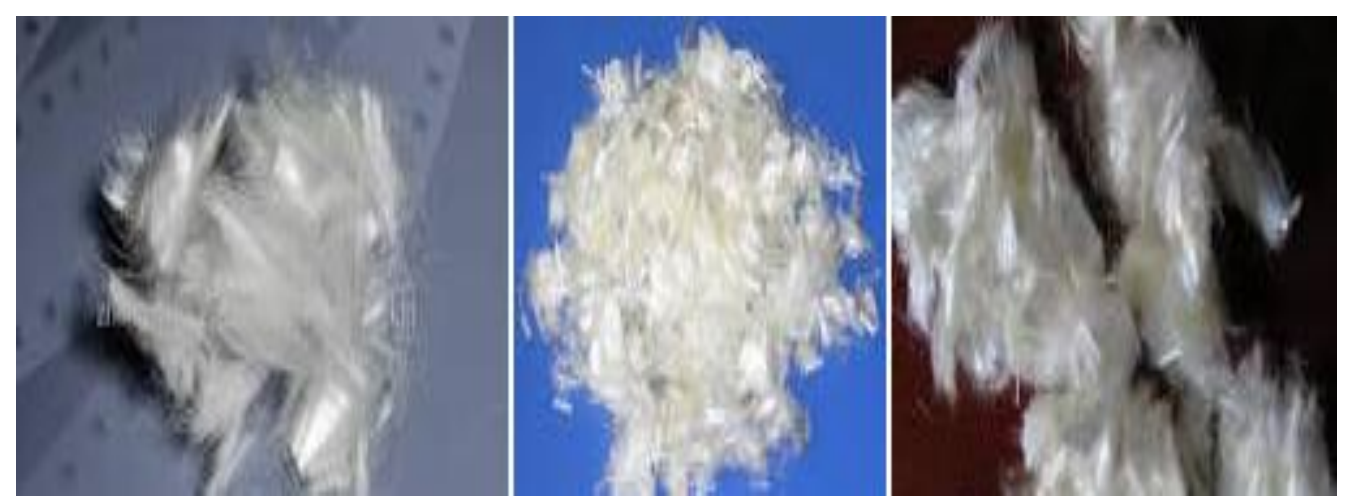

Figure 2.7: Images of Synthetic Fiber (Wang, 2003)

Jang (2014) investigated the effect of PVA fiber-reinforcement on the flexural fatigue behavior of concrete subjected to freezing and thawing cycles. Plain and PVA fiber-reinforced concrete specimens were exposed to freezing and thawing cycles, then a flexural fatigue test using a wheel load was performed with a stress level in the range of $0.5-0.9 \%$. The effect of PVA fiber reinforcement on the flexural fatigue resistance was evaluated by the stress ratio fatigue life relationship. The flexural fatigue test results showed that repeated freezing and thawing actions not only reduced the static strength but also dramatically diminished the resistance to fatigue failure PVA fiber reinforcement. This enhanced the flexural fatigue strength of concrete 
subjected to freezing and thawing cycles due to increase in the resistance for freezing and thawing action and the resistance for flexural fatigue failure.

Galal (2015) stated that strain-hardening property of FRC with PVA fiber is mainly attributed to the mix composition. The fire-resistivity of such concretes is questionable and a matter of concern, specifically when non-fire resistant fibers are used. The most well-known utilized nonfire resistant fibers, such as PVA fibers, are unable to withstand a critical high temperature of $400{ }^{\circ} \mathrm{C}$, despite their unique properties under normal conditions. At this critical temperature, PVA fibers thermally decompose into gases, create voids and thus lead to a disappearance of the strain-hardening behavior and decrease other hardened properties. On one hand, the developed voids due to melting of PVA fibers might prevent explosive spalling from occurring under the effect of pressurized pore water vapor.

PVA fiber reinforced ECC mixes were developed by incorporating locally available crushed sand/mortar sand aggregates and fly ash/ slag/ metakaolin/ volcanic ash as a replacement of cement (Sahmaran et al., 2009 ; Ozbay et al., 2012,2013; Sherir 2015 ; Hossain et al., 2015; Hossain and Anwar 2014; Sherir et al., 2014). Although each material influenced the mechanical and durability properties of the hardened ECC, but similar responses were attained as observed in experimental results.

Taormina (2012) and Taormina and Hossain (2013) conducted research on the structural performance of double skin composite walls (DSCWs) consisting of profiled steel sheeting and concrete-infill subjected to elevated temperatures of up to $800^{\circ} \mathrm{C}$ incorporating emerging high performance concrete (HPC) of different types namely Self-Consolidating Concrete (SCC), PVA fiber reinforced ECC, and steel fiber reinforced Ultra High Performance Concrete (UHPC). Performance of Double Skin Composite Walls (DSCWs) subjected to elevated temperatures was judged compared to unheated walls based on physical changes, residual axial load capacity, load-deformation response, stiffness/ductility, load-strain characteristics, steel-concrete interaction, concrete cracking, steel sheet buckling and overall failure modes. The use of High 
Performance Concrete (HPC) improved both structural (strength and ductility) and fire durability characteristics of the proposed DSCWs. Analytical models for determining the residual axial strength of DSCWs were developed and their performance validated. The research provided useful information for the development of design guidelines for DSCWs exposed to elevated temperatures.

Sherir et al., $(2012,2013)$ investigated the influence of micro silica sand and local crushed sand, and different supplementary cementing materials on the mechanical properties of ECCs with PVA fiber. The use of local aggregates in ECC production can lower its cost to mitigate the obstacles of wider commercial use. The experimental results showed that multiple-cracking behavior was developed under fatigue loading for fly ash ECC (FA-ECC) mixtures, and the number of cracks was lower at both lower fatigue stress level and higher fatigue number of cycles. FA-ECC mixtures with silica sand exhibited higher deflection evolution under fatigue loading than FA-ECC mixtures with crushed sand. Based on the experimental results on link slab specimens, both FA-ECC mixtures with silica and crushed sands exhibited almost the same creep behavior.

Hossain and Samani (2015) conducted experimental investigation on $1 / 4^{\text {th }}$ scale link slabs for joint-free bridge deck construction subjected to monotonic and fatigue loading incorporating different PVA ECC mixtures and self-consolidating concrete. The structural performance for the link slabs were evaluated based on the load-deformation/moment-rotation responses, strain developments, cracking patterns, ductility index and energy absorption capacity. Test results of a $1 / 6^{\text {th }}$ scale full scale joint free bridge with ECC link slab tested under monotonic loading up to service stage was also described. The experimental link slab moment resistance and its length were compared with those obtained from theoretical and design specifications. The ECC link slabs demonstrated superior performance exhibiting high residual strength and energy absorbing capacity and prolonged life (associated with enduring large number of fatigue cycles) compared to their SCC even though subjected to higher fatigue stress levels. Research 
confirmed the viability of ECC link slab to construct joint-free bridges satisfying serviceability and design specifications.

Chu (2014), Chu and Hossain $(2014,2015)$ conducted research on the axial load behavior of circular, square and rectangular concrete filled steel tube (CFST) columns incorporating highperformance self-consolidating concretes such as steel fiber reinforced ultra-high strength concrete (UHSC), PVA fiber reinforced ECC, lightweight concrete (LWC), and crumb rubber concrete (CRC). Seventy-four CFST specimens with varying slenderness, shape, concrete type and presence of internal bar reinforcements are tested experimentally under axial compression loading. The effect of these variables on axial load-deformation response, strain characteristics, failure modes, concrete confinement and axial strength are evaluated through experimental results. Performance of existing analytical/code based models for axial strength and concrete confined strength is evaluated. Concretes without coarse aggregates including UHSC proved less effective at enhancing axial strength of filled tube columns through confinement.

Rafiei (2011) and Rafiei et al., (2013, 2015) investigated the behavior of a new form of composite shear wall system consisting of two skins of profiled steel sheeting and an infill of concrete under in-plane monotonic, cyclic and impact loading. The extensive experimental, analytical and numerical investigations of composite shear walls provided information on strength, stiffness, load-deformation response, steel sheet-concrete interaction, stress-strain characteristics and failure modes. Eight composite wall specimens with overall dimensions of $1626 \mathrm{~mm}$ (height) $\times 720 \mathrm{~mm}$ (width) were tested under monotonic, cyclic and impact loading. Steel sheet-concrete connections were provided by intermediate fasteners to generate composite action. Two types of steel sheets classified based on strength as mild and high strength and also, two types of concrete-infill namely SCC and PVA fiber reinforced ECC were used to construct the walls. An analytical model for shear resistance of the composite wall was developed based on existing models taking into account the shear capacity of the steel sheets, concrete core and steel sheet-concrete interaction. Moreover, two non-linear finite element models for the composite wall under monotonic/cyclic and impact loading were developed 
using proprietary ABAQUS/CAE software. The performance of developed numerical models was validated against experimental results and then the models were utilized to carry out an extensive parametric study to understand the influence of material and steel-concrete interaction on the structural behavior of the walls.

Issani (2012) and Issani and Hossain (2013) investigated flexural stiffness or effective width of floor slab acting as coupling beam in Coupled Shear Wall (CSW) building. New generation of high performance concretes provide an alternative to conventional concrete to enhance the performance of coupling slabs. Research investigated the flexural behavior of coupling slabs incorporating PVA ECC compared to conventional SCC. The high strain capacity and low crack width makes ECC an ideal material for coupling slab. Non-linear coupling action of ECC slabs is investigated experimentally with small-scale models having variable geometric parameters under monotonic loading. The performance is judged based on moment-rotation response, flexural stiffness/effective width, deflection, cracking, strain development and failure modes. Design charts for flexural stiffness/effective width of coupling slabs are presented in precracking/cracking/post-yielding stages. CSW systems with ECC are found stronger and ductile than their SCC counterparts confirming the viability of constructing such structures.

\subsubsection{Glass Fiber Reinforced Concrete}

A reduction in bleeding is observed by addition of glass fibers in the glass fiber concrete mixes. The reduction in bleeding improves the surface integrity of concrete, improves its homogeneity and reduces the probability of cracks. The use of glass fiber also increases the compressive, flexural and split tensile strength (Chandramoulik, 2010). Images of glass fibers are shown in figure 2.8 . 


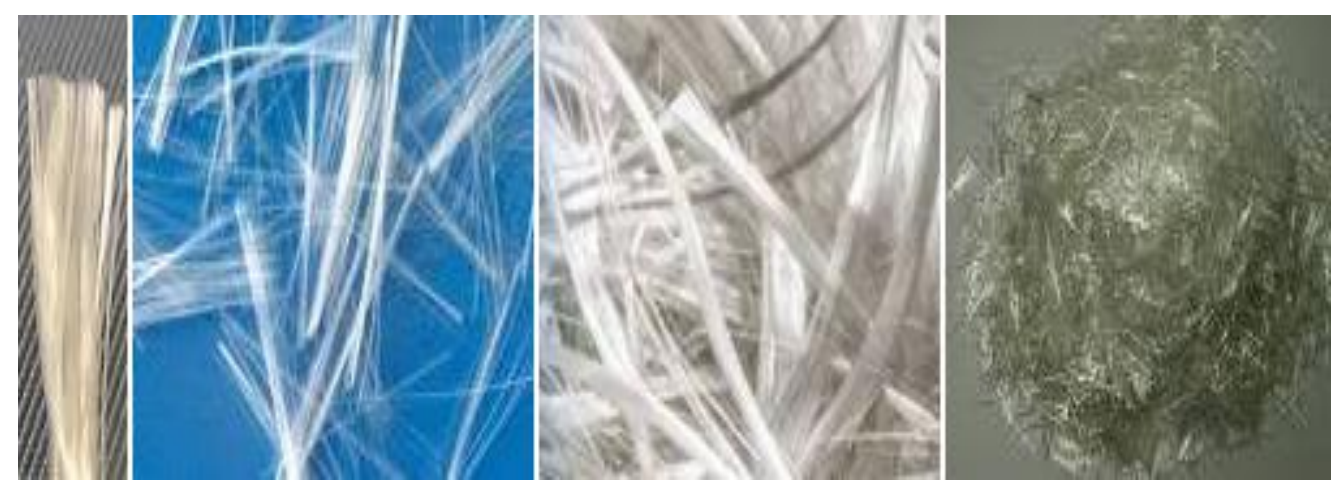

Figure 2.8: Images of Glass Fiber (Yu, 2016)

$\mathrm{Yu}$ (2016) presents the development of Ultra-Lightweight Fiber Reinforced Concrete (ULFRC) applying expanded waste glass in the form of lightweight aggregates. The density, mechanical properties and thermal conductivity of the developed ULFRCs were measured and analyzed. ULFRCs with a dry density of $750 \mathrm{~kg} / \mathrm{m}^{3}$ were produced. Compared to the other lightweight concretes with the same density, the ULFRC (developed in this study) had improved mechanical properties and lower thermal conductivity -therefore it can be utilized as a new material for the production of floating structures, insulating elements or even for load bearing applications.

Esnaola (2016) studied the influence of volume fractions of different fibers (glass, carbon and natural fibers) on specific energy and absorption capability of concrete. Samples made with $40 \%$ and $60 \%$ fiber content showed similar shear strength values, around $35-40 \mathrm{MPa}$. It had been found that by increasing the fiber percentage from $40 \%$ to $47 \%$ the specific energy absorption values of the material increased. For specimens with fiber volume fraction above $47 \%$, the total amount of energy dissipation was similar. An increase of fiber content increased the density of the concrete.

\subsubsection{Carbon Fiber Reinforced Concrete}

The addition of carbon fiber as fiber reinforcing material showed improved mechanical strength properties. High strength concrete with the addition of carbon fiber showed higher increase in 
flexural strength and deflection capacity (Kinayekari, 2014).Images of carbon fibers are presented in figure 2.9 .

Fibrous carbon materials have been attracted many researchers' attentions (Jiang, 2015). Carbon fibers have been developed as one of the most important industrial materials for modern science and technology since 1960s. Due to the superior mechanical properties including high-specific strength/modulus, low density and thermal expansion, heat resistance and chemical stability, carbon fibers as reinforcement materials have provided the impetus for researchers in developing high-performance composite materials.

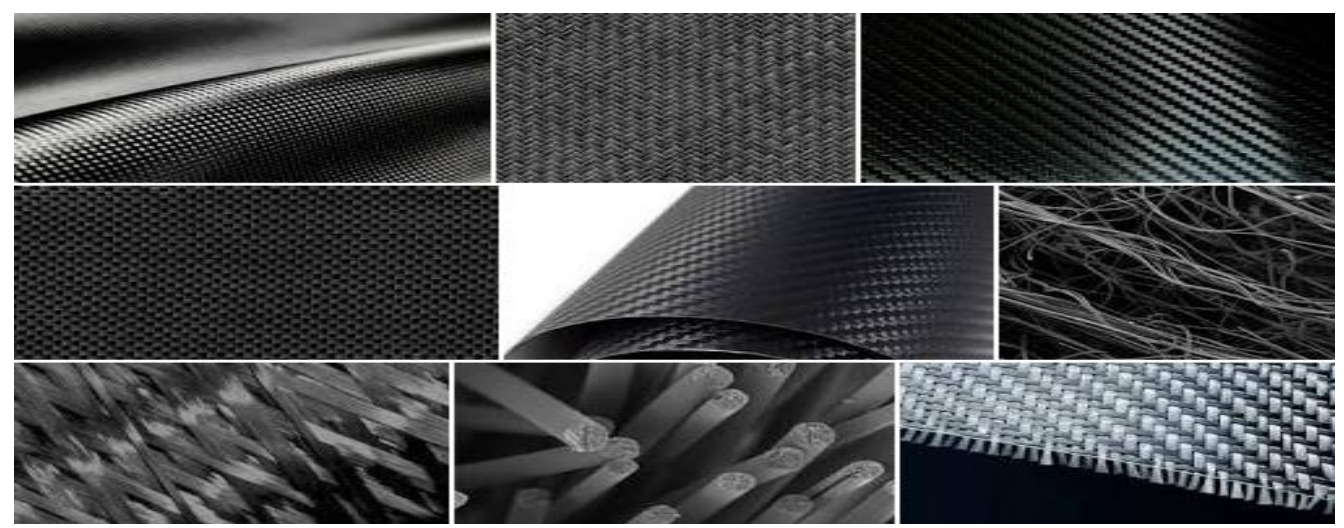

Figure 2.9: Images of Carbon Fiber (Kinayekari, 2014)

\subsubsection{Natural Fiber Reinforced Concrete}

Natural fibers can improve characteristics of concrete, increase flexural strength, toughness and impact resistance. It reduces shrinkage and cracking and improves durability by stabilization of micro cracks and decrease in permeability (Kurtis, 2007). Images of natural fibers are shown in figure 2.10 . 

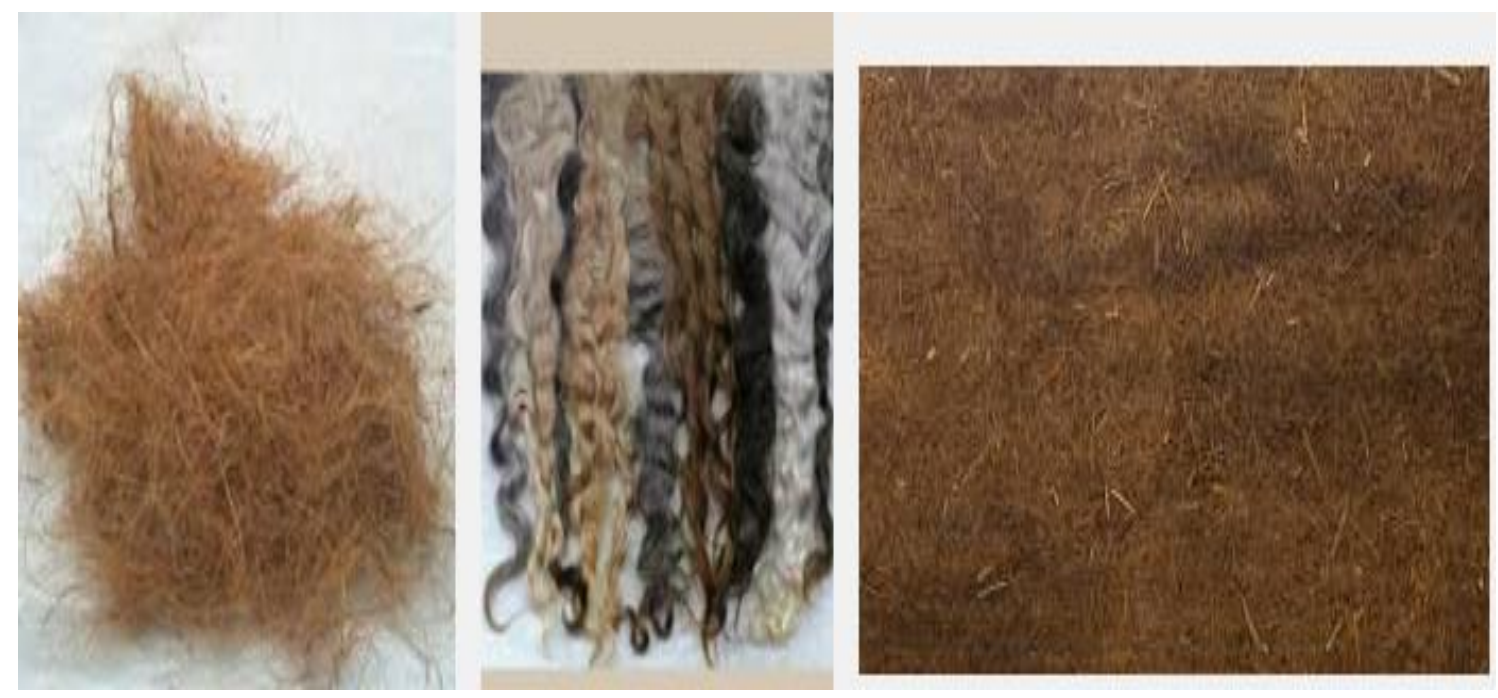

Figure 2.10: Images of Natural Fibers: Coconut, Elephant grass and Wood (Kurtis, 2007)

The influence of synthetic fibers (PVA) and natural fiber was investigated (Juarez et al., 2015) at volume fractions of $0.1 \%$ and $0.7 \%$. Thirty eight prismatic mortar specimens were freshly cast on top of a grooved and hard concrete substrate, providing a bottom restraint; this resulted in cracking in the freshly placed overlay, which was detected as a function of time. The effectiveness of the fibers was evaluated by reduction in the number of cracks and total crack area under these conditions. The results showed that natural fibers were effective in controlling restrained plastic shrinkage cracking like the commercially available PVA fibers; the total crack areas were also reduced by at least $93 \%$ compared with plain mortar specimens.

\subsection{General Discussion on Properties of FRC}

Over the decades, lots of research had been carried out on FRCs. A summary of mechanical and durability properties of FRCs is provided in this section. 


\subsubsection{Mechanical Properties of FRC}

The average compressive strength of steel FRC is 75-120 MPa. The concrete made of short fiber had better strength than long fiber and the case is same for all type of fibers (Sato, 2000).

The average tensile strength of steel FRC is 3-25 MPa and the highest tensile strength of glass fiber is $50 \mathrm{MPa}$ (Table 2.2).Different researches led to the conclusion that the fibers play an important role, not only on the fresh state of the concrete, but also on the mechanical properties of hardened concrete. It is found that the increase of fiber content increased the compressive, splitting tensile and flexural strengths, and toughness of concrete (Soulioti, 2011). The increase of fiber content also increased the fracture energy of the specimens.

\subsubsection{Durability Properties, Rapid Chloride Permeability Test (RCPT)}

Researchers are attempting to develop high performance concretes by using fibers and other admixtures in concrete up to certain proportions. The rapid chloride permeability tests were conducted using glass fiber reinforced concrete for a period of 90, 180, 365 and 720 days and addition of $0.03 \%, 0.06 \%$ and $0.1 \%$ of glass fiber. The test results showed that the addition of glass fibers exhibited better performance (Chandramoulik, 2010). Same is true for all type of fibers.

According to Abhishek (2010), chloride permeability of polypropylene and glass fiber reinforced concrete showed less penetration of chlorides compared with $0 \%$ fiber concrete. The polypropylene and glass fibers reduced the cracks which made the interconnecting voids to be minimum. Due to the addition of $0.04 \%$ of glass fibers and $0.03 \%$ of polypropylene fibers there was a decrease in chloride permeability at 7,14,28 and 56 days (Abhishek, 2010). 


\subsubsection{Comparison between Plain Concrete and FRC}

Plain concrete fails suddenly once the deflection corresponding to the ultimate flexural strength is exceeded. On the other hand, FRC continues to sustain loads even at deflections considerably in excess of the fracture deflection of the plain concrete. The typical graphical presentation of tensile load-deformation response of FRC and plain concrete is shown in figure 2.11.

Plain concrete fails suddenly once the deflection corresponding to the ultimate flexural strength is exceeded; on the other hand, fiber-reinforced concrete continue to sustain considerable loads even at deflections considerably in excess of the fracture deflection of the plain concrete.

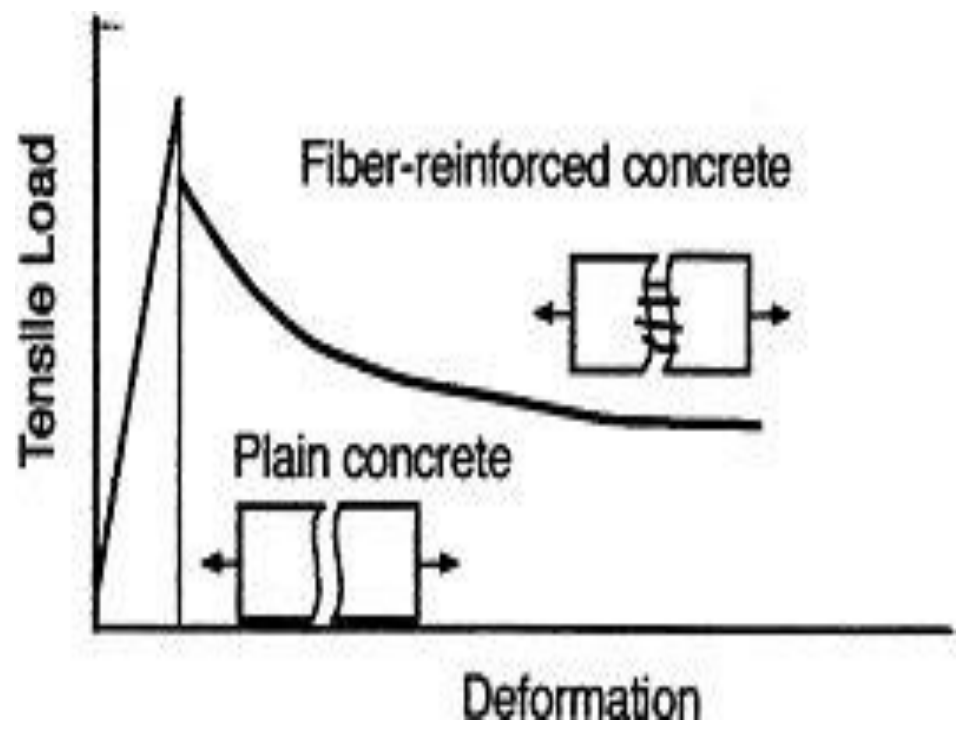

Figure 2.11: Tensile Load-Deformation Responses of Plain Concrete without Fiber and FRC (Nemati, 2005)

Examination of fractured specimens of FRC shows that failure takes place primarily due to fiber pull-out or deboning. Thus unlike plain concrete, a fiber-reinforced concrete specimen does not break immediately after initiation of the first crack (Li, 2013). This has the effect of increasing the work of fracture, which is referred to as toughness and is represented by the area under the load-deflection curve. 
In FRC, crack density is increased, but the crack size is decreased. The failure mechanism is by pull-out and it never exceeds the tensile strength of the fiber. The bond is much weaker and among fibers, steel fiber in terms of durability is the best (Wang, 2003). The addition of any type of fibers to plain concrete reduces the workability. Concrete mixtures containing fibers possess very low consistencies; however, the place ability and compact ability of concrete is much better than reflected by the low consistency (Li, 2004; 2003; 2002; 1992).

The ultimate compressive strain normal concrete is $0.0030-0.0035$ while for FRC; the value is 1.5 to $4.8 \%$. The tensile stress-strain characteristics of FRCs of different classifications are shown in figure 2.12. The most important contribution of fiber reinforcement in concrete is not to strength but to the flexural toughness of the material. When flexural strength is the main consideration, fiber reinforcement of concrete is not a substitute for conventional reinforcement. The greatest advantage of fiber reinforcement in concrete is the improvement in flexural toughness and the FRCs can behave as high strength, high ductility concrete.

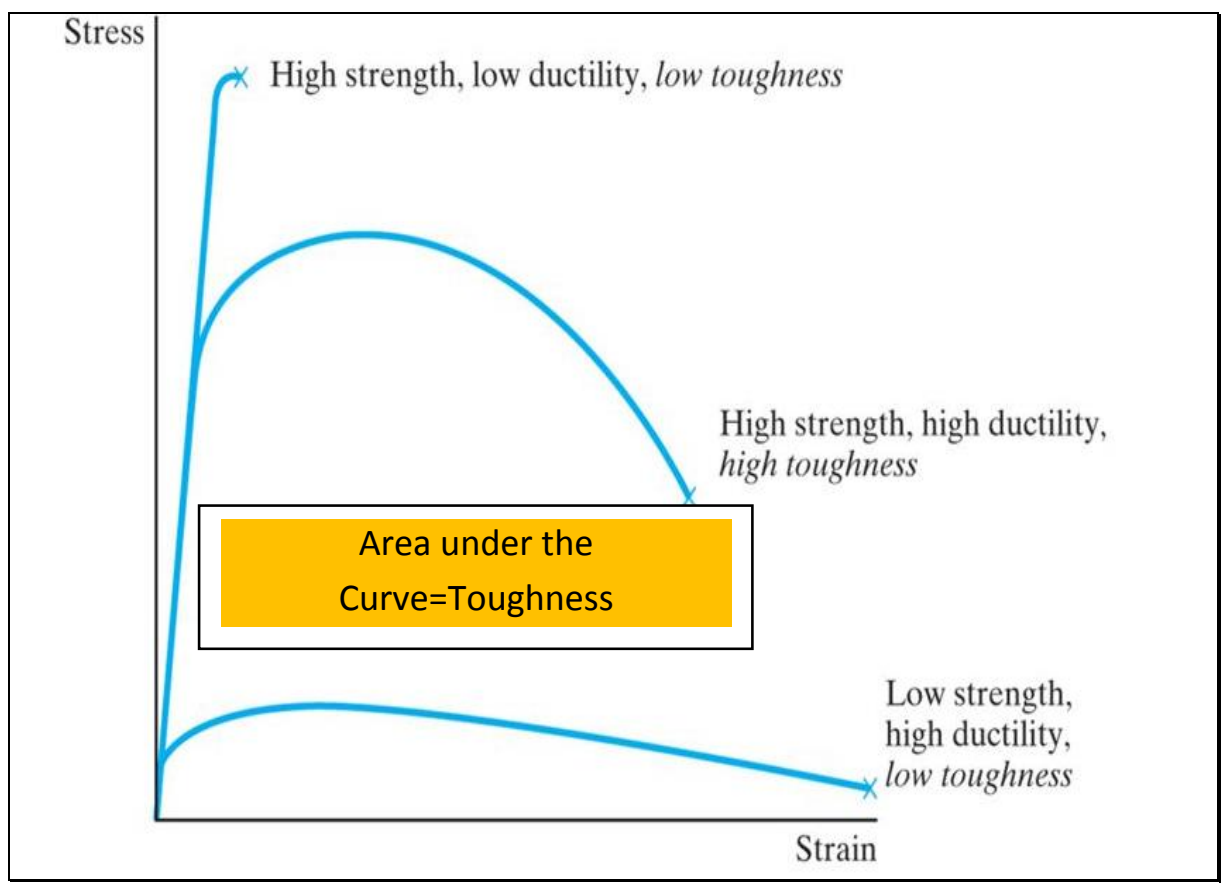

Figure 2.12: Strength of FRC (Nemati, 2005) 


\subsection{Role of Superplasticizer}

Superplasticizers also known as high range water reducer sallow increase in workability without sacrificing strength. Superplasticizer addition to concrete or mortar allows the reduction of the water to cement ratio, increases the workability of the mixture, and enables the production of self-consolidating concrete and flow able high performance concrete including FRC. Typical flow able concrete with superplasticizer is shown in figure 2.13.

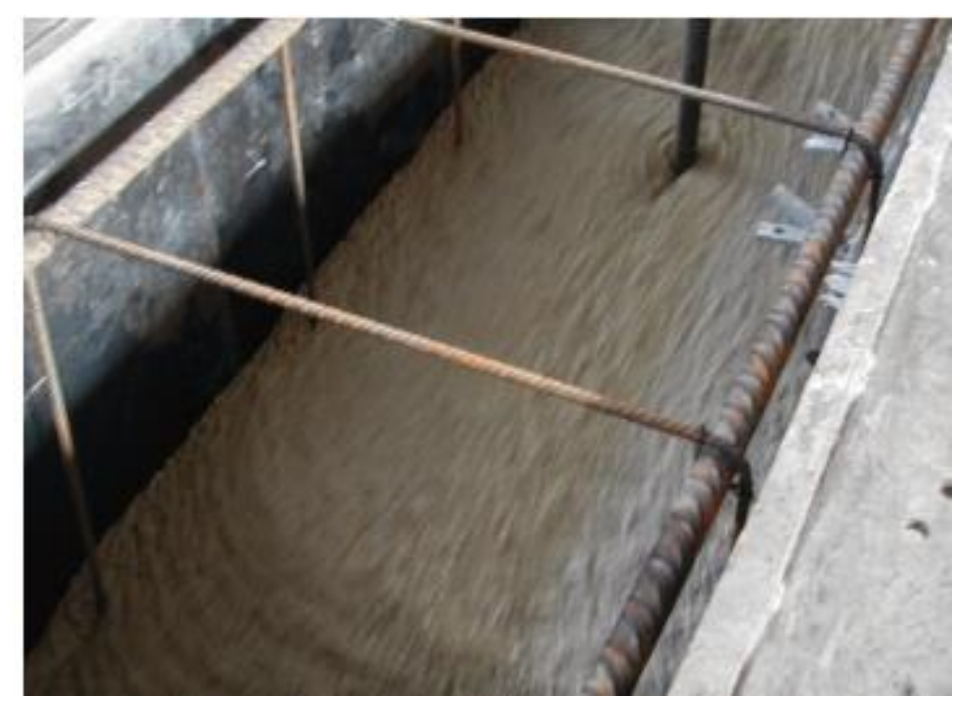

Figure 2.13: Effect of Superplasticizer use in Flowable Concrete (Grace, 2015)

Several different approaches can be used to develop flow able concrete or self- consolidating concrete (SCC) or FRC (Hossain et al., 2012; Hossain and Lachemi, 2010). One approach is to replace the coarse aggregates by sand at a ratio of $5 \%$ to $4 \%$, which in turn requires a high volume of cement (Lachemi et al., 2003). Another method is to design SCC by incorporating viscosity modifying admixture (VMA) or superplasticizer to improve the stability. VMAs are water soluble polymers which enhance the ability of cement paste to retain its constituents in suspension and also increase the viscosity of the mixture. Using VMA with super-plasticizers can ensure adequate workability without segregation. The last technique is to increase significantly the amount of fine materials such as fly ash, volcanic ash and slag cement without changing the 
water content compared to common concrete. This method is the least expensive of the three mentioned above and these supplementary cementing materials help create highly flow able cohesive mixtures at a lower cost with high durability (Lachemi et al., 2003; Hossain and Lachemi, 2010).

\subsection{Review Conclusion}

It is possible to achieve a combination of high compressive strength and tensile ductility in one concrete material, particularly fiber reinforced concrete. Such material leads to high energy absorption, which is critical for structures to withstand extreme loading conditions.

Literature review confirmed that extensive research has been conducted on fiber reinforced concrete using different types and combination of fibers particularly steel fibers. However, the role of different types of fibers on fresh, mechanical and durability properties still needs to be investigated. The synergy between fibers and superplasticizers in the production of high strength and high ductility FRC is still unknown for many kinds of fibers. This research makes an effort to study fresh state, mechanical and durability properties of high strength polyethylene FRC based on range of tests including scanning electron microscopy (SEM). The combined influence of polyethylene fiber and superplasticizer dosage on FRC properties is studied and results of this research will contribute to the existing high strength FRC technology. 


\section{CHAPTER THREE}

\section{EXPERIMENTAL PROGRAM}

\subsection{Introduction}

This chapter presents the mix designs of polyethylene fiber reinforced concrete (FRC) developed specifically for this study. It presents properties of materials, tests and testing procedures to determine the fresh state, mechanical, durability and micro-structural characteristics of high strength FRC mixtures with varying fiber and superplasticizer dosages.

\subsection{Materials Used and Their Properties}

GU (General Use) Portland cement fulfilling chemical and physical requirements of ASTM C 150 (2007) was used. The chemical and physical properties of cement are provided in table 3.1.

Table 3.1: Chemical and Physical Properties of Portland cement (Hossain, 2010)

\begin{tabular}{|c|c|}
\hline Chemical Composition (\%) & \\
\hline Silica (SiO2) & 19.4 \\
\hline Aluminum Oxide $\left(\mathrm{A}_{12} \mathrm{O}_{3}\right)$ & 5.3 \\
\hline Ferric Oxide $\left(\mathrm{Fe}_{2} \mathrm{O}_{3}\right)$ & 2.3 \\
\hline Sodium Oxide ( $\left.\mathrm{Na}_{2} \mathrm{O}\right)$ & 0.2 \\
\hline Potassium Oxide $\left(\mathrm{K}_{2} \mathrm{O}\right)$ & 1.0 \\
\hline Calcium Oxide $(\mathrm{CaO})$ & 61.8 \\
\hline Magnesium Oxide (MgO) & 2.3 \\
\hline Sulphur Trioxide $\left(\mathrm{SO}_{3}\right)$ & 3.8 \\
\hline \multicolumn{2}{|l|}{ Physical Property } \\
\hline Specific Gravity & 3.15 \\
\hline Fineness $\left(\mathrm{cm}^{2} / \mathrm{g}\right)$ & 3740 \\
\hline
\end{tabular}


The chemical and physical properties of silica fume used for FRC mixes are listed in table 3.2.It is highly reactive during sintering, which leads to improved ceramic bonding at reduced firing temperatures.

Table 3.2: Chemical and Physical Properties of Silica Fume

\begin{tabular}{|c|c|c|}
\hline Chemical Name (\%) & & \\
\hline Element & Unit & Value \\
\hline Silica $\left(\mathrm{SiO}_{2}\right)$ & $\% \min$ & 98.4 \\
\hline Aluminum Oxide $\left(\mathrm{Al}_{2} \mathrm{O}_{3}\right)$ & $\% \max$ & 0.2 \\
\hline Ferric Oxide $\left(\mathrm{Fe}_{2} \mathrm{O}_{3}\right)$ & $\% \max$ & 0.001 \\
\hline Sodium Oxide $\left(\mathrm{Na}_{2} \mathrm{O}\right)$ & $\% \max$ & 0.15 \\
\hline Potassium Oxide $\left(\mathrm{k}_{2} \mathrm{O}\right)$ & $\% \max$ & 0.03 \\
\hline Calcium Oxide $(\mathrm{CaO})$ & $\% \max$ & 0.2 \\
\hline $\mathrm{SO}_{3}$ & $\% \max$ & 0.1 \\
\hline $\mathrm{CL}$ & $\% \max$ & 0.001 \\
\hline $\mathrm{H}_{2} \mathrm{O}$ & $\% \max$ & 0.2 \\
\hline Physical Property & & \\
\hline Loss of Ignition & $\% \max$ & 0.5 \\
\hline Coarse Particles $>45 \mu m$ & $\% \max$ & 0.2 \\
\hline$p H$ Value & & 6.8 \\
\hline Bulk density undensified & $\mathrm{kg} / \mathrm{m}^{3}$ & 300 \\
\hline
\end{tabular}

The properties of natural grain silica sand used in this research are shown in Table 3.3. The most common constituent of silica sand is silica (silicon dioxide, or $\mathrm{SiO}_{2}$ ), usually in the form of quartz. 
Table 3.3: Properties of Silica Sand Natural Grain

\begin{tabular}{|l|l|}
\hline Physical State & Sand \\
\hline Appearances and odor & White-No odor \\
\hline Specific Gravity & 2.65 \\
\hline pH Level & $6-7$ \\
\hline Solubility in Water & Insoluble \\
\hline Boiling Point & $2230^{\circ} \mathrm{C}$ \\
\hline Vapour Pressure & $10 \mathrm{~mm} @ 1730^{\circ} \mathrm{C}$ \\
\hline
\end{tabular}

The ADVA cast 575 superplasticizer was used in the FRC mixtures. It is a high efficiency, low addition rate polycarboxylate-based high range water reducer designed for the production of a wide range of concrete mixes, from conventional to self-consolidated concrete. It is designed to impart extreme workability without segregation to the concrete. ADVA cast meets the requirement of ASTM C494 (2007) as a Type A and F and ASTM C1017 (2007) Type I plasticizer. Advantages of using ADVA 575 are:

- Excellent dosage efficiency, moisture control and air control

- Superior air entrainment control

- Enhanced concrete cohesiveness with low viscosity for rapid placement

- Superior finish on cast surfaces

- $\quad$ Enhanced strength development. 
Ultra-high molecular weight polyethylene (UHMWPE) fiber used in this research was odorless, tasteless, and nontoxic material (Wong, 1994). It is highly resistant to corrosive chemicals except oxidizing acids; has extremely low moisture absorption and a very low coefficient of friction; is self-lubricating; and is highly resistant to abrasion, in some forms being 15 times more resistant to abrasion than carbon steel. It's coefficient of friction is significantly lower than that of nylon and acetyl. The properties of polyethylene (PE) fiber is shown as per table 3.4.

Table 3.4: Geometry and Mechanical /Physical Properties of PE Fiber

\begin{tabular}{|l|l|l|l|l|l|}
\hline Diameter & Length & $\begin{array}{l}\text { Nominal } \\
\text { Strength }\end{array}$ & $\begin{array}{l}\text { Young's } \\
\text { Modulus }\end{array}$ & $\begin{array}{l}\text { Specific } \\
\text { Gravity }\end{array}$ & $\begin{array}{l}\text { Melting } \\
\text { Temp }\end{array}$ \\
\hline $38 \mu \mathrm{m}$ & $20 \mathrm{~mm}$ & $3000 \mathrm{MPa}$ & $100 \mathrm{GPa}$ & 0.97 & $150^{\circ} \mathrm{C}$ \\
\hline
\end{tabular}

\subsection{Mixture Design, Preparation and Mixing Procedures}

Four FRC mixtures designated as P19S26, P19S46, P10S26, and P10 S46 was used in this research. $\mathrm{P}$ stands for polyethylene fiber, first numeric represents $\mathrm{PE}$ fiber amount in $\mathrm{kg} / \mathrm{m}^{3}, \mathrm{~S}$ stands for superplasticizer and $2^{\text {nd }}$ numeric stands for dosages of superplasticizer in $\mathrm{kg} / \mathrm{m}^{3}$. Mix designs of four FRC mixtures are presented in table 3.5.

Table 3.5: Mix Design of FRC Mixtures

\begin{tabular}{|l|c|c|c|c|c|}
\hline Ser & Material & $\begin{array}{c}\text { Quantity } \\
\left(\mathrm{kg} / \mathrm{m}^{3}\right)\end{array}$ & $\begin{array}{c}\text { Quantity } \\
\left(\mathrm{kg} / \mathrm{m}^{3}\right)\end{array}$ & $\begin{array}{c}\text { Quantity } \\
\left(\mathrm{kg} / \mathrm{m}^{3}\right)\end{array}$ & $\begin{array}{c}\text { Quantity } \\
\left(\mathrm{kg} / \mathrm{m}^{3}\right)\end{array}$ \\
\hline \multicolumn{2}{|c|}{ Mix Code } & P19S26 & P19S46 & P10S26 & P10S46 \\
\hline 1 & Cement & 818 & 818 & 818 & 818 \\
\hline 2 & Silica Sand & 899 & 899 & 925 & 925 \\
\hline 3 & Silica Fume & 204 & 204 & 204 & 204 \\
\hline 4 & PE Fibers & 19 & 19 & 10 & 46 \\
\hline 5 & Superplasticizer & 26 & 46 & 26 & 221.8 \\
\hline 6 & Water & 221.8 & 221.8 & 221.8 & 10 \\
\hline
\end{tabular}




\section{Preparation of FRC mixtures involved the following steps:}

- The dry powders were mixed for a minimum of two minutes or until a homogeneous distribution of the powders was achieved. Dry powders are cement, silica sand and silica fume.

- The water was slowly introduced with half of the plasticizer and mixed for 4 minutes.

- The second half of the super plasticizer was introduced slowly.

- When the mixture became self-consolidating, usually 3-5 minutes after the addition of the second half of the super plasticizer, the fibers were dusted over the mix to allow for even dispersion, and to avoid fiber clumping .The concrete was mixed for one minute after the inclusion of the fibers. The mixture can continue for 5-10 minutes more to have a proper mixing.

- Few working steps during preparations shown in figure 3.1.

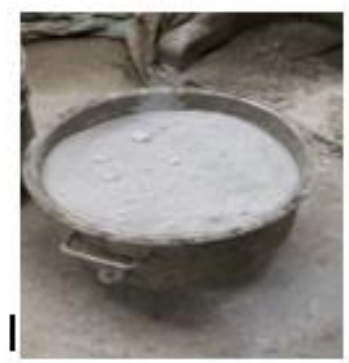

(a)

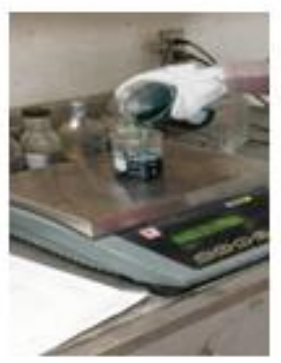

(b)

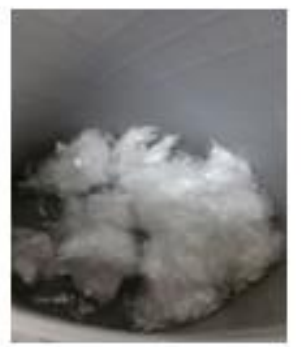

(c)

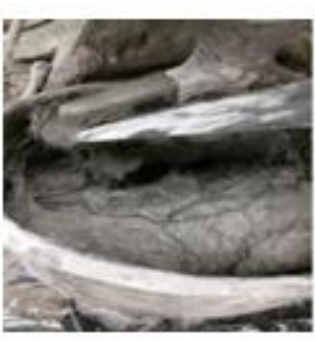

(d)

Figure 3.1: Mix Design Preparation ( $L$ to R): (a) Powder Mix (b) Superplasticizer Addition (c) PE Mixing (d) Final FRC Mix

\subsection{Tests}

A series of tests was carried out to determine fresh state properties, mechanical properties, durability characteristics and microstructure of FRC mixtures. The tests carried out are described below: 
- Fresh State Properties

Slump Flow test - ASTM Standard C1611/C1611M (2007).

Time-temperature Response- Initial Setting Time- Hossain (2008).

- Mechanical Properties

- $\quad$ Compressive Strength (Cube) - ASTM Standard C 942 (2007).

- $\quad$ Compressive Strength (Cylinder) - ASTM C39 / C39M (2007).

- $\quad$ Flexural Strength -ASTM C1609/C1609M (2007).

- Modulus of Elasticity

- Durability Properties

Rapid Chloride Permeability Test (RCPT)-ASTM Standard C1202 (2007).

- Micro-structure

Scanning Electronic Microscopy (SEM).

\subsection{Testing Procedures}

\subsubsection{Fresh Concrete Tests}

Slump Flow Test: Immediately after concrete mixing, the slump flow test was conducted. The slump flow test was used to evaluate flowability in the absence of obstructions. For slump flow measurement, concrete was poured into a standard slump cone without consolidation. A sample of freshly mixed concrete is placed in a mold shaped as the frustum of a cone (Hossain, 2013). The concrete is placed in one lift without tamping or vibration. The mold is raised, and the concrete allowed spreading. After spreading ceases, two diameters of the concrete mass are measured in approximately orthogonal directions, and slump flow is the average of the two diameters. A set up during test in lab is shown at figure 3.2. 

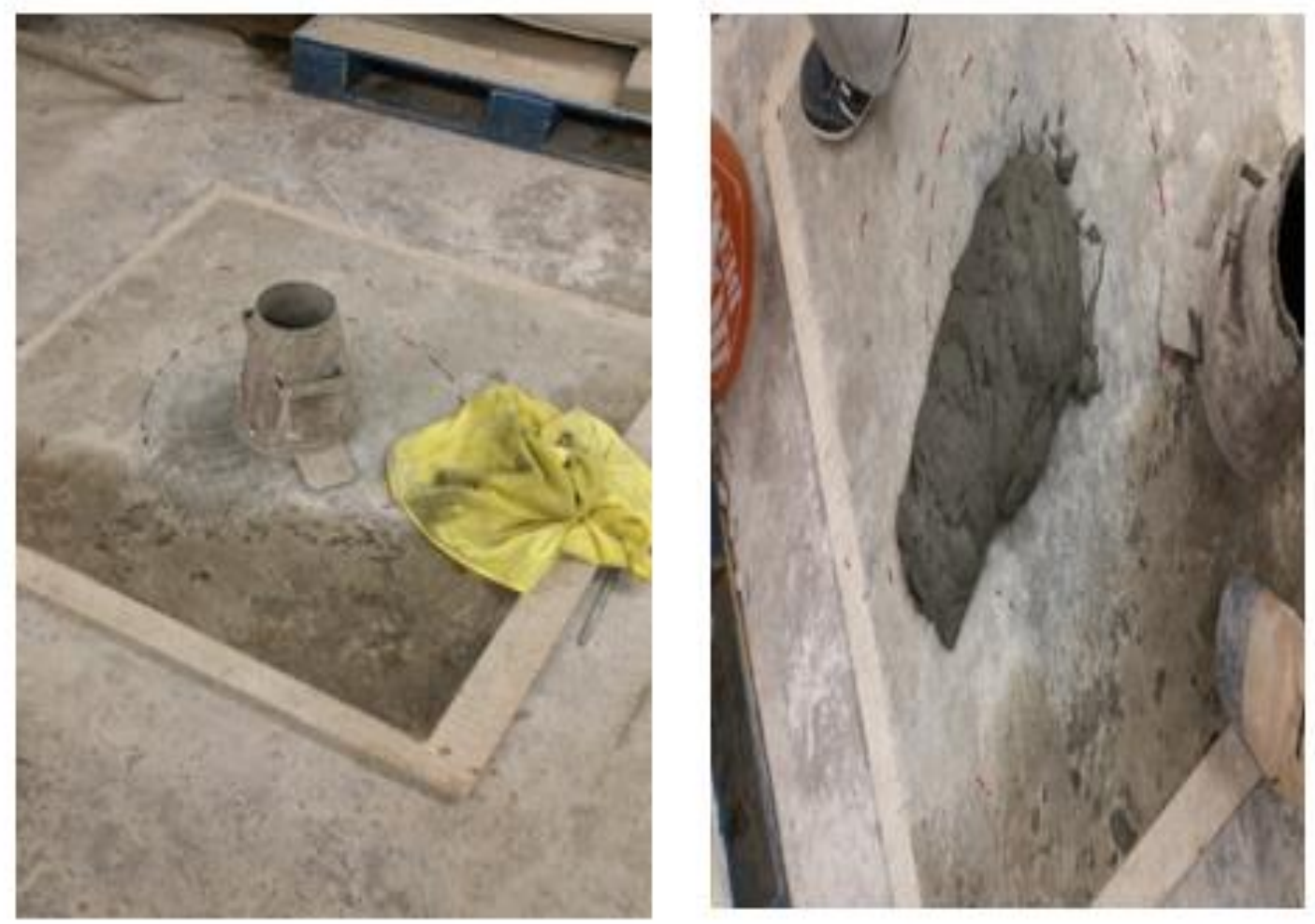

Figure 3.2: Slump Flow Test in Laboratory

Time-Temperature response and Setting Time Determination: A cylinder $(100 \mathrm{~mm}$ dia and $200 \mathrm{~mm}$ height) specimen was prepared and temperature development was monitored with time immediately after casting using a thermocouple embedded in the concrete connected to a computer aided data acquisition system (Hossain, 2008).Test-set up consisting of concrete cylinder with thermocouple and data acquisition system is shown in figure 3.3. The performance FRC mixes was compared based on the temperature vs. time responses using laboratory data. Final setting time of concrete mixtures was also calculated by $2^{\circ} \mathrm{C}$ temperature increase in one hour based on "box method" (Hossain, 2008). 

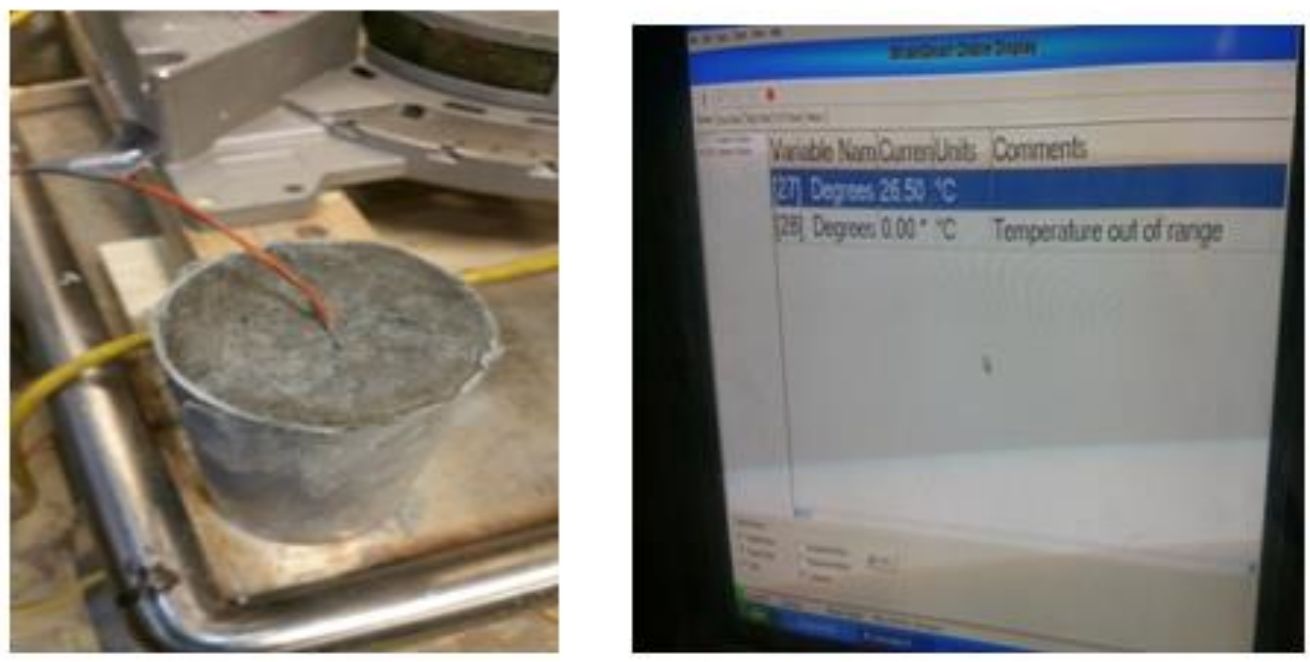

Figure 3.3: Sample and Set up of Time-Temperature Curve Test

\subsubsection{Mechanical Property Tests}

Compressive Strength: Compressive strength is the capacity of a material to withstand loads tending to reduce size. It can be measured by plotting applied concentric compressive force against deformation in a testing machine. Some materials fracture at their compressive strength limit; others deform irreversibly, so a given amount of deformation may be considered as the limit for compressive load. Compressive strength is a key value for design of structures. ASTM Standard C 942-99 (2007) was followed to conduct the test. $50 \mathrm{~mm} \times 50 \mathrm{~mm} \times 50 \mathrm{~mm}$ cube samples (Figure 3.3) was cast for each of the FRC mixtures and cured in curing room until testing at the age of 7,14,21 and 28 days. Mean value of two samples was taken to determine compressive strength at each age. In addition to cube test, cylinder test (Figure 3.3) was also carried out to determine the compressive strength. Cylinder of dimensions $100 \mathrm{~mm}$ in diameter and $200 \mathrm{~mm}$ in height was used. The concrete specimens in the form of cylinders and cubes were removed from molds after $24 \mathrm{~h}$ of casting and then placed in a curing room at $23 \pm 2^{\circ} \mathrm{C}$ 
with95\% humidity until testing (figure 3.5). Compressive strengths were determined by crushing 100 x200 mm cylinders as per ASTM C-39 at 7, 14, 21 and 28days. Mean value of at least two cylinders tested at each selected age was used. If strength of any specimen varied by more than 15 per cent of average strength, results of such specimen was be rejected (Hossain, 2008 and 2013).
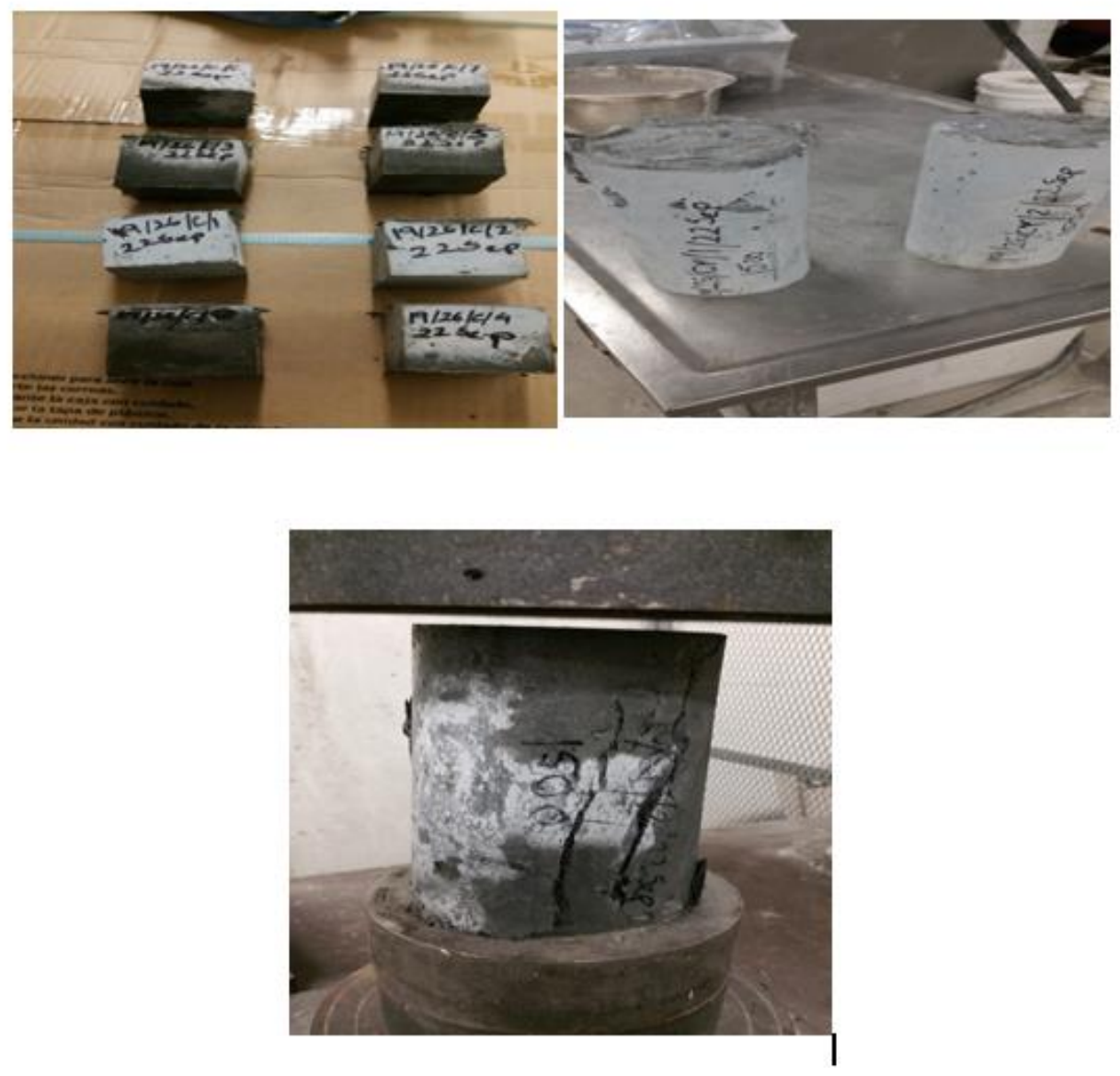

Figure 3.4: Compressive Strength Test on Cylinder and Cube Sample as per ASTM Standard

Flexural Strength: Flexural strength is the resistance of a material to longitudinal stress measured by the minimum amount longitudinal stress required to rupture the material. The 28days flexural strength of FRC mixes was determined by using $76 \mathrm{~mm} \times 50 \mathrm{~mm} \times 355 \mathrm{~mm}$ beams 
with four-point loading according to ASTM C 78 (2007) as shown in figure 3.5 and figure 3.6. Loads were applied at a loading rate of $<1 \mathrm{MPa} / \mathrm{min}$ and a computer-aided data acquisition system were used to record load-central deflection response up to failure. At least three beam samples were tested at each age to determine the mean strength. The samples were cured until testing similar to cube samples described earlier.

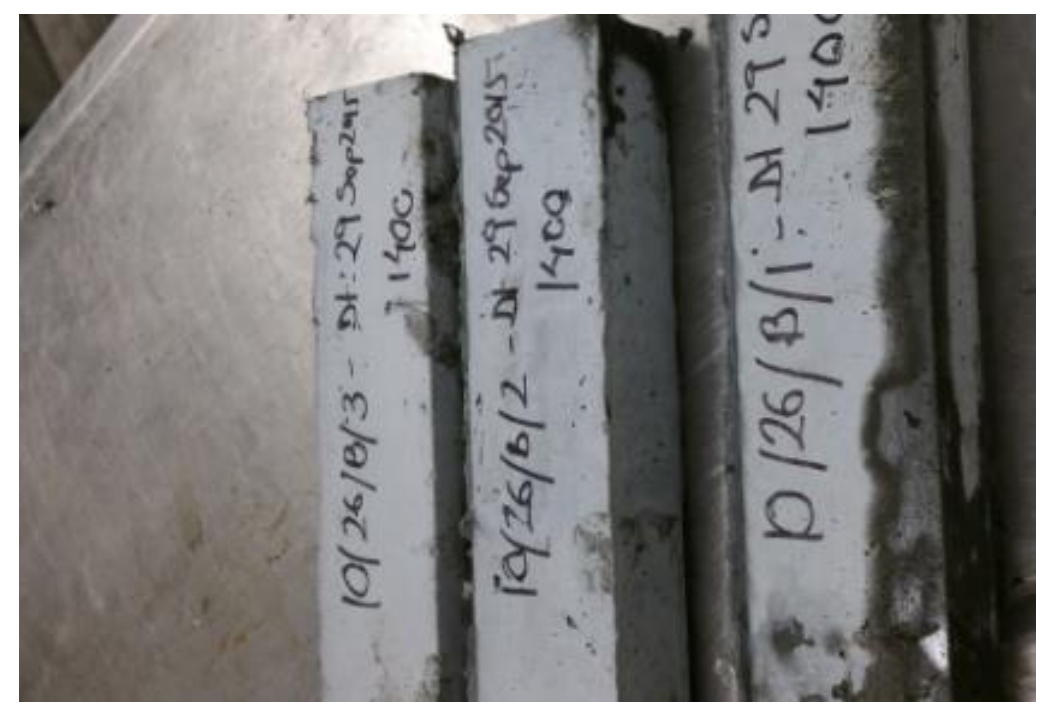

Figure 3.5: Beam Sample for Flexural Strength

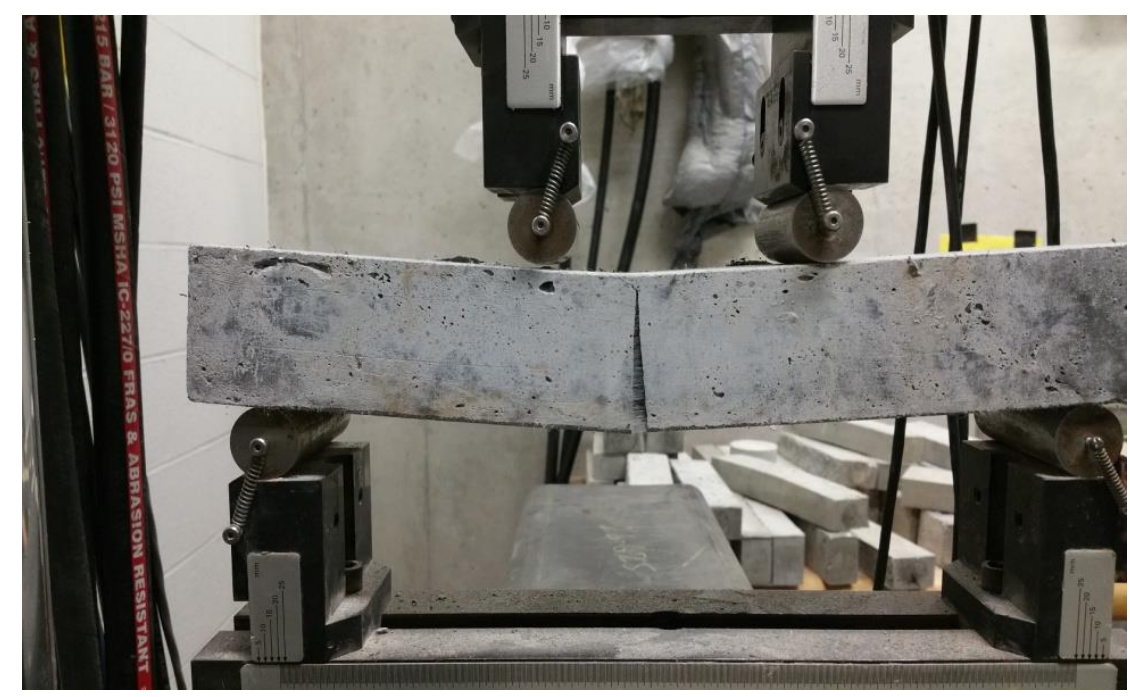

Figure 3.6: Flexural Strength Set Up and Beam Sample Under Four Point Loading 
Fracture Energy: $\quad$ Beam specimens $(76 \mathrm{~mm} \times 50 \mathrm{~mm} \times 355 \mathrm{~mm}$ ) having a central notch ( $4 \mathrm{~mm}$ wide and $11 \mathrm{~mm}$ in depth) as per figure 3.7 and Figure 3.8 were tested to failure less than three points loading to determine fracture energy. At least three samples were tested for each FRC mix at 28 days to determine mean value. A computer-aided data acquisition system was used to monitor load-mid-span deflection response (measured by linear variable differential transducer) throughout loading history until failure. According to test, the fracture energy $\left(G_{f}\right)$ of concrete is defined based on the energy absorbed per unit crack area in widening the crack from zero to failure, and can be calculated based on the equation 3.1 (Hossain, 2013):

$$
G_{\mathrm{f}}=\frac{W_{o}+m g d_{o}}{A_{\text {lig }}}
$$

where $G_{f}$ is the fracture energy $(\mathrm{N} / \mathrm{m}), W_{\mathrm{o}}$ is the area under load-deflection curve $(\mathrm{N} / \mathrm{m})$, the weight $(\mathrm{kg})$ of the beam between supports plus weight of the loading arrangement, which is not attached to the machine but follows the beam until failure, $g$ is the acceleration due to gravity $\left(9.81 \mathrm{~m} / \mathrm{s}^{2}\right), d_{\mathrm{o}}$ is the ultimate deformation at failure of the beam $(\mathrm{m}), b$ is the width of the beam $(\mathrm{m}), d$ is the depth of the beam $(\mathrm{m}), a_{\mathrm{o}}$ is the depth of the notch and $A_{\text {lig }}\left(=b d-b a_{\mathrm{o}}\right)$ is the area of ligament.

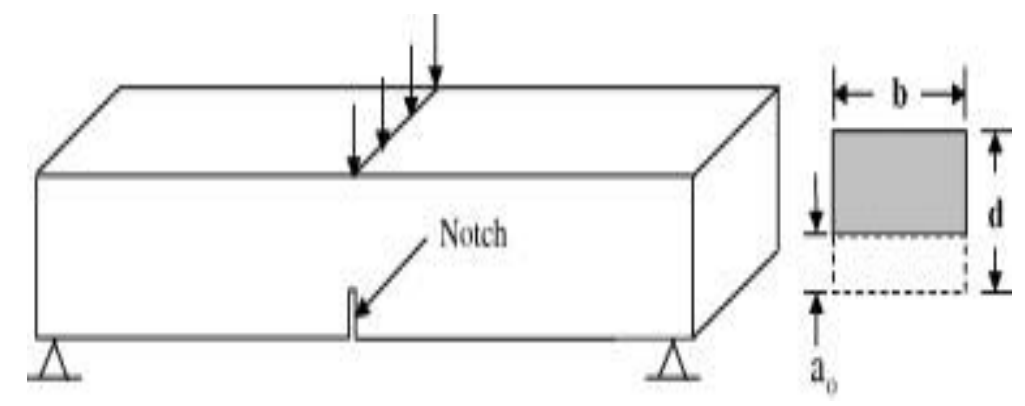

Figure 3.7: Notched Beam and Test Setup for Fracture Energy 


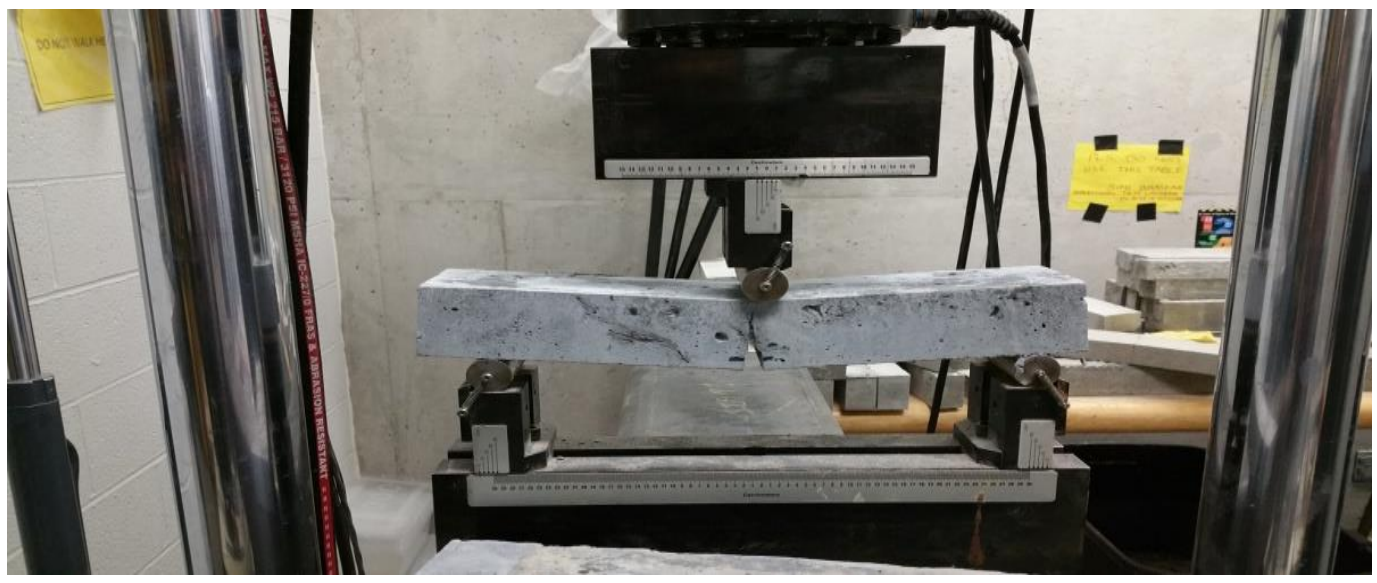

Figure 3.8: Fracture Energy Test Setup and Failed Notched Beam Specimen

Modulus of Elasticity: $\quad$ The $100 \mathrm{~mm}$ diameter and $50 \mathrm{~mm}$ in eight cylindrical samples was tested under compression loading to failure. During testing load-displacement response as well as load-axial strain response (recorded from two strain gauges installed on the FRC surfaces) was monitored using a computer aided data acquisition system. The load was converted to stress and modulus of elasticity (E) was calculated as the slope of the initial linear response from the stress-strain plot.

\subsubsection{Durability Tests}

The rapid chloride permeability (RCP) test was carried out as per ASTM C 1202 (2007). The $100 \mathrm{~mm}$ diameter concrete cylinder was cast and cured in a moist room for 28 days. After curing, the cylinder was cut into $50 \mathrm{~mm}$ thick specimens and prepared as per ASTM C 1202. Each specimen was then placed between two cells filled with $0.3 \mathrm{~N} \mathrm{NaOH}$ and $3.0 \% \mathrm{NaCl}$ solutions. The total charge in Coulombs passed through the $50 \mathrm{~mm}$ thick specimens within $6 \mathrm{~h}$ was considered the resistance of the specimen to chloride ion penetration. Set up for the test is shown in figure 3.9 (Hossain, 2008; Hossain, 2011). 


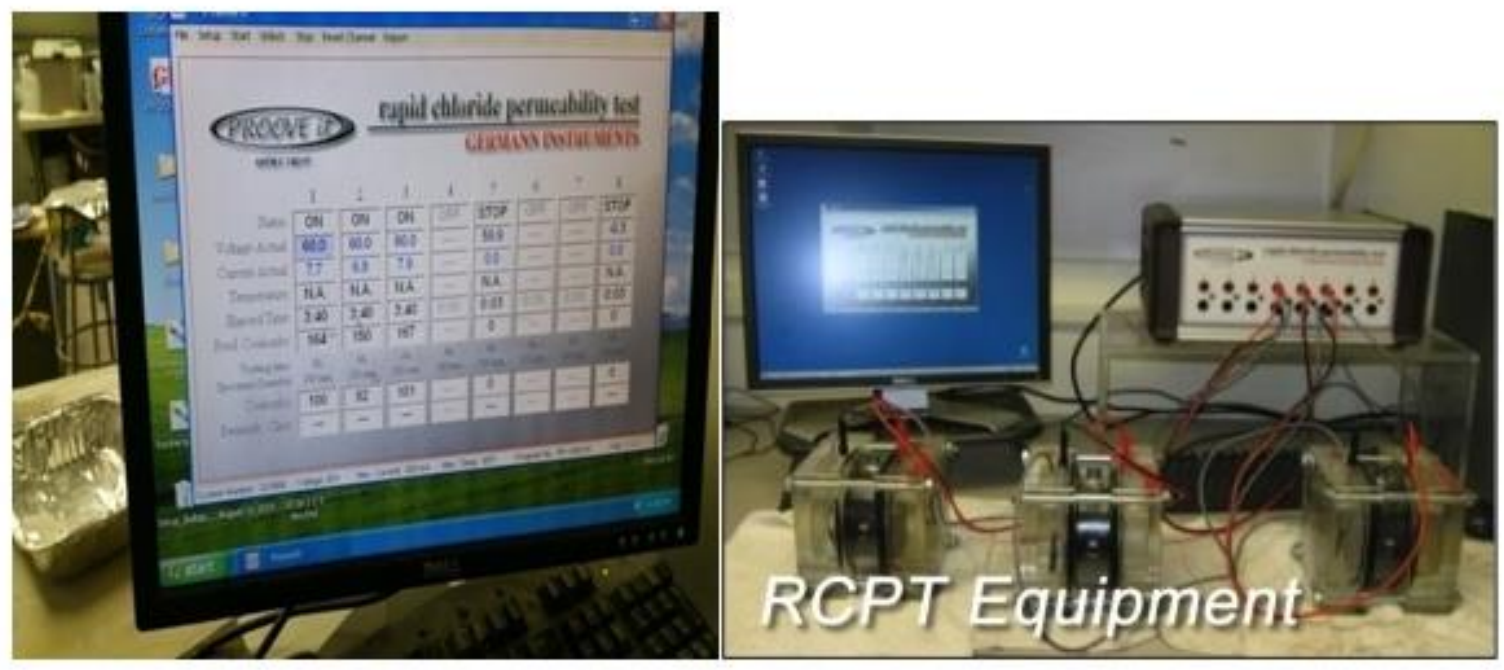

Figure 3.9: RCP Test Set-up

\section{Micro-structural Testing Using Scanning Electronic Microscopy (SEM)}

The SEM specimens $(1 \mathrm{~cm} \times 1 \mathrm{~cm})$ of FRC mixtures were prepared by coring, sawing, or otherwise removing concrete from the original specimens. Unless otherwise specified, the section for observation should be approximately perpendicular to the layers in which the concrete was placed or perpendicular to the finished surface. After that the specimen was cleaned and dried thoroughly in an oven at $100-200{ }^{\circ} \mathrm{F}\left(38-93^{\circ} \mathrm{C}\right)$ for several hours. The polished surface was then black end by pressing a wet stamp pad with ink (not over saturated) several times. The specimen was then completely dried in an oven for several hours until the ink is completely dry. Regrind The surface was then regrinded for a short time as possible with a fine abrasive paper or 1000 (P2000) grit SiC to remove ink stains from the white pigmented epoxy. Voids should appear white against the dark background creating a specimen ideal for manual or automated microscopic observations. The specimen and SEM test set up are shown in figures 3.10 and 3.11 . 


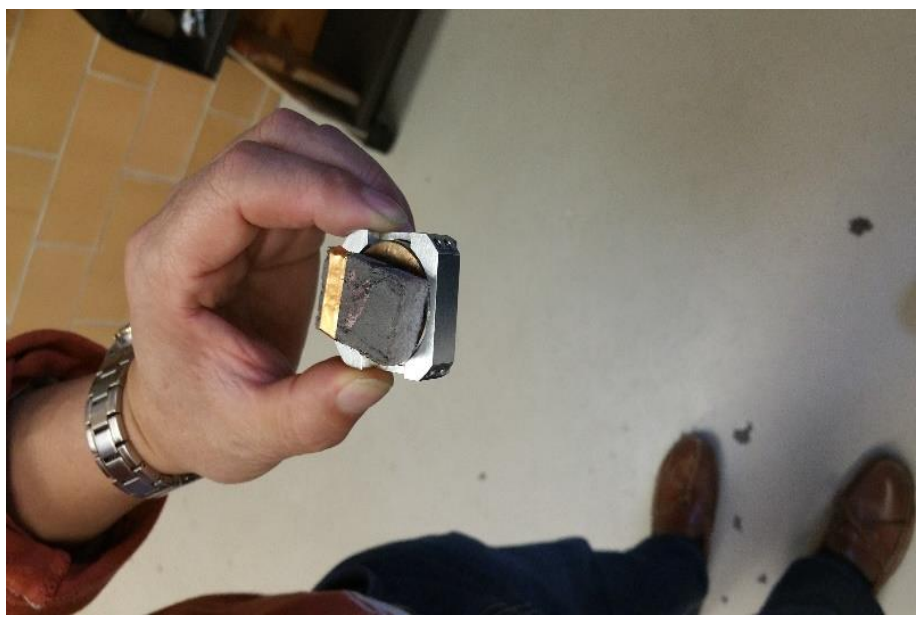

Figure 10: SEM Specimen

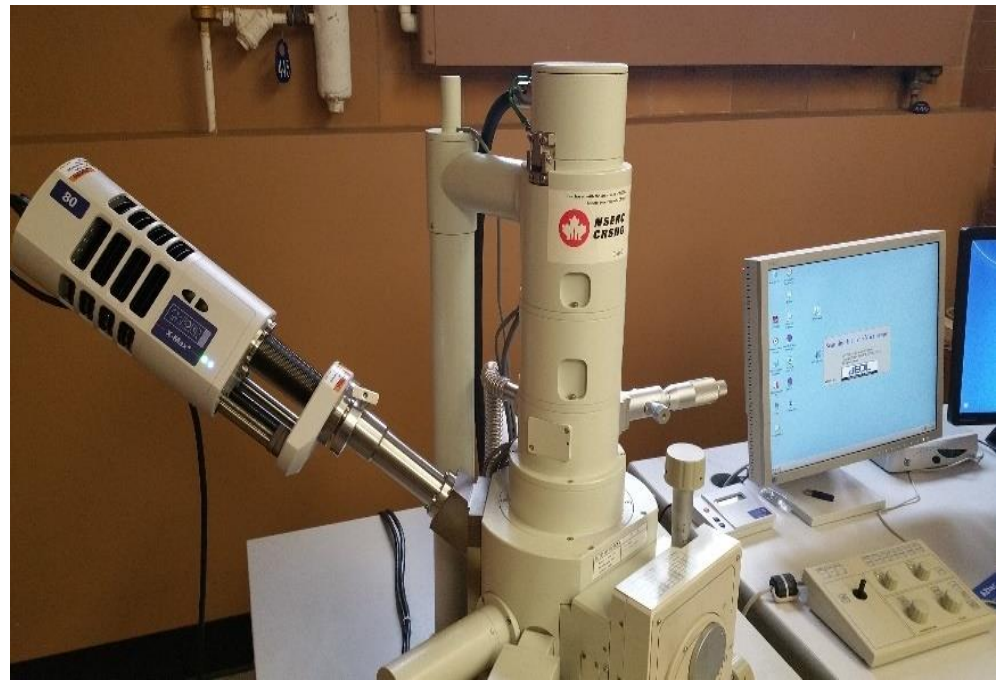

Figure 3.11: SEM Test Set Up

\subsection{Summary}

Experimental research program is described by illustrating concrete specimen preparation, material properties and test procedures. A total of 65 samples were prepared and tested. The test results will be presented and described in Chapter Four. 


\section{CHAPTER FOUR}

\section{EXPERIMENTAL RESULTS AND DISCUSSIONS}

\subsection{Introduction}

This chapter discusses the experimental results and analyzes the influence of fiber and superplasticizer dosages on fresh, mechanical and durability properties as well as micro structural characteristics of FRC mixes.

\subsection{Fresh State Properties of FRC Mixes}

\subsubsection{Flowability and Workability}

The slump flow test was carried out as per ASTM Standard C1611/C1611M (2007).As per ASTM standard, $\mathrm{t}_{500}$ (time to reach $500 \mathrm{~mm}$ slump flow) could not be estimated as all the FRC mixtures were very cohesive, sticky and not flowable. According to European SCC specifications, the minimum specified slump flow for flowable concrete is $550 \mathrm{~mm}$. FRC mixtures were not flow able despite the increase of superplasticizer (26 to $46 \mathrm{~kg} / \mathrm{m}^{3}$ ) and decrease of polyethylene fiber (from 19 to $10 \mathrm{~kg} / \mathrm{m}^{3}$ or $3 \%$ to $1.5 \%$ of total volume of concrete). However, all four FRC mixes were workable (despite not flowable) for casting specimens for this research project.

\subsubsection{Time -Temperature Response and Setting Time}

Figures 4.1 to 4.4 presents the evolution of temperature with time for FRC mixes P19 S26 and P10 S26. Table 4.4 summarizes the $2^{\circ} \mathrm{C}$ increase in temperature in 1 hour for both mixes with required time (considered as setting time of the concrete mixtures), maximum temperature and time to reach maximum temperature. 


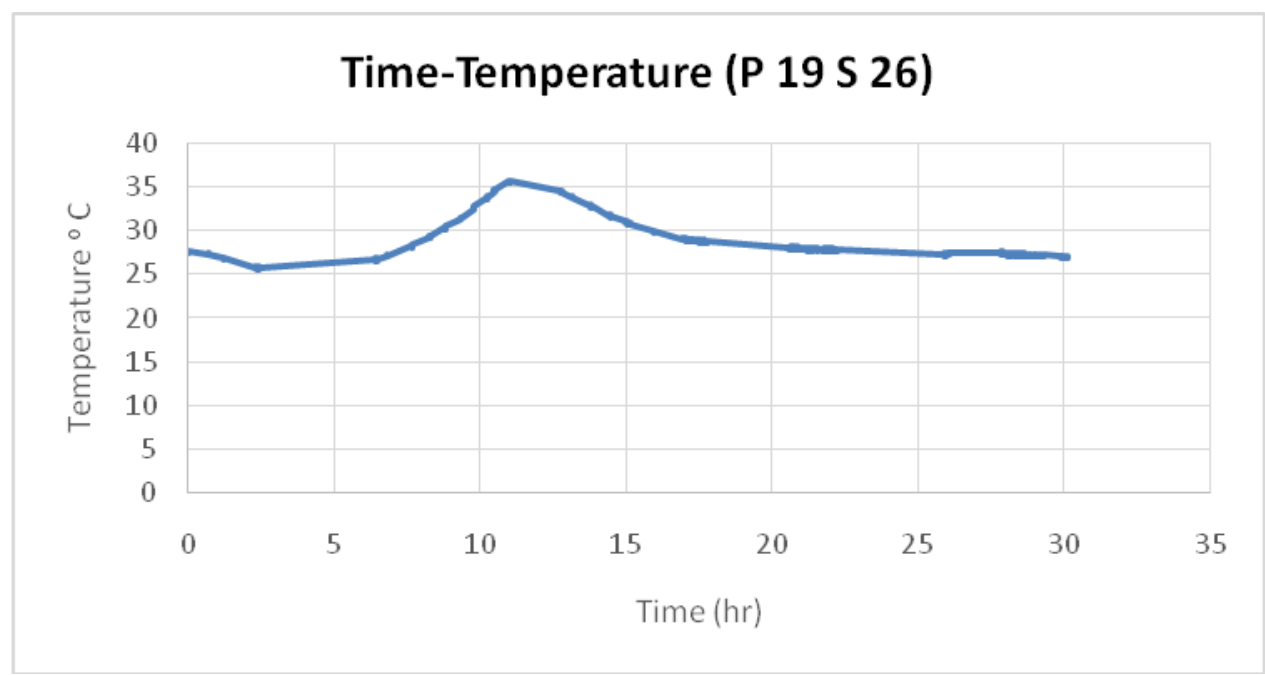

Figure 4.1: Time vs. Temperature Graph for FRC Mix P19 S26

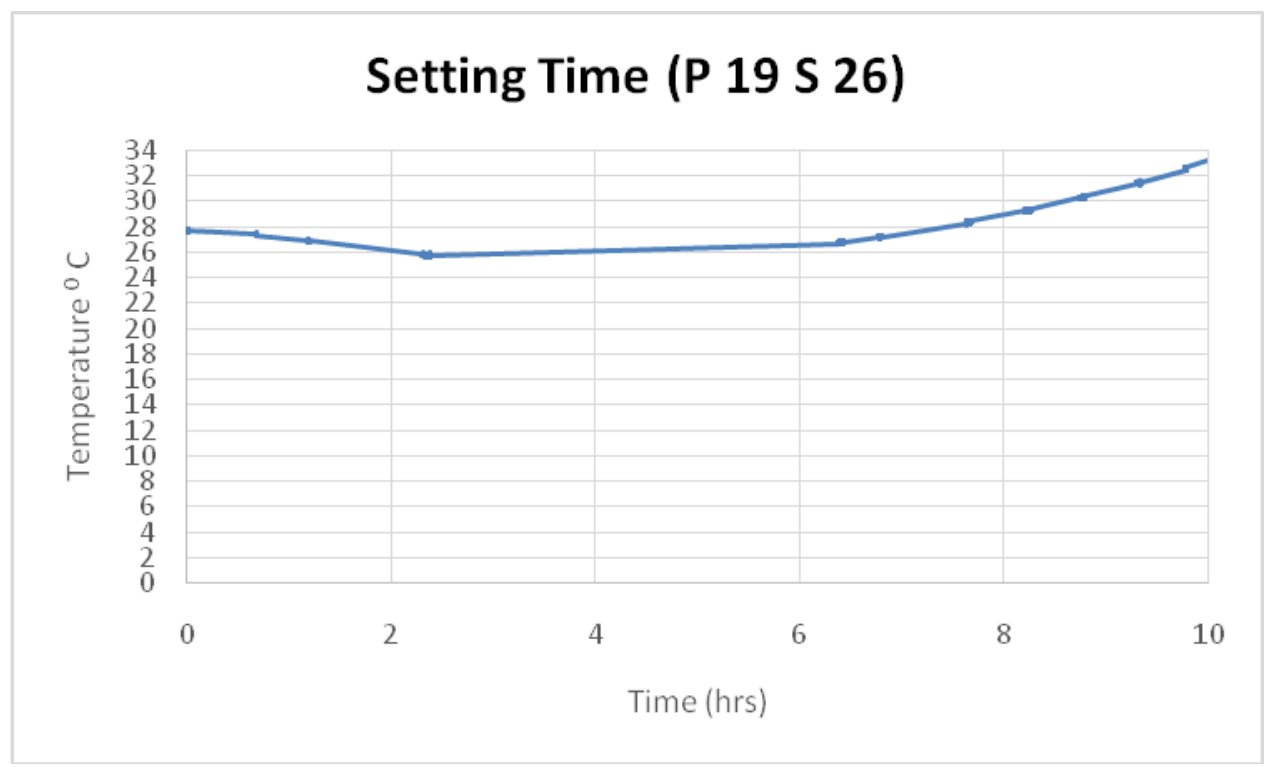

Figure 4.2: Time vs. Temperature Graph for FRC Mix P19 S26 ( $\left.2^{\circ} \mathrm{C}\right)$ 


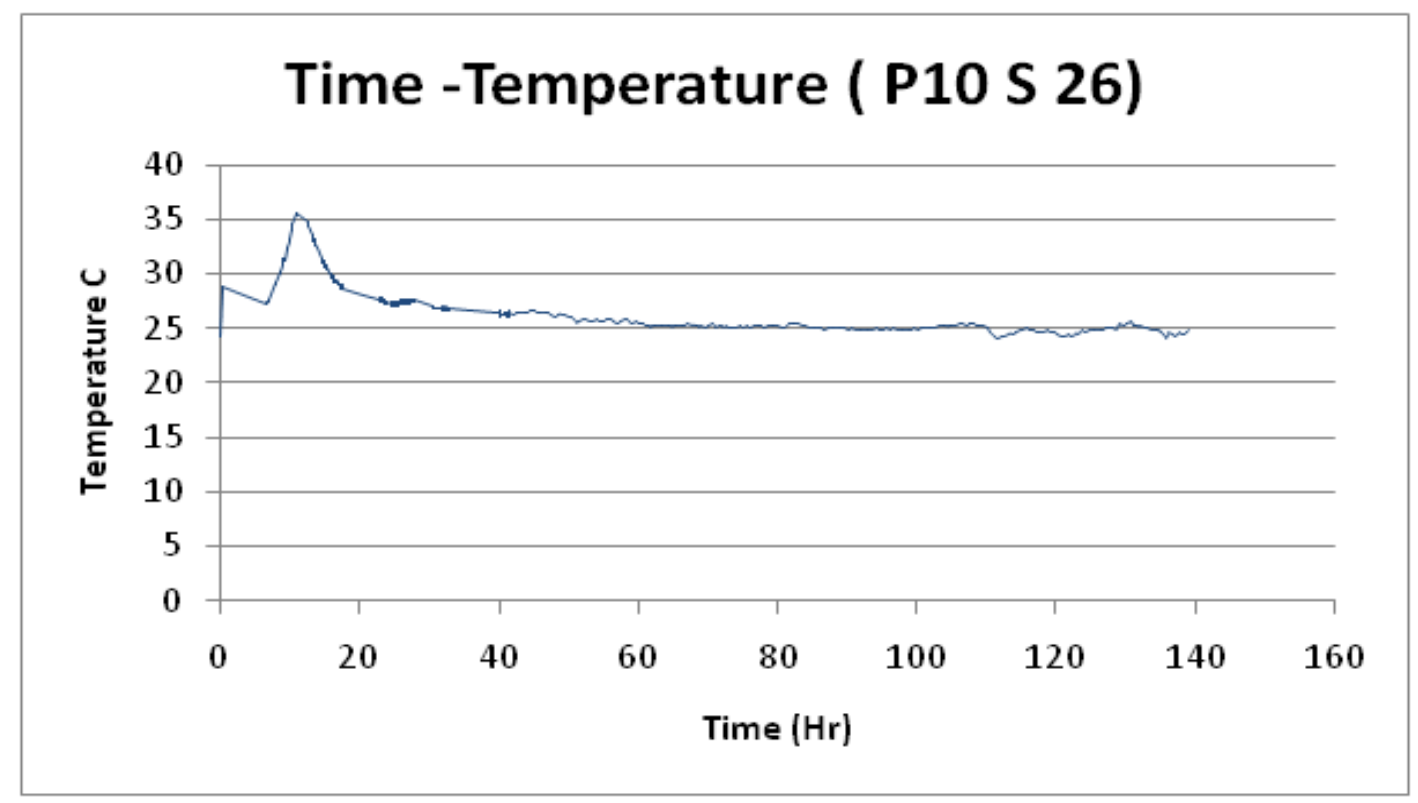

Figure 4.3: Time vs. temperature Graph for P10 S26

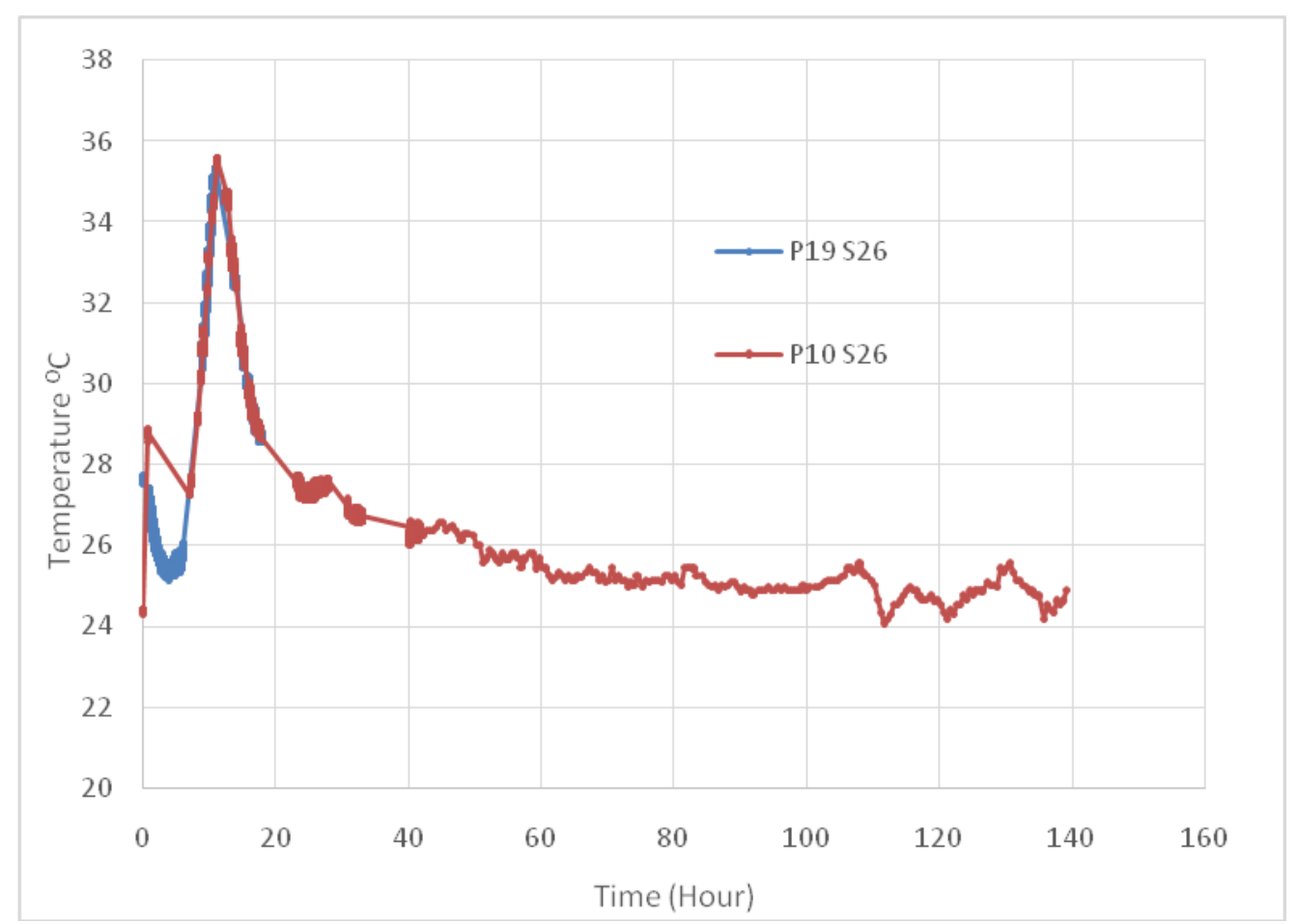

Figure 4.4: Comparison of Time vs. Temperature Responses of FRC Mixes 
Table 4.1: Summary of Temperature-Time Evolution and Setting Time (P19 S26 and P10 S26)

\begin{tabular}{|c|c|c|c|c|c|}
\hline $\begin{array}{l}\text { FRC } \\
\text { mixes }\end{array}$ & $\begin{array}{l}\text { Time } \\
\text { (hrs) }\end{array}$ & $\begin{array}{c}\text { Temperature } \\
\left({ }^{\circ} \mathrm{C}\right)\end{array}$ & $\begin{array}{l}\text { Temperature } \\
=\text { Difference } \\
\left({ }^{\circ} \mathrm{C}\right)\end{array}$ & $\begin{array}{l}\text { Time to Reach } \\
\text { Maximum } \\
\text { Temperature }\end{array}$ & $\begin{array}{c}\text { Maximum } \\
\text { Temperature } \\
\left({ }^{\circ} \mathrm{C}\right)\end{array}$ \\
\hline P19 & 8.43 & 29.61 & \multirow{2}{*}{2.00} & \multirow{2}{*}{11} & \multirow{2}{*}{$35^{\circ} \mathrm{C}$} \\
\hline S26 & $9.43^{*}$ & 31.61 & & & \\
\hline P10 & 8.00 & 28.82 & \multirow[b]{2}{*}{2.00} & \multirow{2}{*}{$\begin{array}{l}15 \\
\text { *setting time by } 2^{\circ} \mathrm{C} \\
\text { temperature rise method }\end{array}$} & \multirow[b]{2}{*}{$35^{\circ} \mathrm{C}$} \\
\hline S26 & $9.005^{*}$ & 30.82 & & & \\
\hline
\end{tabular}

It is found that from figure 4.1 to 4.4 and table 4.1 that setting time increased (from 9 hours to 9.43 hours) with the increase of fiber quantity from 10 to $19 \mathrm{~kg} / \mathrm{m}^{3}$. The calculation of setting time was based on $2^{\circ} \mathrm{C}$ temperature difference in 1 hour concept (Hossain, 2008). P19S26 sample has final setting time 9.43 hours than 9 hours for P10 S 26 sample. In both case maximum temperature was $35{ }^{\circ} \mathrm{C}$ but it came at 11 hours for P19 S26 sample and 15 hours for P10 S26 samples. The setting time mostly depends on hydration of cement producing microscopic mineral products that link adjacent cement grains to each other. As hydration progresses, each cement grain is bound more tightly to its neighbors, so that it becomes more difficult for an outside force to deform the concrete. The increase of setting time with the increase of fiber may be attributed to the decrease of inert silica sand (associate with the reduction of paste content) in the P19S26 mixture that reduced the hydration reaction. The reduced hydration reaction of P19 S26 was also evident from the lower early temperature development of this mixture compared to P10S26. Both mixtures showed similar trend of variation of temperature evolution with time despite different dosages of polyethylene fiber. 


\subsection{Mechanical Properties of FRC Mixtures}

\subsubsection{Compressive Strength}

Figure 4.5 shows the evolution of cube compressive strength for four FRC mixtures with time (up to 28 days). Generally the cube strength increased rapidly up to the age 7 days and then rate decreased. Table 4.2 summarizes the cube and cylinder strength of all four FRC mixtures. The 14-days and 28-days cube compressive strengths of the P19 S26 concrete mix were $80 \mathrm{MPa}$ and $96 \mathrm{MPa}$, respectively (Table 4.2). The 14-days cube compressive strength ranged for all mixes ranged between $65 \mathrm{MPa}$ and $80 \mathrm{MPa}$. On the other hand, 28-days cube compressive strength ranged between $86 \mathrm{MPa}$ and $96 \mathrm{MPa}$. The 28-day cylinder strength for FRC mixes ranged between $93 \mathrm{MPa}$ to $100 \mathrm{MPa}$. The increase of PE fiber content improved the compressive strength but not that significantly. A 5\% change in compressive strength showed that fiber addition did not have a significant influence on the compressive strength of FRC. Previous research studies have also found this to be true. This can be attributed to the fact that the fiber addition causes some perturbation of the matrix, which can result in higher void. Voids can be seen as defects where micro cracking starts. In addition to fiber quantity, perturbation also depend the ability of the matrix to accommodate fibers, which is an important property of the mortar fraction of the concrete. Therefore, the influence of fibers on the compressive strength may be seen as the balance between micro-crack bridging and additional voids caused by fiber addition (Hossain 2008 and 2013).As the percentage of fibers is increased, the sudden and brittle failure of sample is resisted. Increase in fiber-cement ratio tends to create voids in concrete (though thoroughly compacted) because of improper bonding of materials in concrete with increase in fibers (Naaman 2005).

Concrete compressive strength requirements can vary from $17 \mathrm{MPa}$ for residential concrete to $28 \mathrm{MPa}$ and higher in commercial structures. Higher strengths up to and exceeding 70MPa are specified for certain applications. The 28-days cylinder compressive strengths as per table 4.2 are 99.34 MPa (P19 S26), 92.25 MPa (P19 S46), 94.83MPa (P10 S26) and 95.44 MPa (P10 S 
46). So, all FRC mixtures can be treated as high strength concrete (Hossain 2013, Lin 1999, Li 2001, 2002b).

Effect of increasing superplasticizer content on compressive strength of FRC mixtures was not significant (Figure 4.5 and Table 4.2).

Table 4.2: Compressive Strength of FRC Mixes

\begin{tabular}{|l|c|c|c|c|c|}
\hline FRC Mixes & \multicolumn{5}{|c|}{ Mean Compressive Strength (MPa) } \\
\hline & \multicolumn{5}{|c|}{ Cube } \\
\hline & 7 day & 14Day & 21 Day & 28 Day & 28 Day \\
\hline P19S26 & 79.17 & 79.71 & 82.09 & 95.76 & 99.34 \\
\hline P19 S46 & 39.83 & 64.13 & 65.07 & 86.32 & 92.25 \\
\hline P10 S26 & 64.07 & 70.65 & 90.30 & 92.16 & 94.83 \\
\hline P10 S46 & 65.59 & 66.65 & 70.20 & 95.44 & 95.44 \\
\hline
\end{tabular}

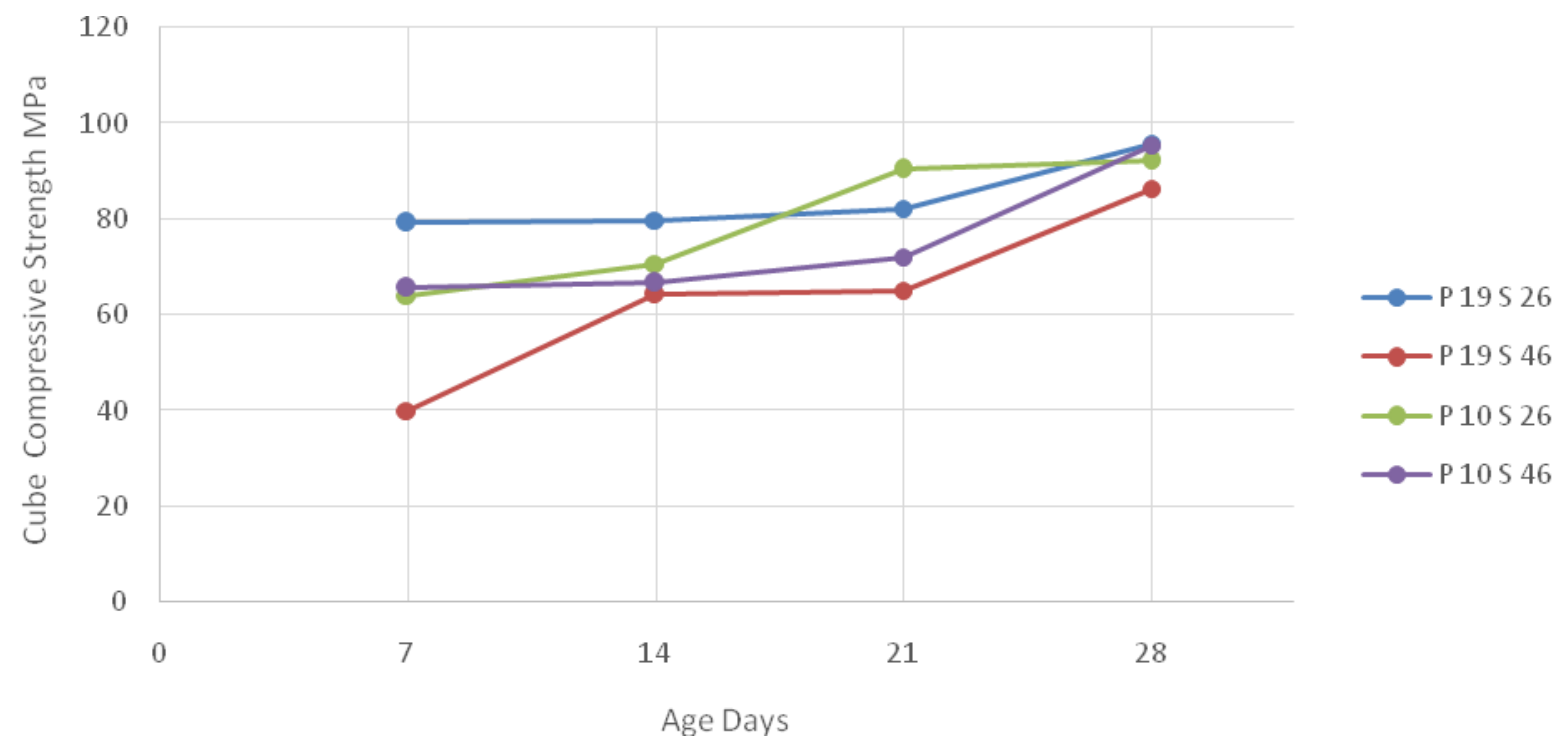

Figure 4.5: Evolution of Cube Compressive Strength with Age 


\subsubsection{Flexural Strength}

For FRC mixtures, the 28-days flexural strength ranged between14.0 MPa and 15.0 MPa (Table 4.3).A 28-days flexural strength increase of $7 \%$ was obtained for the FRC mixture with $1.5 \% \mathrm{PE}$ fiber compared to those with 3\% (by volume of mixture). Usually increase in PE fiber should increase the flexural strength of FRC but in this study a slight decrease was observed with the increase in fiber (Hossain, 2013). The decrease in paste volume with the increase in fiber may be attributed to this fact.

Figure 4.7 shows flexural load-displacement response of FRC mixtures. FRC mixtures showed sudden drop in load immediately after the first peak (sowing brittle behavior with no strain hardening though post-peak response was characterized by increase in load. The length of fiber also may be a factor. In this study $20 \mathrm{~mm}$ long PE fiber was used compared to $12.7 \mathrm{~mm}$ used by Ranade (2013). High strength FRCs developed by Ranade (2013) showed ductile behavior. FRC carries increasing loads after the first cracking of the matrix if the pull-out resistance of the fibers at the first crack is greater than the load at first cracking. At the cracked section, the matrix does not resistant tension and the fibers carry the entire load taken by the composite. With an increasing load on the composite, the fibers will tend to transfer the additional stress tithe matrix through bond stresses. This process of multiple cracking will continue until either fibers fail or the accumulated local deboning will lead to fiber pull-out.

Table 4.3: Flexural Strength of FRC Mixtures

\begin{tabular}{|l|c|c|}
\hline \multicolumn{1}{|c|}{ FRC Mix } & \multicolumn{2}{|c|}{} \\
\hline & $\begin{array}{c}\text { Flexure Strength } \\
\text { (MPa)-28 Days }\end{array}$ & $\begin{array}{c}\text { Fracture Energy } \\
(\mathrm{N} / \mathrm{m}) \\
\mathbf{2 8} \text { days }\end{array}$ \\
\hline & Flexure & Fracture \\
\hline P19S26 & 14.0 & 130 \\
\hline P19 S46 & 14.2 & 129.54 \\
\hline P10 S26 & 15.5 & 76.45 \\
\hline P10 S46 & 15.0 & 76.10 \\
\hline
\end{tabular}




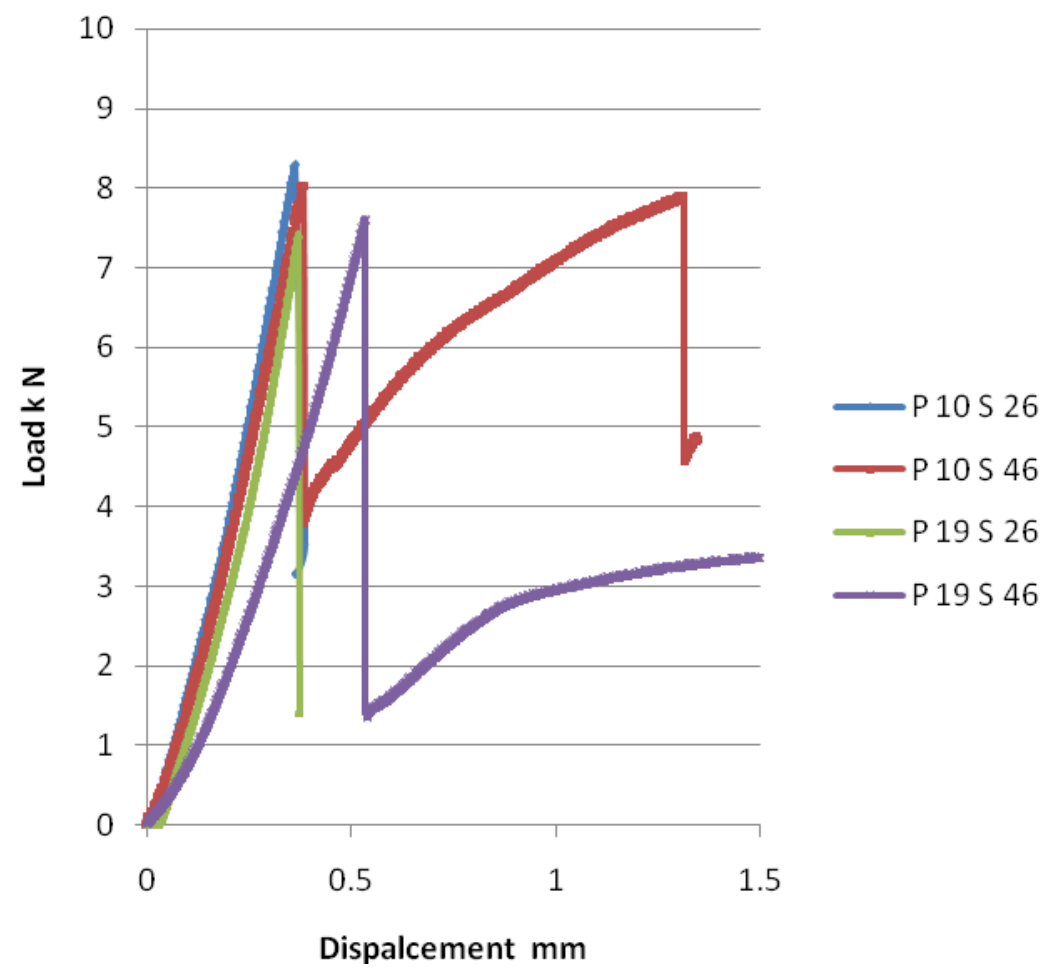

Figure 4.6: Flexural Load-Displacement Responses of FRC Mixtures

With respect to PE based FRCs in this study, the following facts can be summarized:

- To bridge the large number of micro cracks in the FRC composite under load and to avoid large strain localization, it is necessary to have a large number of short fibers. The uniform distribution of short fibers can increase the strength and ductility of the composite (Figure 4.6).

- Long fibers are needed to bridge discrete macro cracks at higher loads; however the volume fraction of long fibers can be much smaller than the volume fraction of short fibers. The presence of long fibers significantly reduces the workability of the mix as observed in this study.

- The concrete with polyethylene fiber is too strong with strong bonding. Thus there is no flexibility for long fiber in strong bond and finally breaks at a lower strength as fiber cannot put any effect in increasing load at $1.5 \%$ or $3 \%$ by volume of concrete (which was the case for this study). 
- An effort had been made to continue the test after the first crack. It is found that in matrix due to tension at the bottom and compression at the top, the bottom fibers tend to tear. The concrete has high bond strength and it only permitted tearing of fiber from matrix.

- Even in SEM analysis (as will be described later) there were no sign of fiber pull out and the fibers are too long to be pulled out from the matrix.

- Reduction of PE fiber dosages and fiber length may provide ductility and strain hardening properties.

- The superplasticizer actually did not have a significant effect on flexural strength as can be seen from table 4.3 and figure 4.6 .
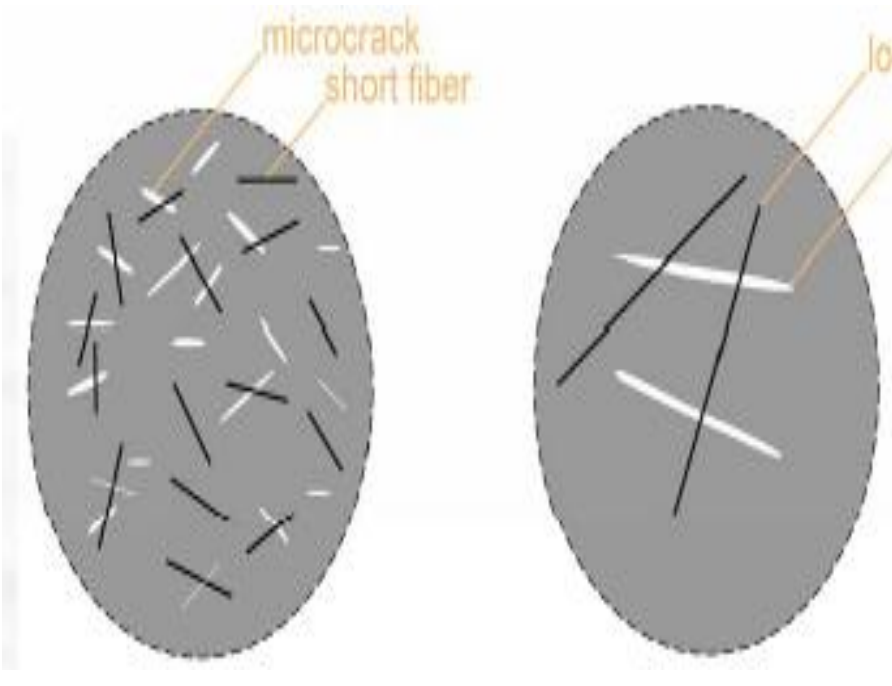

Figure 4.7: Effects of Short Fiber on Micro-Cracking and Long Fiber on Macro-Cracking (Ranade, 2013)

\subsubsection{Fracture Energy}

Figure 4.8 shows load-deflection curves from fracture energy tests. Generally, an increase in fiber volume increased the area under the load-deflection curve, which signifies the higher 
fracture energy of the mixtures. The 28-days fracture energies were $130 \mathrm{~N} / \mathrm{m}$ and $77 \mathrm{~N} / \mathrm{m}$ for FRC mixes with PE fiber content of $3 \%$ and $1.5 \%$ by volume, respectively (Table 4.3 ).

The increase in strength and fracture energy is assumed to be due to the fact that the interaction of PE with cement forms a molecular bond - cement slurry is attracted by PE and makes chemically attracted layer which peels of the surface of PE fiber forming strong bonding between fiber and cement matrix.

The superplasticizer dosage did not have a significant influence on fracture energy of FRC mixes (Table 4.3).

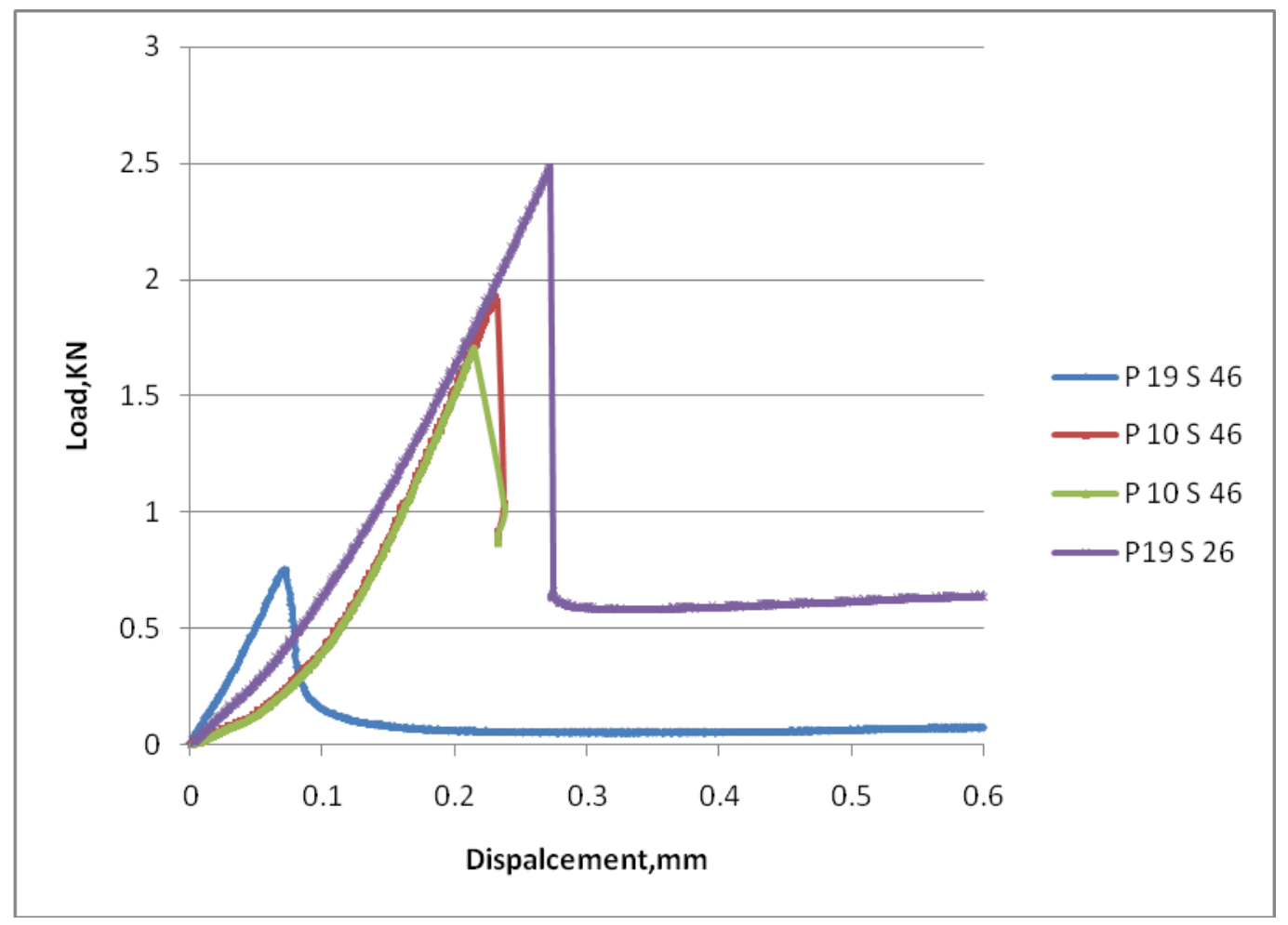

Figure 4.8: Load -Displacement Responses of FRC Mixtures from Fracture Energy Tests 


\subsubsection{Modules of Elasticity and Stress-Strain Characteristics}

Figures 4.9 to 4.14 show load-strain and stress-strain curves for FRC mixtures. P19S26 and P10S26 showed ultimate compressive strain of 0.0038 and 0.0039 , respectively (compared to 0.003 of normal concrete).

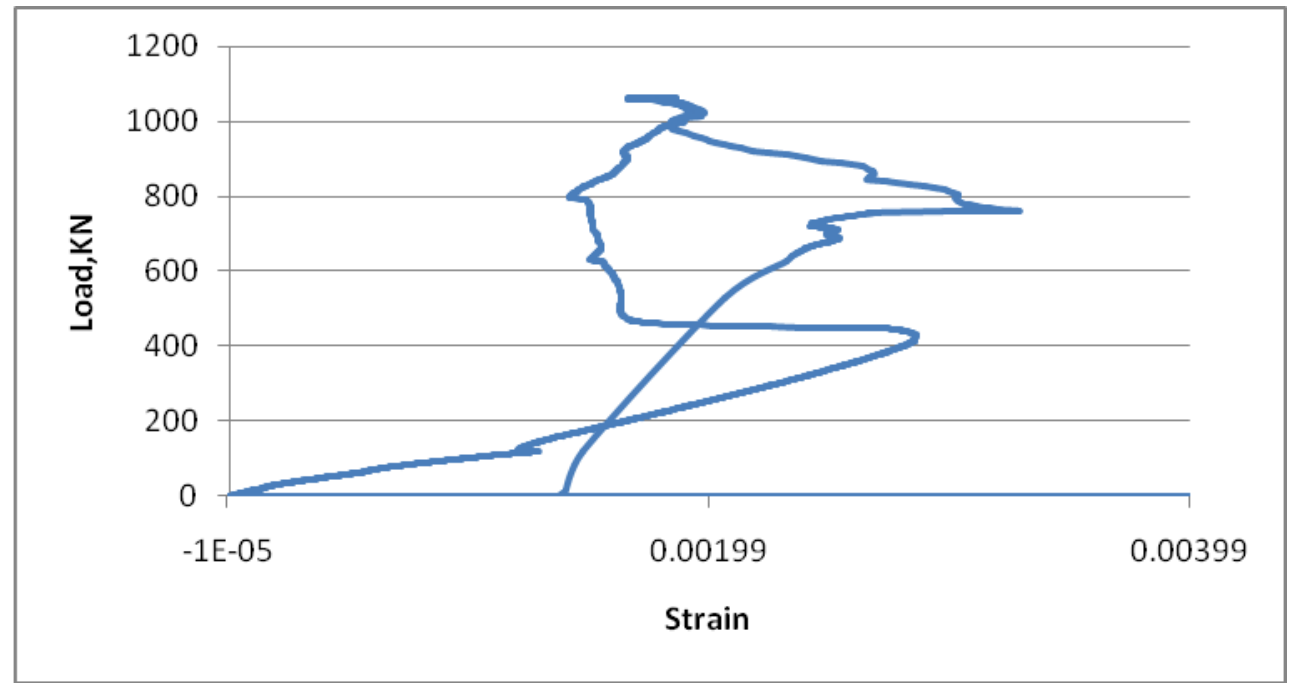

Figure 4.9: Load vs. Strain Graph (P19 S26)

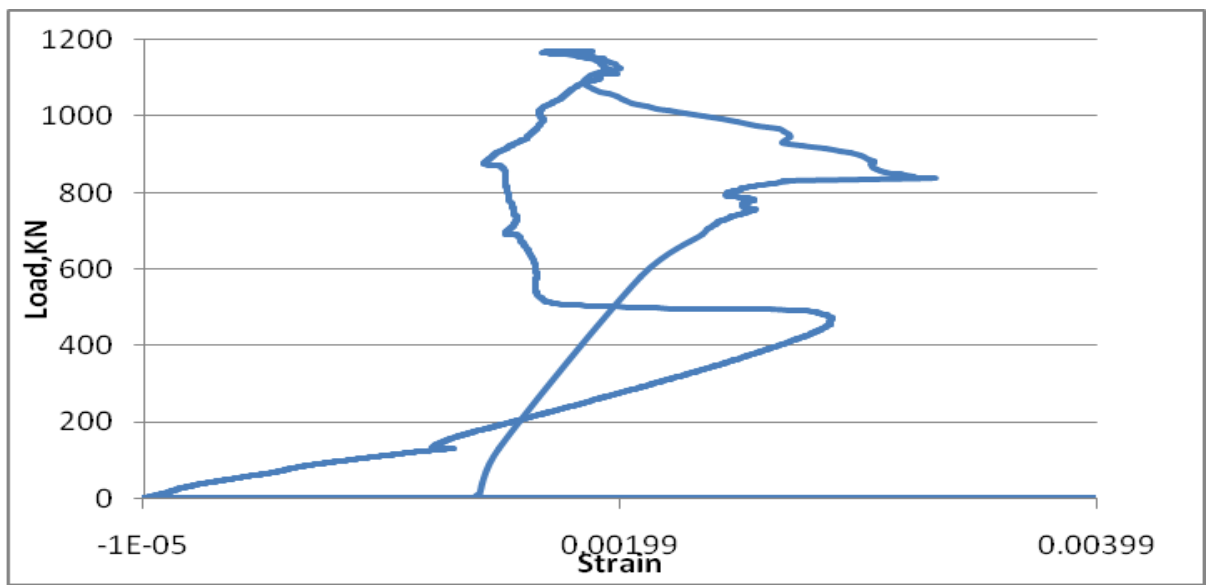

Figure 4.10: Load vs. Strain Graph (P10 S26) 


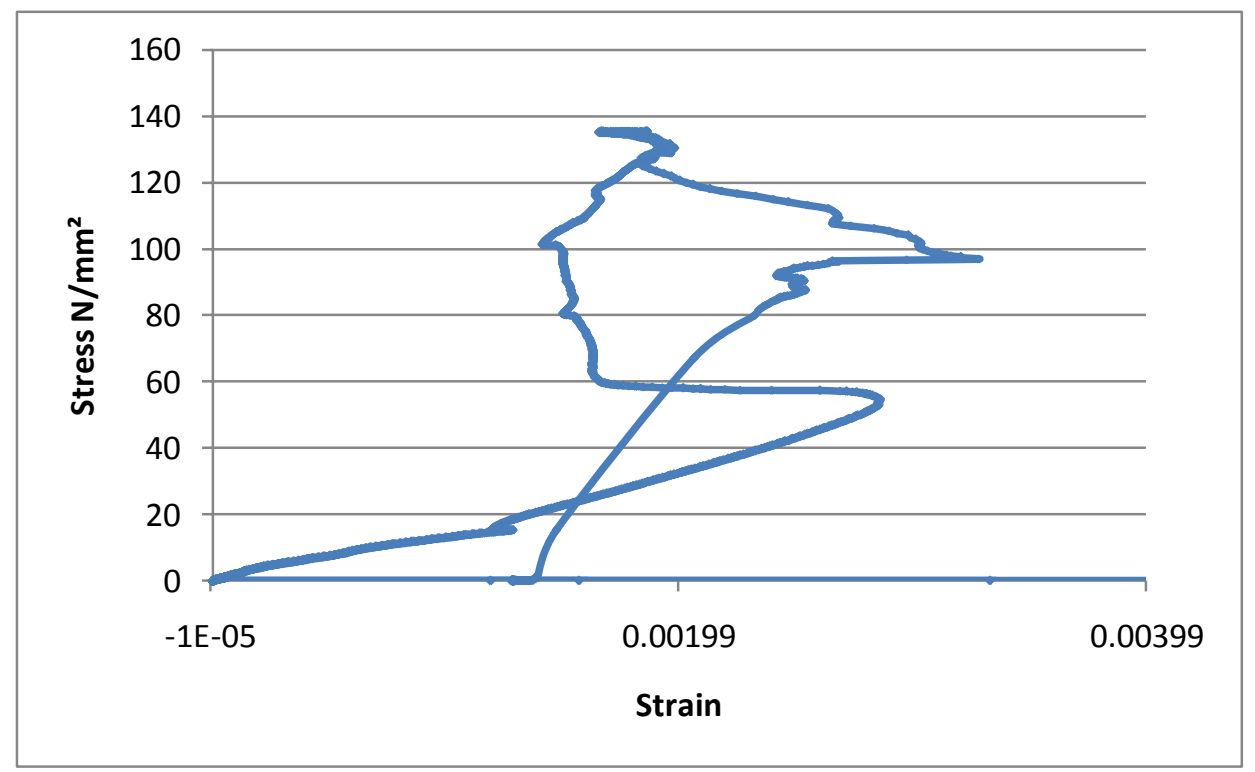

Figure 4.11: Stress vs. Strain Graph (P19 S26)

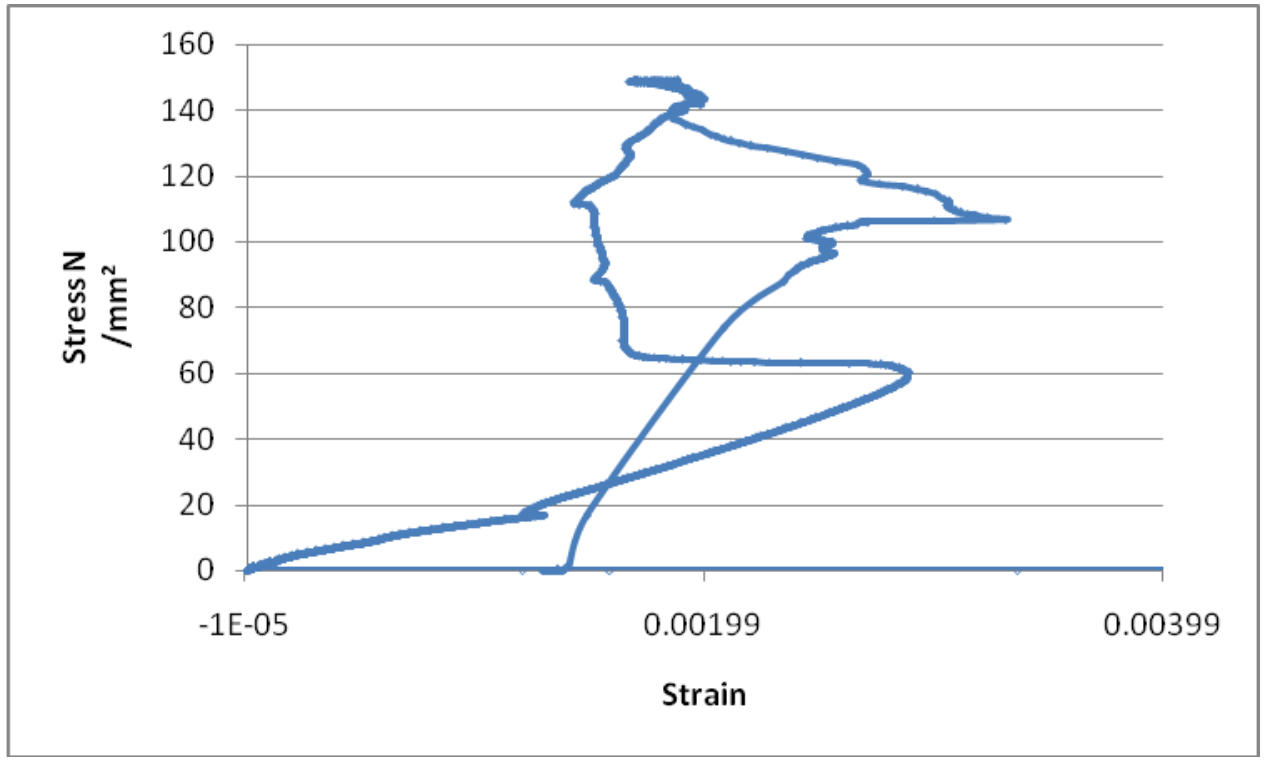

Figure 4.12: Stress vs. Strain Graph (P10 S26) 


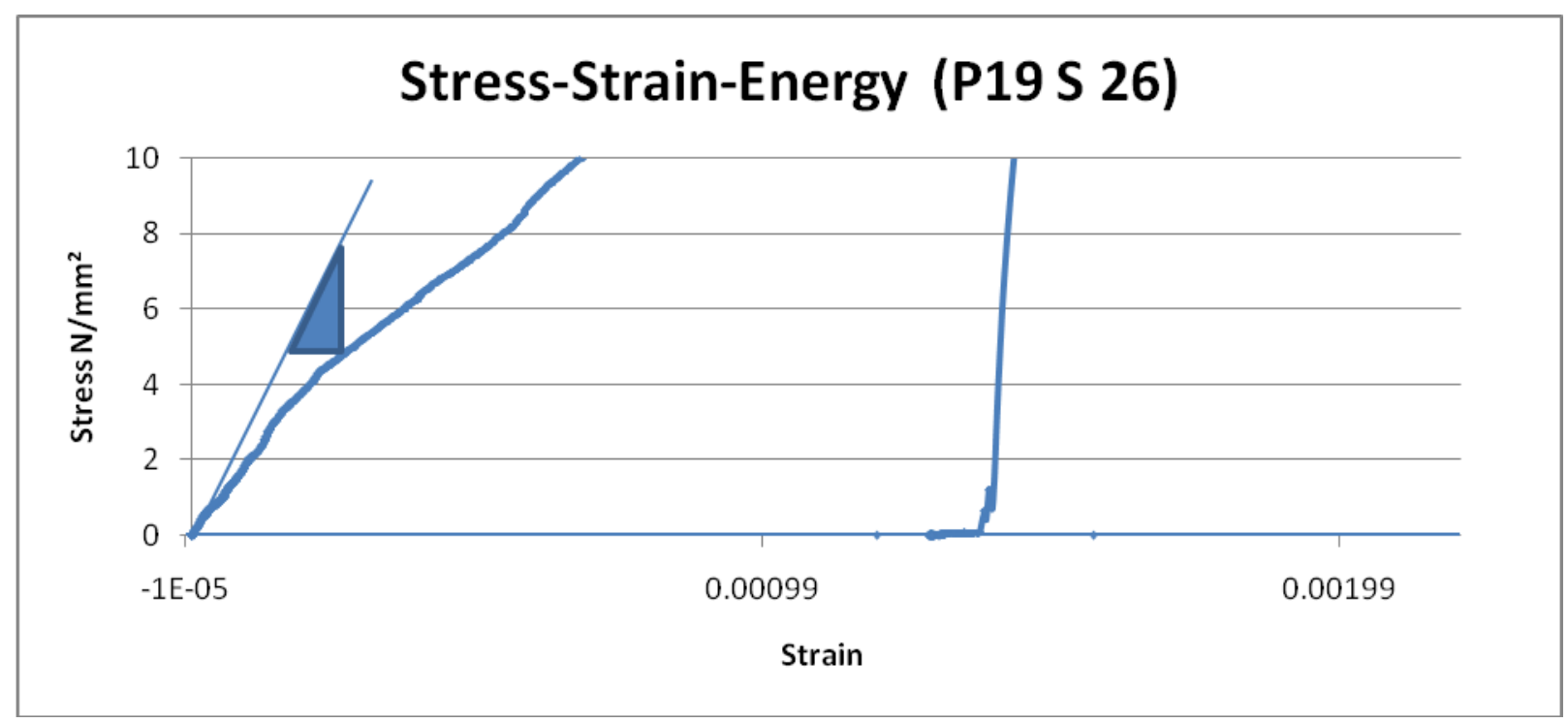

Figure 4.13: Stress vs. Strain Graph (P19 S26)

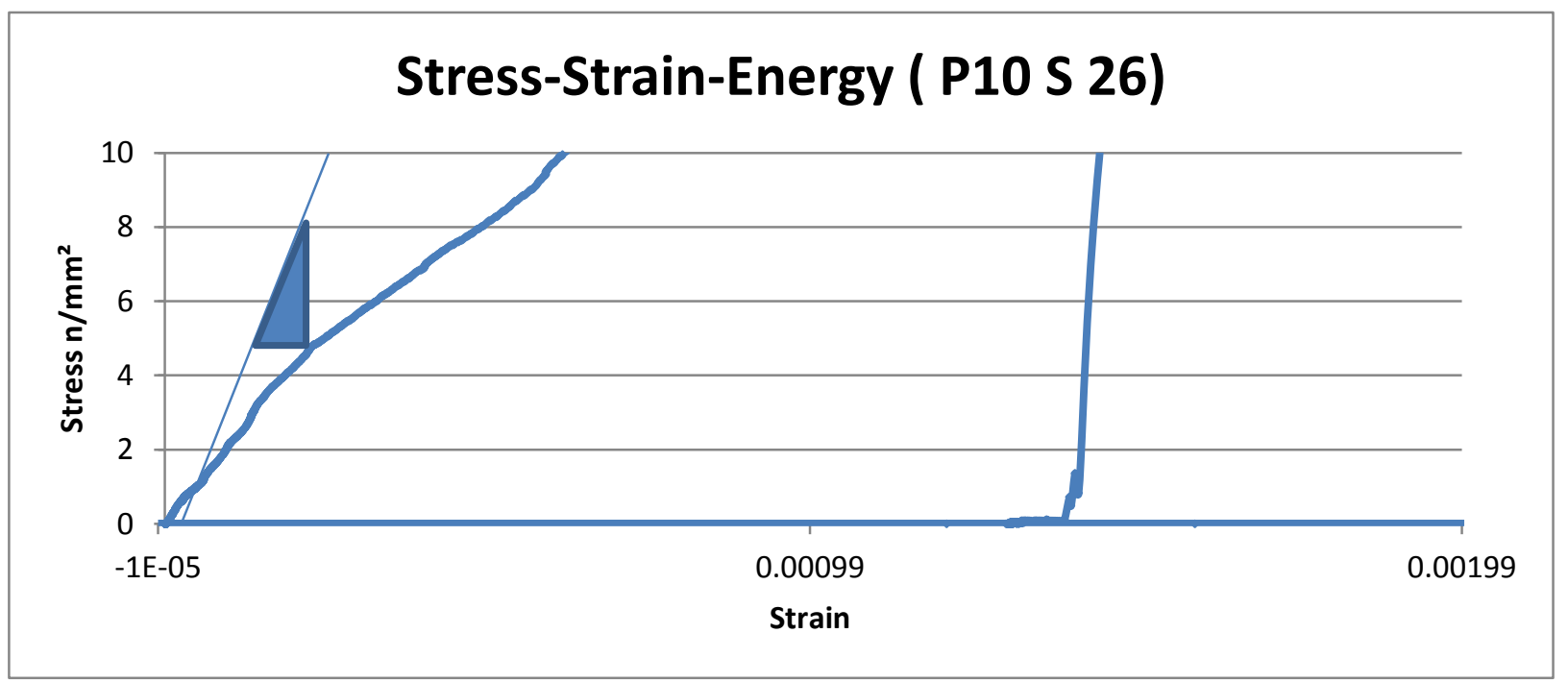

Figure 4.14: Stress vs. Strain Graph (P10 S 26)

Modulus of elasticity $(E)$ is a number that measures substance's resistance to being deformed elastically (non-permanently) when a force is applied to it. Based on figure 4.13 and figure 4.14, the E values for P19S26 and P10S26 are 32.4 GPa and $32.0 \mathrm{GPa}$, respectively. The E value of normal concrete is 17 GPA and high strength concrete is $30 \mathrm{GPa}$ (Nougchi, 2009). So the modulus of elasticity of FRC mixes with PE fiber is higher than normal concrete and close to 
high strength concrete. Although the value of is not significantly different, FRC mixes with higher PE fiber showed higher E value. Again no significant effect of superplasticizer was observed on the modulus of elasticity.

\subsection{Durability Properties of FRC mixes}

Table 4.4 presents rapid chloride permeability (RCP) of FRC mixtures. In general, chloride penetration resistance decreased with the addition of fibers (Hossain, 2010). But in this study, no significant influence of PE fiber and superplasticizer on RCP values of FRC mixtures was observed. According to ASTM C 2012 (2007) specification presented in table 4.5, the chloride permeability of all four FRC mixtures is "very low". The chloride permeability of PE FRC mixtures was found to be significantly lower than those made with PVA (Hossain, 2010). The too denser FRC mixes (density is $2475 \mathrm{~kg} / \mathrm{m}^{3}$ ) is the reason for the very low permeability.

Table 4.4: RCP Test Summary of FRC Mixes

\begin{tabular}{|c|c|c|c|c|c|}
\hline $\begin{array}{c}\text { Mix } \\
\text { Design }\end{array}$ & $\begin{array}{c}\text { Reading 1 } \\
\text { (Coulombs) }\end{array}$ & $\begin{array}{c}\text { Reading 2 } \\
\text { (Coulombs) }\end{array}$ & $\begin{array}{c}\text { Reading 3 } \\
\text { (Coulombs) }\end{array}$ & $\begin{array}{c}\text { Avg. RCP } \\
\text { (Coulombs) }\end{array}$ & Remarks \\
\hline P19 S26 & 125 & 175 & 187 & 162 & Very Low \\
\hline P19 S46 & 133 & 159 & 196 & 162 & Very Low \\
\hline P10 S26 & 163 & 148 & 167 & 159 & Very Low \\
\hline P10 S46 & 162 & 149 & 168 & 160 & Very Low \\
\hline
\end{tabular}

Table 4.5: Specification of Ion Penetrability on Charge Passed ASTM C 1202(2007)

\begin{tabular}{|l|l|}
\hline Charge Passed (Coulombs) & Chloride lon Penetrability \\
\hline$>4000$ & High \\
\hline $2000-4000$ & Moderate \\
\hline $1000-2000$ & Low \\
\hline $100-1000$ & Very Low \\
\hline$<100$ & Negligible \\
\hline
\end{tabular}




\subsection{Micro structural Properties of FRC mixtures}

Micro structural investigation using scanning electron microscopy (SEM) was conducted to describe fiber typology, fiber-matrix bond and the mechanical/durability properties of the FRC

mixtures. Specimens of FRC mixtures were examined by SEM and Energy Dispersive Spectroscopy (EDS).SEM and EDS analyses with photographs are presented in Appendix A as per table 4.6.

Table 4.6: SEM and EDS Analyses of FRC Mixtures

\begin{tabular}{|c|c|c|c|}
\hline FRC Mix & Picture & Resolution & Comments \\
\hline \multirow[t]{7}{*}{ P19 S 26} & SEM P19 S 26 -1 & 700 & \multirow[t]{7}{*}{ Pictures at Appendix $A$} \\
\hline & SEM P19 S $26-2$ & 10,000 & \\
\hline & SEM P19 S 26 -3 & 500 & \\
\hline & SEM P19 S 26 -4 & 1500 & \\
\hline & SEM P19 S $26-5$ & 3000 & \\
\hline & SEM P19 S $26-6$ & 200 & \\
\hline & SEM P19 S $26-7$ & 3000 & \\
\hline \multirow[t]{5}{*}{ P10 S26 } & SEM P10 S26-1 & 50 & \multirow[t]{5}{*}{ Pictures at Appendix A } \\
\hline & SEM P10 S26-2 & 200 & \\
\hline & SEM P10 S26-3 & 2000 & \\
\hline & SEM P10 S26-4 & 7000 & \\
\hline & SEM P10 S26-5 & 500 & \\
\hline
\end{tabular}

Selected SEM and EDS pictures of FRC mixes are chosen in this section for description. SEM photos in figure 4.15 shows no difference of matrix in different parts (uniform matrix) of the sample. The higher fiber content is significant in P19 S26 SEM pictures. The pictures are taken at a different resolution for better fiber location. The presence of carbonation is also present as all the samples were tested after 44 days of keeping in the lab shelf. The Interfacial transition Zone (ITZ) is not very clearly visible as all FRCs have highly dense matrix. 

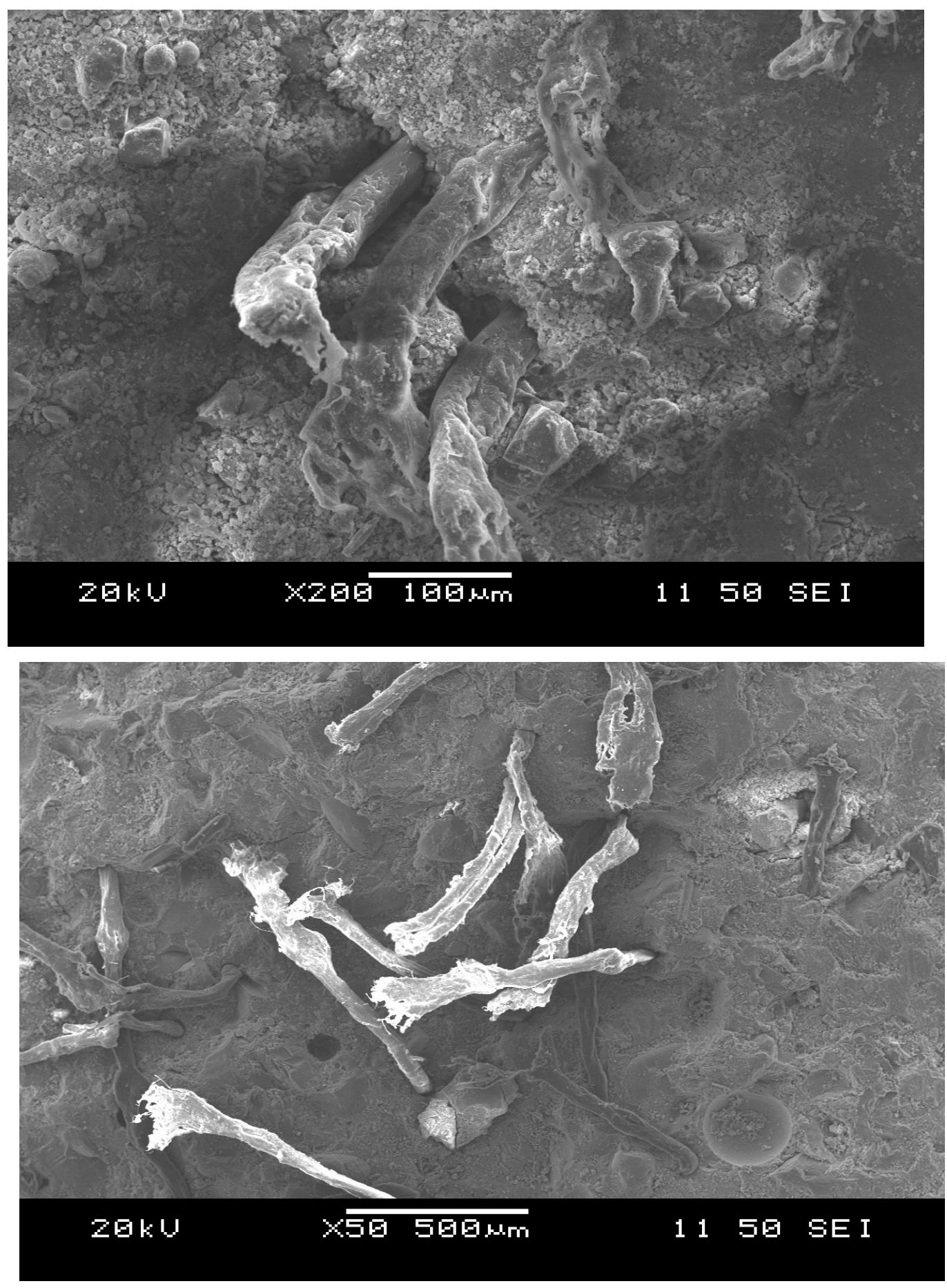

Figure 4.15: SEM Photographs (P19 S26, Bottom and P10 S26, Top) 
In appendix B, the EDS analysis data with photograph are shown for P19 S26 (seven analysis from P19 S26-1 to P19 S26-7) and P10 S26 (three analysis from P10 S26 -1 to P10 S26-3) samples. In both FRC mixes, the concentration of Calcium (Ca) and Silica (Si) are seen at a higher rate (typical ones are shown in Figure 4.16). For P19 S26, Ca concentration is higher and Silica (Si) is lower than P10 S26. This can be attributed to the lower quantity of silica sand in P19 S26 compared to P10 S26. The presence of C also an indication of minor carbonation. In the samples, no $\mathrm{C}-\mathrm{H}$ was found and due to presence of extra silica which reacts with $\mathrm{C}-\mathrm{H}$ to produce $\mathrm{C}-\mathrm{S}-\mathrm{H}$ producing a strong matrix. The following facts can be highlighted from SEM and EDS observations:

- The $\mathrm{C}-\mathrm{S}-\mathrm{H}$ matrix of high strength FRC materials is mainly composed of high density $\mathrm{C}-\mathrm{S}-\mathrm{H}$ characterized by intrinsic higher stiffness and hardness values than Low density C-S-H that dominates normal concrete materials.

- SEM analysis provides strong evidence that there is no weak fiber-matrix interface zone in samples. It is due to the predominant presence of high density C-S-H which ensures a uniform composite behavior.

- SEM analysis shows a defect free interfacial transition zone (ITZ).

- Well compacted and cured FRCs containing PE fibers seem to possess excellent durability as long as fibers remain protected by the cement paste. Highly dense matrix with strong ITZ can be attributed to the development high strength and very low permeability of FRC mixtures. 

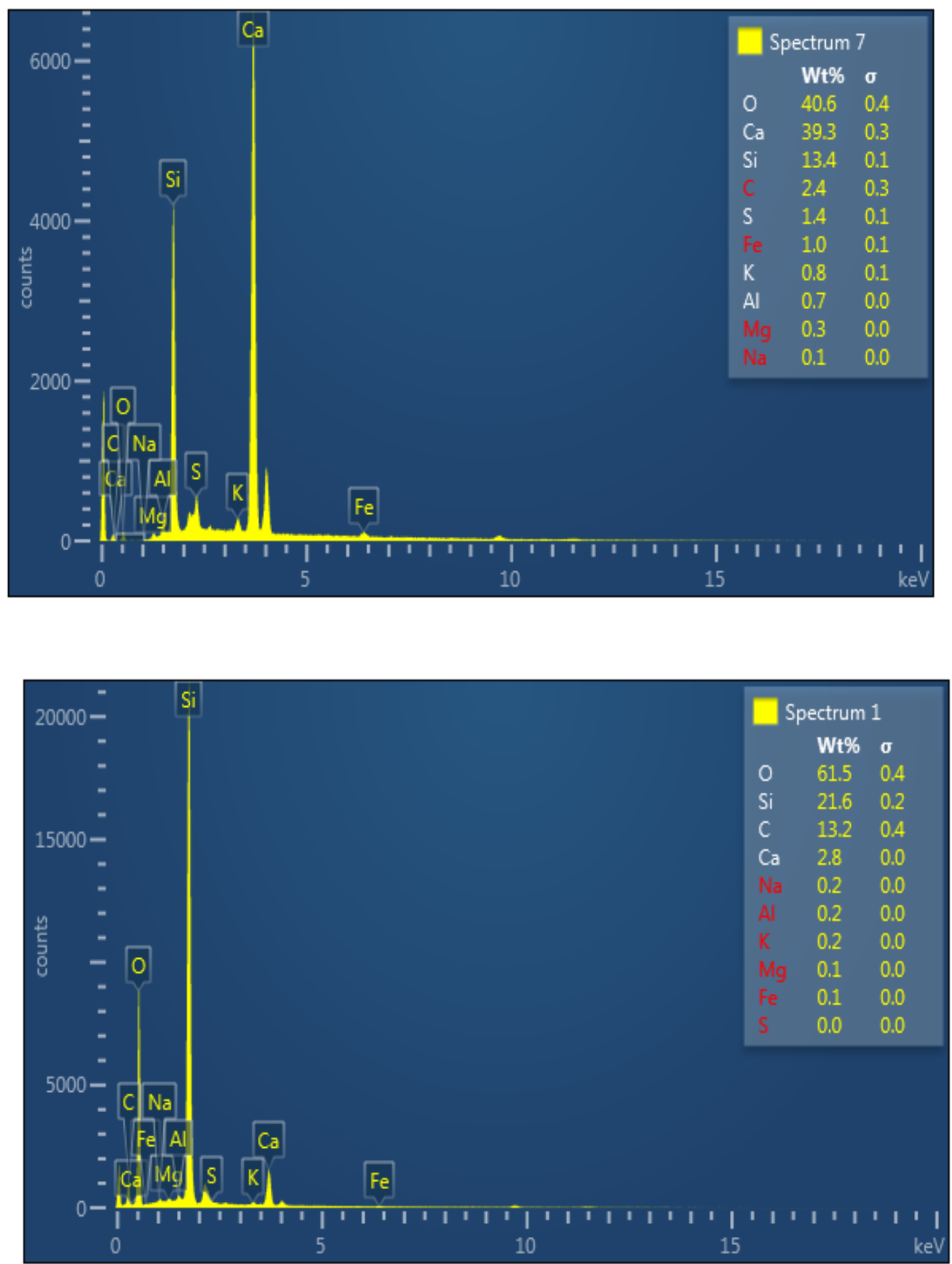

Figure 4.16: EDS Analysis Showing Materials Constituents in Sample -P19 S26 (Top) and P10 S 26 (Bottom) 


\subsection{Summary}

The fresh state, mechanical and durability properties of FRC mixtures with PE fibers are described based on experimental results. Formation of first flexural crack was observed like ordinary concrete and FRC did not show any tensile ductility. The RCPT results were very low for the FRC mixtures. The SEM/EDS analyses showed the presence of $\mathrm{C}-\mathrm{S}-\mathrm{H}$ and no $\mathrm{C}-\mathrm{H}$. The FRC matrix ITZ were defect free and strong. 


\section{CHAPTER FIVE}

\section{CONCLUSIONS AND FUTURE RECOMMENDATIONS}

\subsection{Conclusions}

Four fiber reinforced concrete (FRC) mixtures with different amount of polyethylene (PE) fiber and superplasticizer was investigated for fresh state (flowability, temperature evolution with time and setting time), mechanical properties (compressive/ flexural strength, modulus of elasticity, fracture energy) and durability (rapid chloride permeability 'RCP') properties and micro structural characteristics through scanning electron microscopy (SEM) and Energy Dispersive Spectroscopy (EDS). The main aim was to study the influence of dosages of superplasticizer and PE fiber on the properties of FRC mixtures. The experimental results showed that that the dosage of superplasticizer did not show any significant change in the fresh state, mechanical, durability and microstructure of selected FRC mixtures with PE fiber. However, the varying amount of PE fiber in FRC mixtures influenced the properties which is summarized as follows:

- In general, slump flow (used as measure of flowability) decreased with the use of more than $1 \%$ by volume of PE fiber. All FRC mixtures were cohesive, sticky and not flowable. Even higher dosages of superplasticizer (ranging from 26 to $46 \mathrm{~kg} / \mathrm{m}^{3}$ ) could not make FRCs flowable. Use small fiber of shorter length and lower amount of fiber $\left(<26 \mathrm{~kg} / \mathrm{m}^{3}\right)$ can make the FRC mixtures flowable. However, all FRC mixtures were workable for casting specimens.

- The increase of PE fiber content (from $1.5 \%$ to $3.0 \%$ volume or 10 to $19 \mathrm{~kg} / \mathrm{m}^{3}$ ) improved the compressive strength of FRC mixtures but not significantly (a $5 \%$ increase was observed). The influence of fibers on the compressive strength may be seen as the balance between micro-crack bridging and additional voids caused by fiber addition. No effect of addition of superplasticizer was observed on compressive strength. All FRC 
specimens were classified as high strength as 28-days compressive strength was close to $100 \mathrm{MPa}$.

- 28 days flexural strength was higher for FRC with $1.5 \%$ volume of PE fiber compared to that made of $3 \%$. Usually increase in PE fiber should increase the flexural strength of FRC. The lower flexural strength of FRC with higher PE dosage can be attributed to the lower paste volume in the matrix (associated with higher volume of fiber).

- All FRC mixtures did not exhibit post peak ductile flexural behavior. This can be associated with the use of $20 \mathrm{~mm}$ long fiber in FRC having highly dense/stronger matrix producing high fiber-matrix bond (due to higher embedment length). The flexural failure FRC was like normal concrete (brittle failure - sudden drop in load after first peak and lack of multi-cracking) with fiber didn't contribute to support for additional load. Use of short fiber with lower dosages can provide ductility and strain hardening behavior as observed in previous studies.

- Generally, an increase in PE fiber volume increased the area under the load-deflection curve, which signified the higher fracture energy of the FRC mixtures. The 28-days fracture energies were $130 \mathrm{~N} / \mathrm{m}$ and $77 \mathrm{~N} / \mathrm{m}$ for FRC mixture with $3 \%$ and $1.5 \%$ by volume of PE fiber, respectively.

- The setting time for FRC mixtures was about 9 hours and mixtures with higher PE fiber content had higher setting time. Temperature evolution with time showed similar trend of variation showing no significant influence on dosage of fiber and superplasticizer.

- Modulus of Elasticity increased with the increase of PE fiber by volume. FRC mixtures had a modulus of elasticity of about $32.4 \mathrm{GPa}$. The density of FRC mixture was 2475 $\mathrm{kg} / \mathrm{m}^{3}$. 
- Chloride penetration resistance decreased with the increase PE fibers very slightly. All FRC mixtures PE fiber showed very low chloride permeability.

SEM analysis showed dense matrix with strong interfacial transition zone (ITZ) that supported the high strength and very low chloride permeability of FRC mixtures with PE fibers. There was no weak fiber-matrix interface zone presence in FRC with 1.5 to $3 \%$ by volume of PE fiber. From EDS analysis, higher concentration of Calcium (Ca) and Silica (Si) were observed. The C-H was not found due to presence of extra Si which reacted with $\mathrm{C}-\mathrm{H}$ to produce $\mathrm{C}-\mathrm{S}-\mathrm{H}$ producing high strength matrix.

\subsection{Recommendations for Future Research Studies}

The following recommendations are suggested for future research studies:

- Investigate experimentally and theoretically the fresh state, mechanical and durability properties and microstructure of high strength FRC mixtures using shorter PE fiber (between 10-12 $\mathrm{mm}$ ) with smaller dosages in an attempt to produce high strength high ductility matrix.

- Carryout investigations to produce high strength high ductility FRC with combinations of different types of fibers such as steel, polyethylene, polyvinyl alcohol etc. 


\section{APPENDIX-A: SEM PHOTOGRAPH}

Sample P 19 S 26

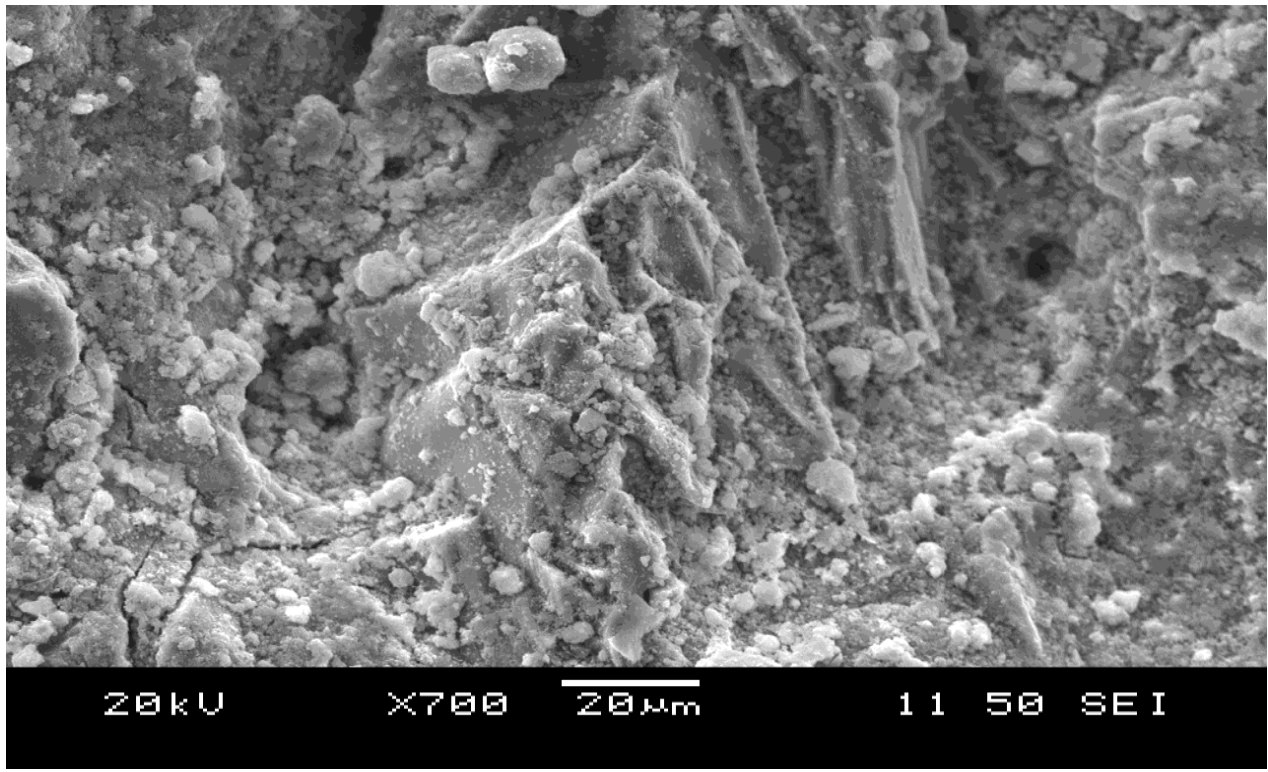

Figure 1: SEM P19 S 26 -1

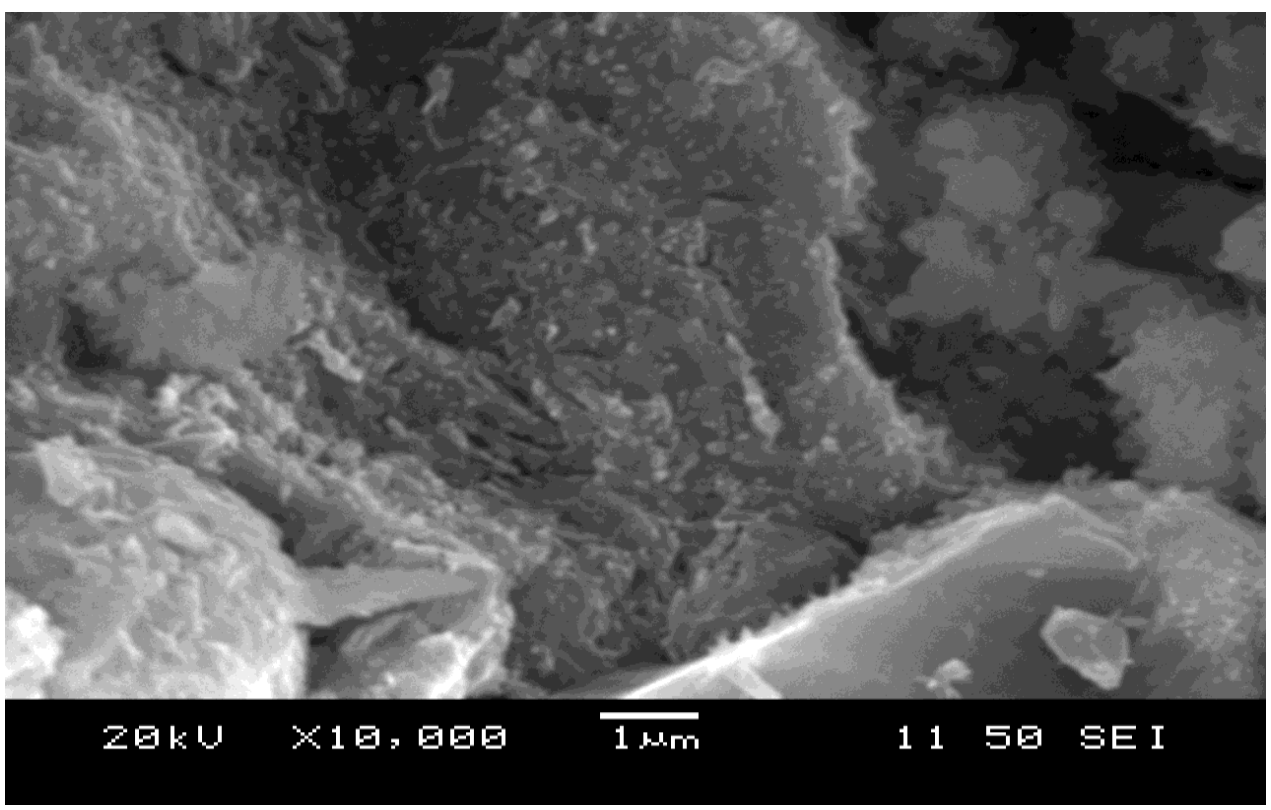

Figure 2: SEM P19 S 26 -2 


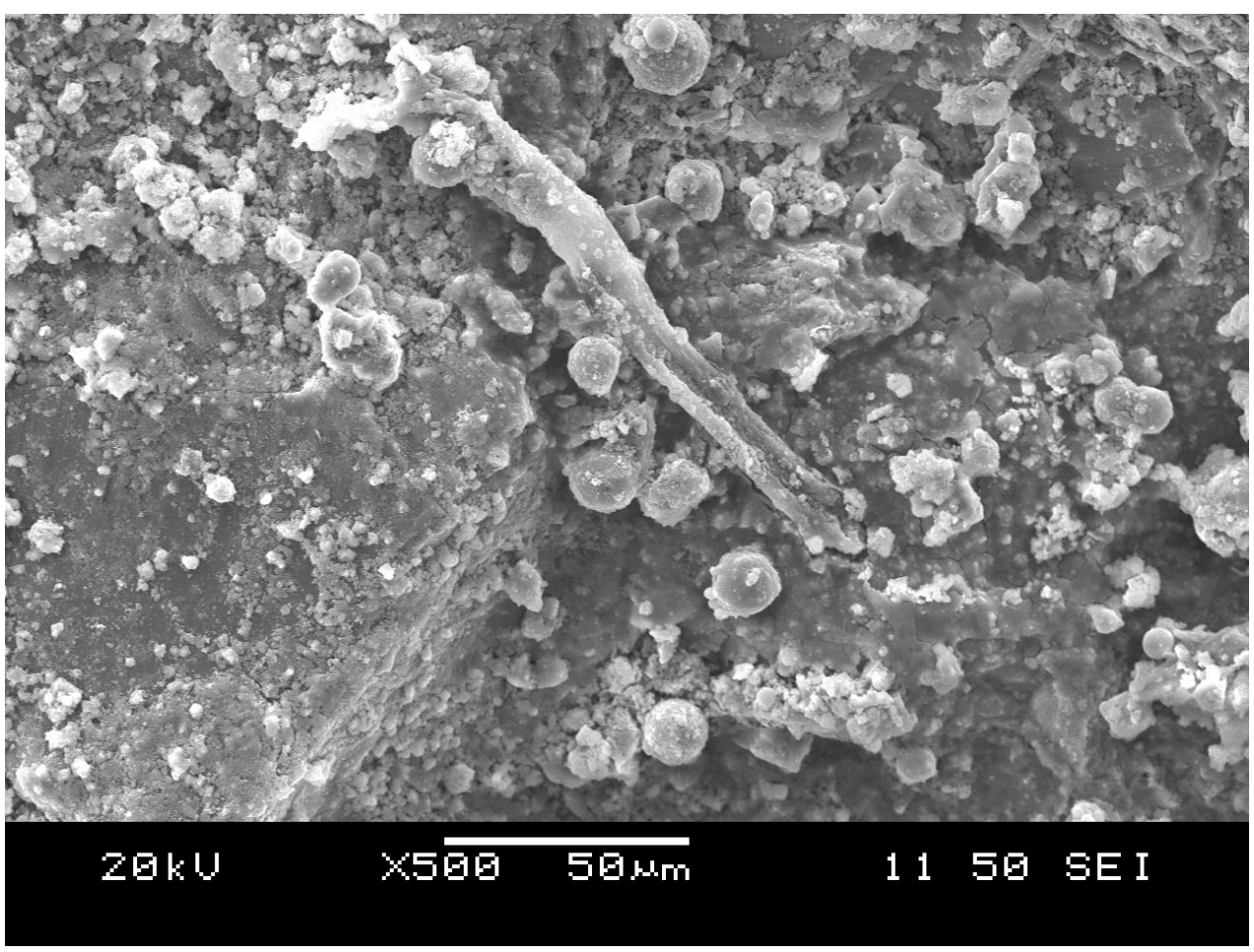

Figure 3: SEM P19 S 26 -3

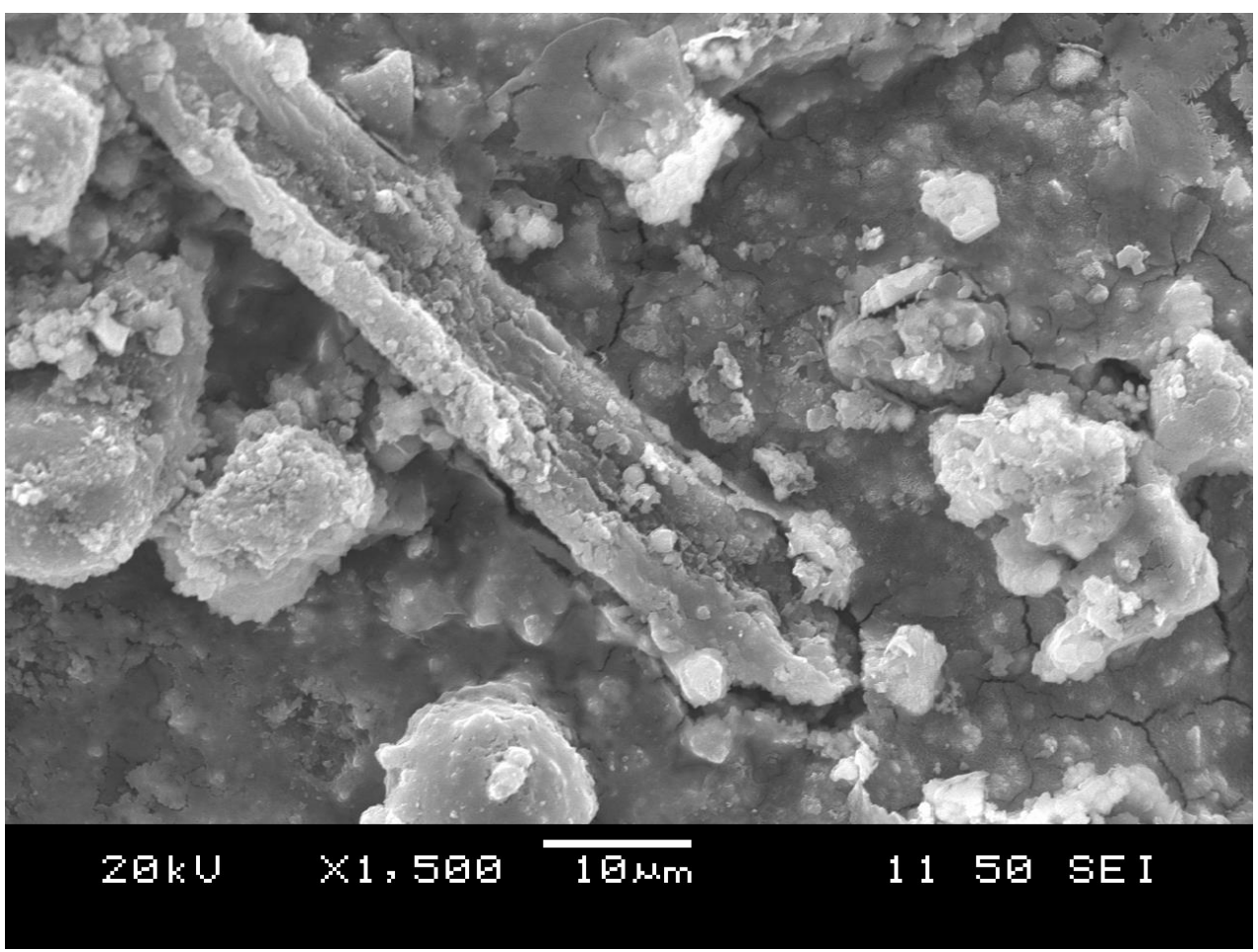

Figure 4: SEM P19 S 26 -4 


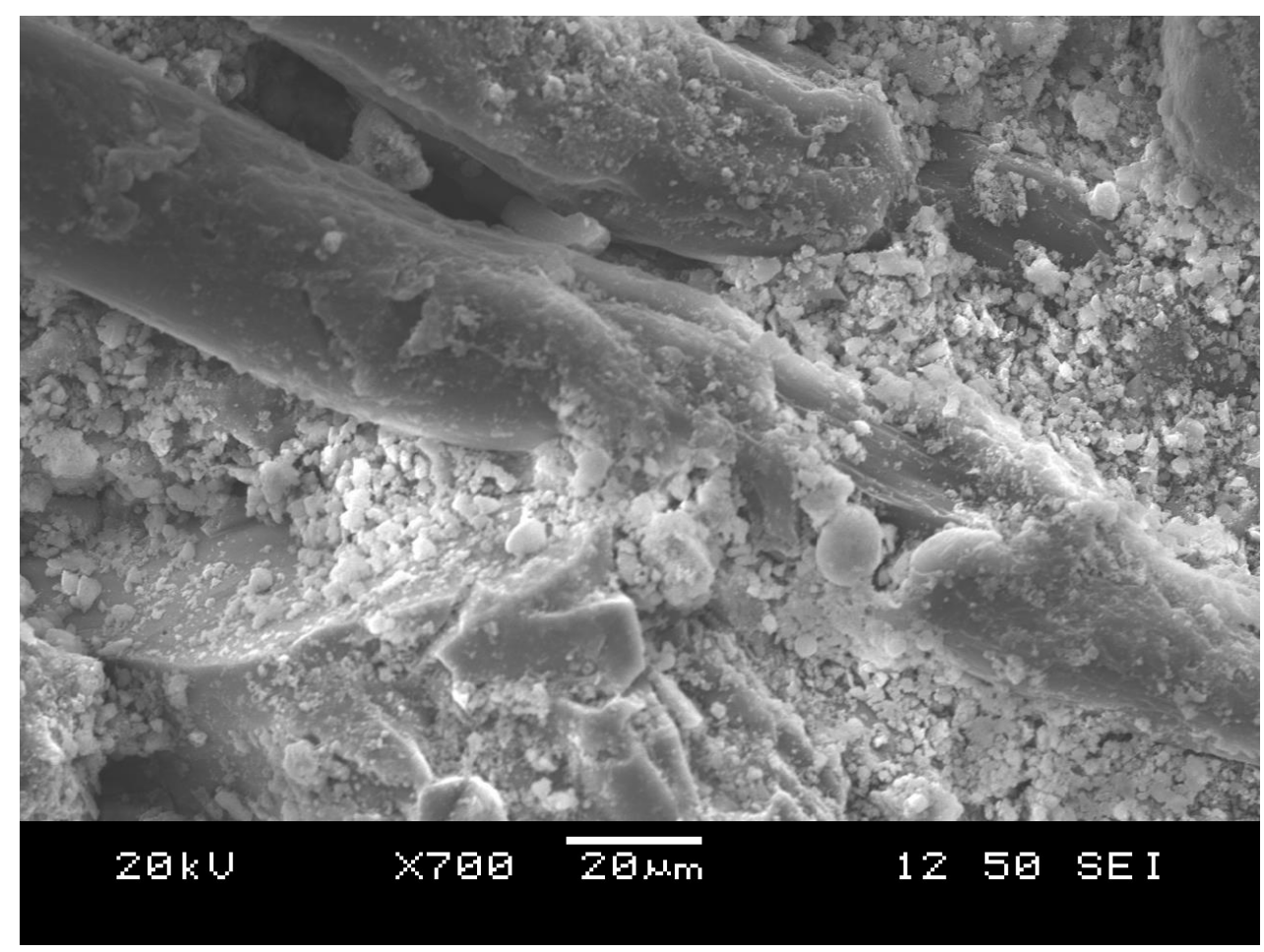

Figure 5: SEM P19 S 26 -5

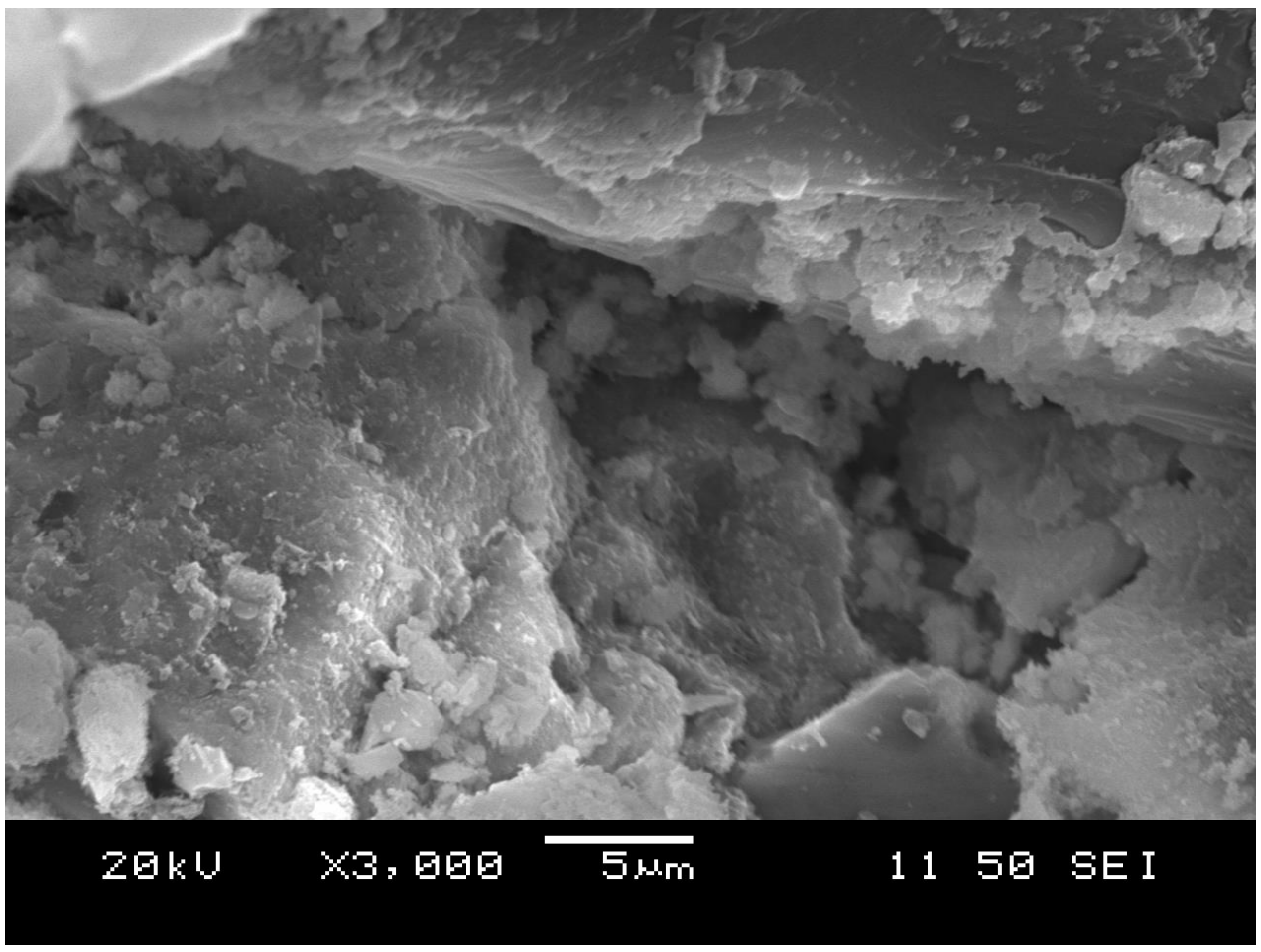

Figure 6: SEM P19 S 26 -5 


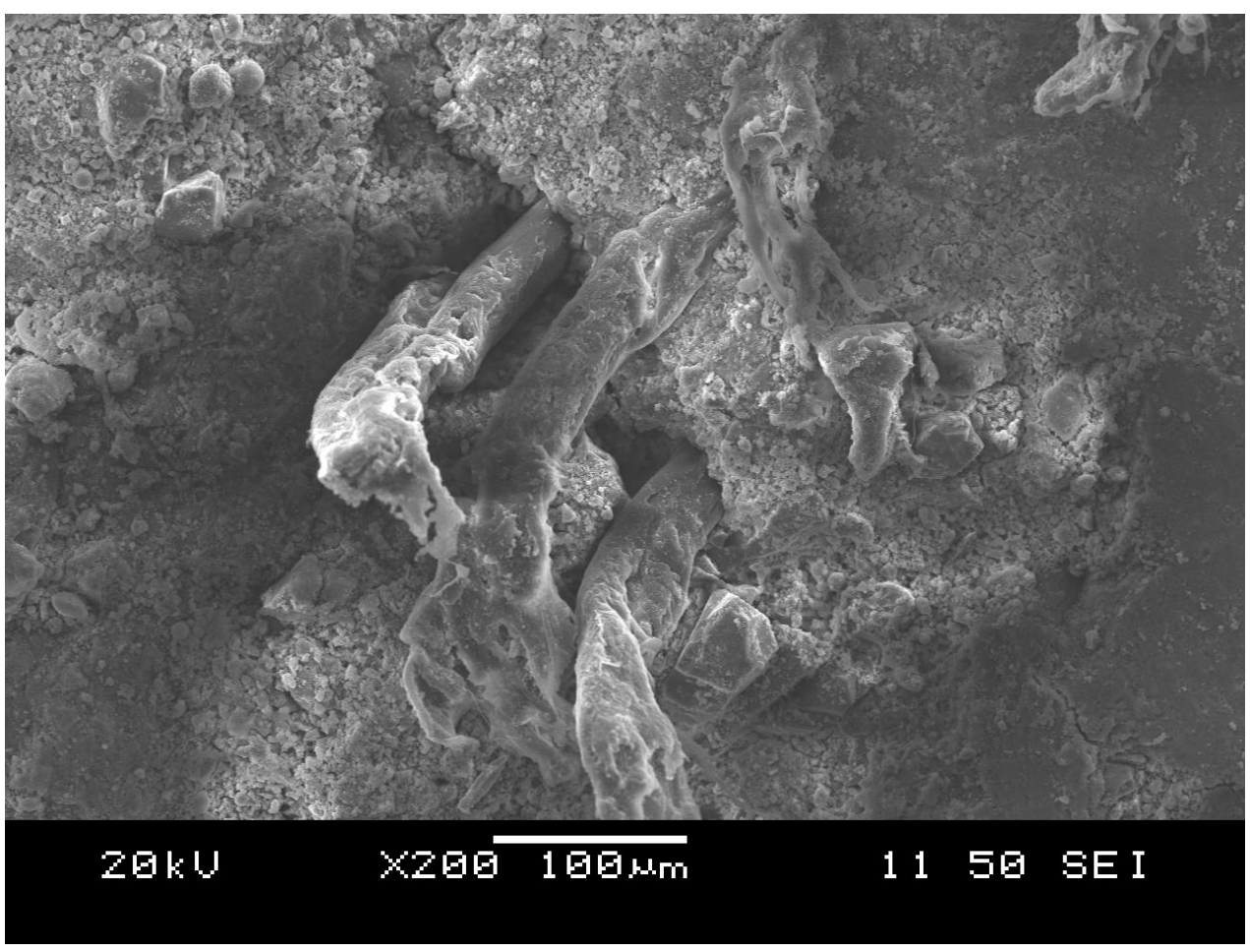

Figure 7: SEM P19 S 26 -7 
Sample P 10 S 26

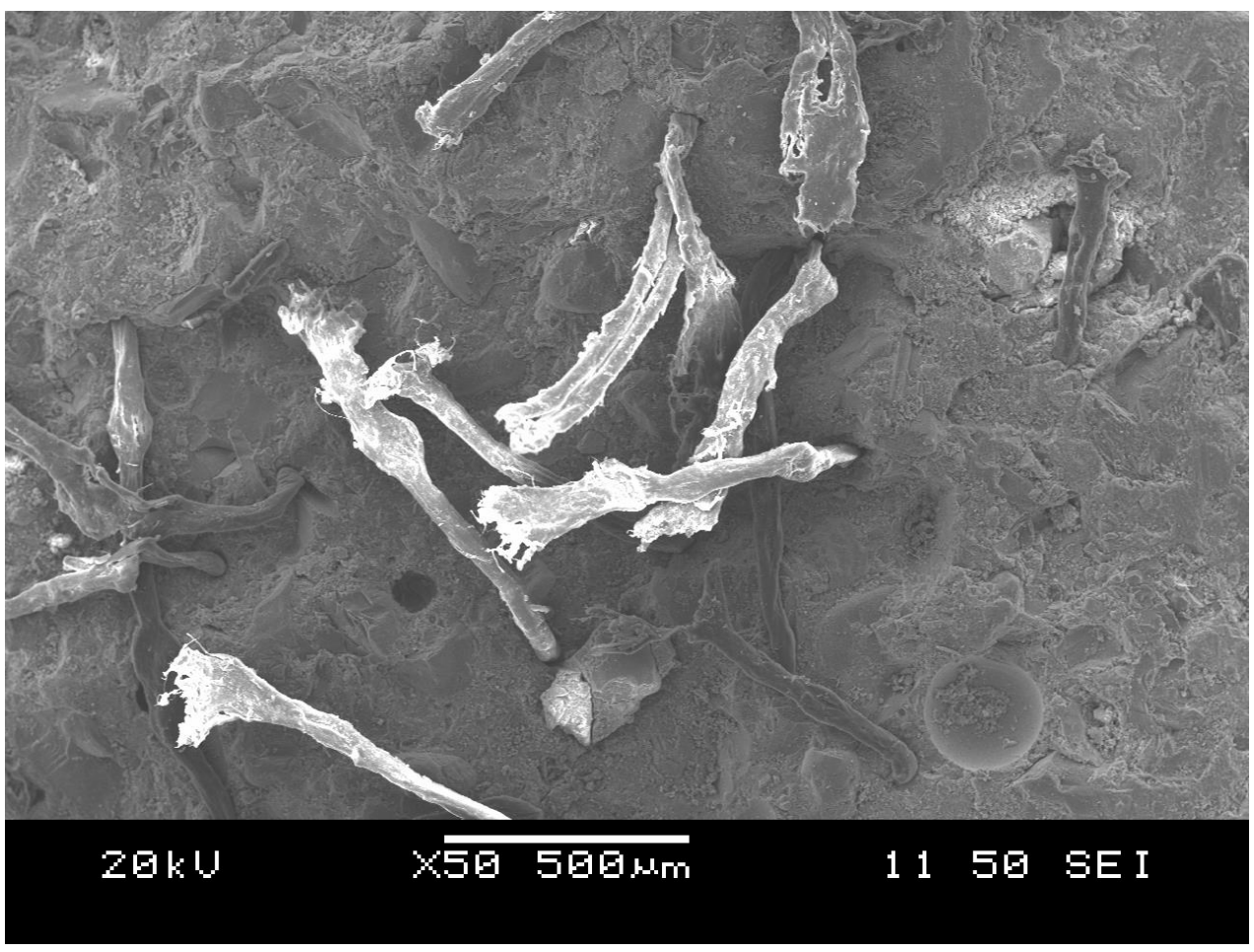

Figure 8: SEM P10 S26-1

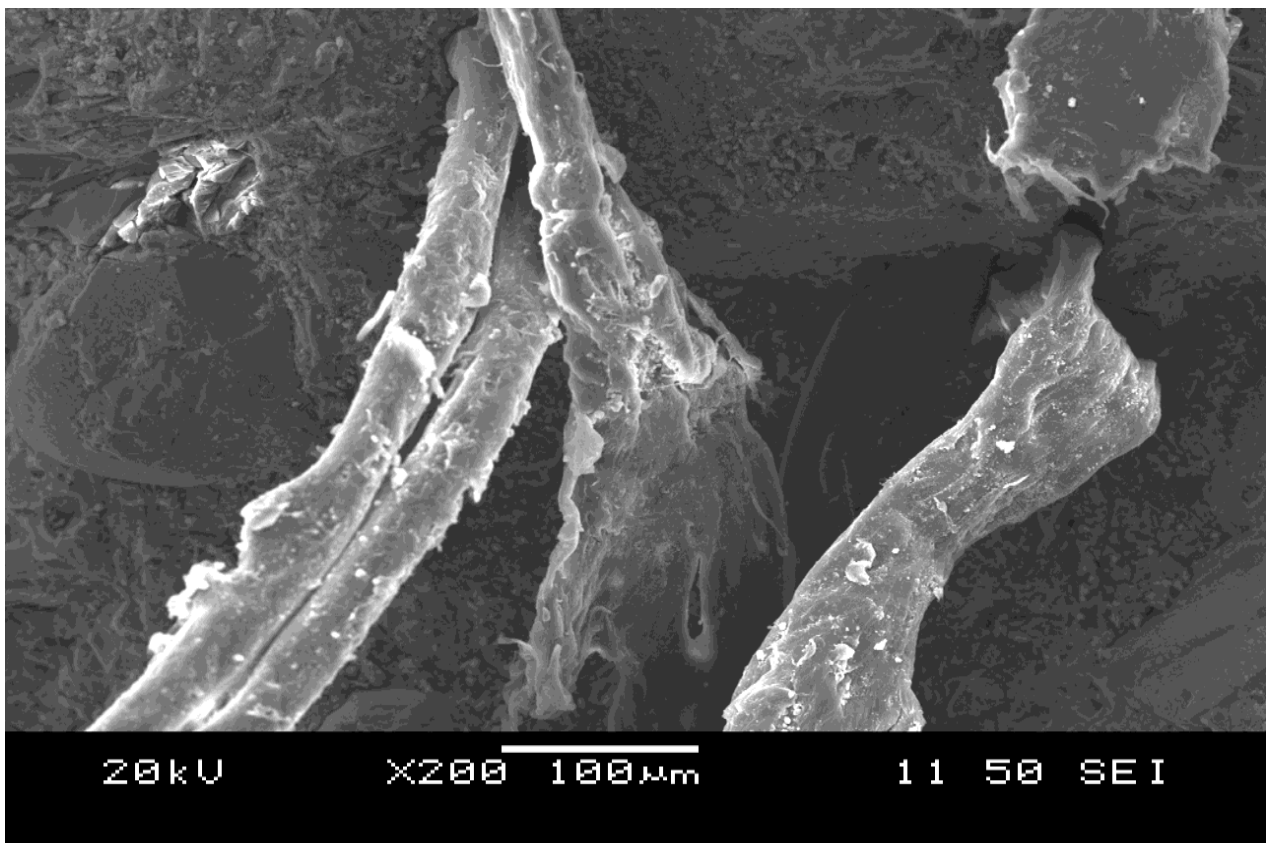

Figure 9: SEM P10 S26-2 


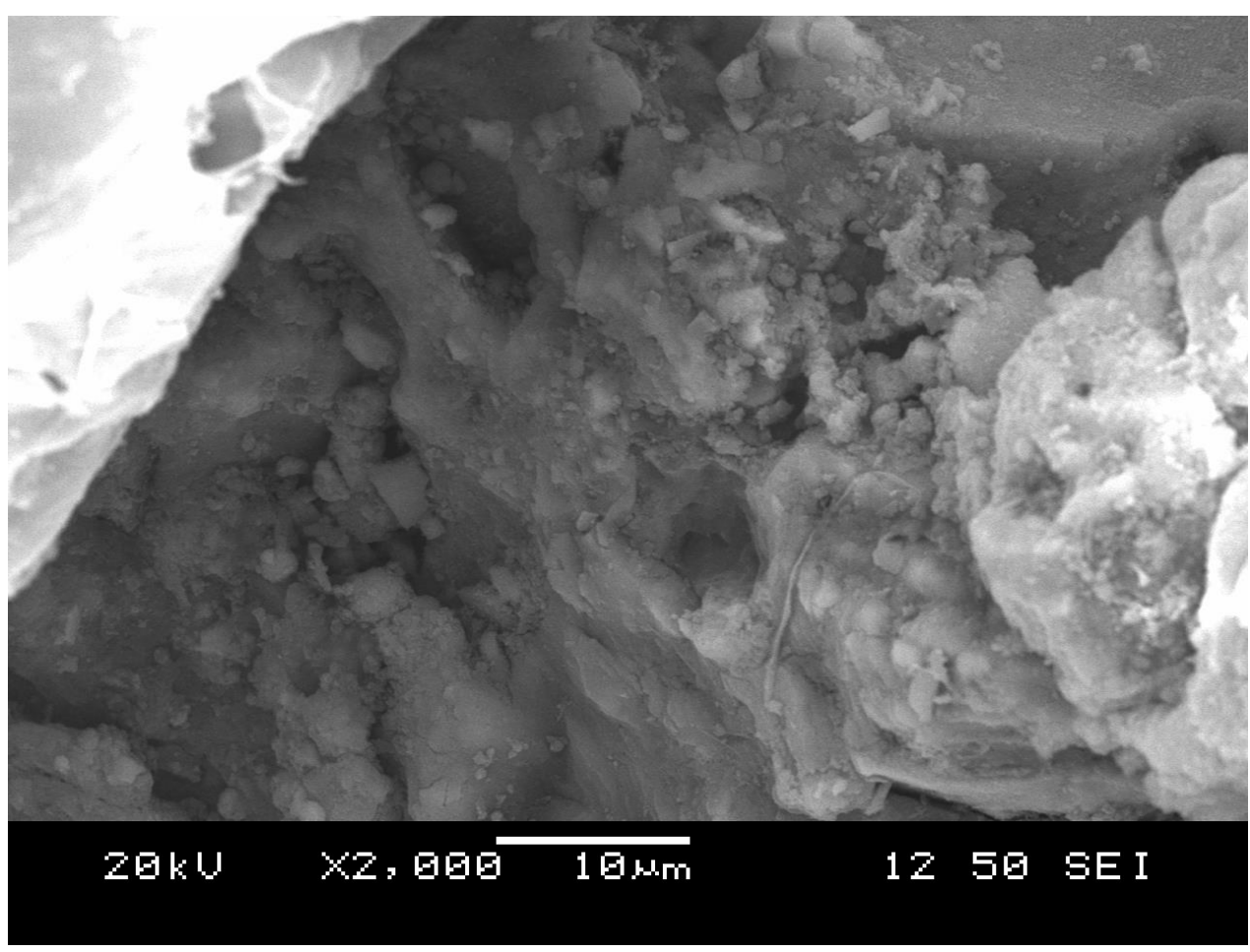

Figure 10: SEM P10 S26-3

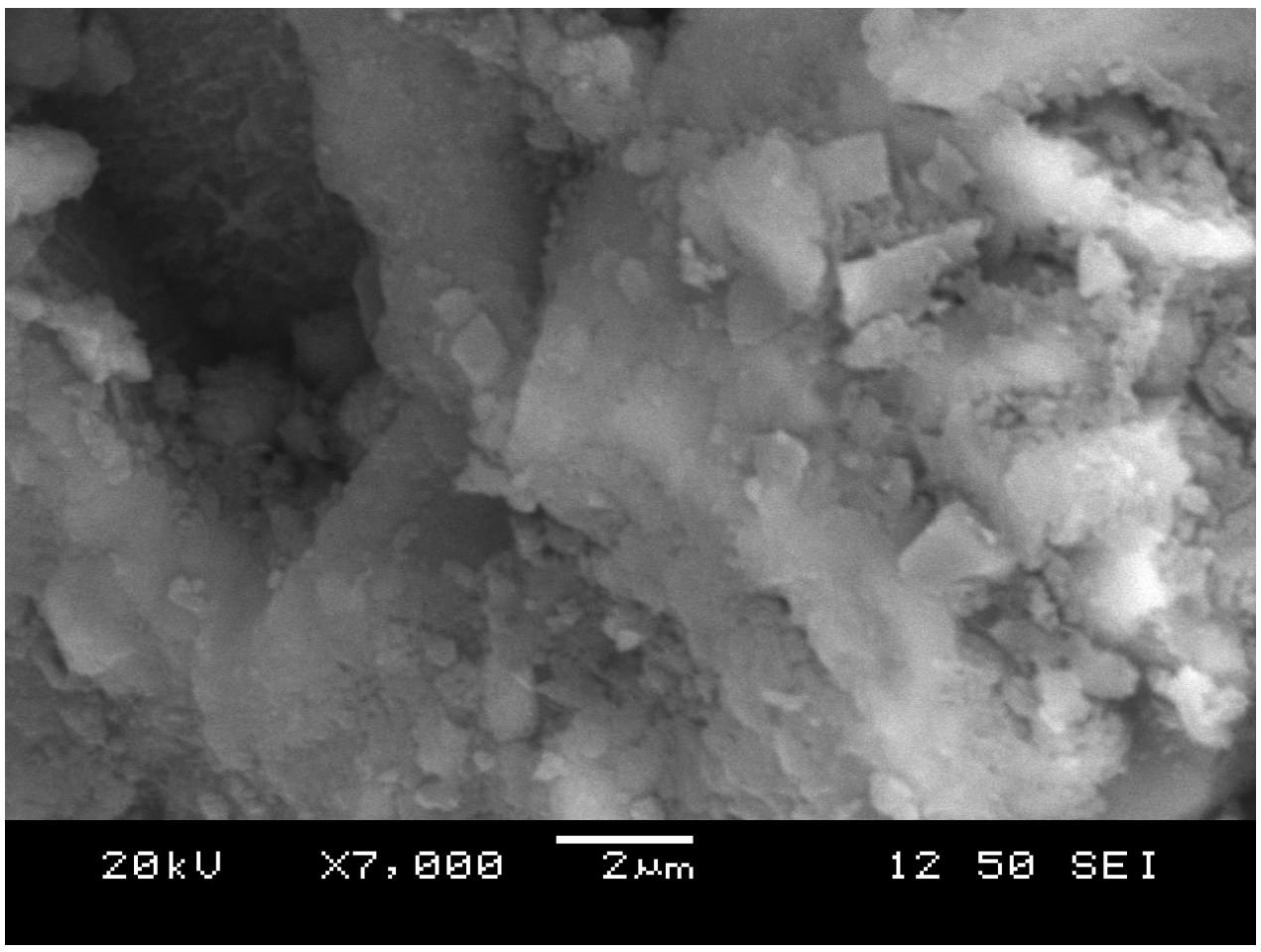

Figure 11: SEM P10 S26-4 


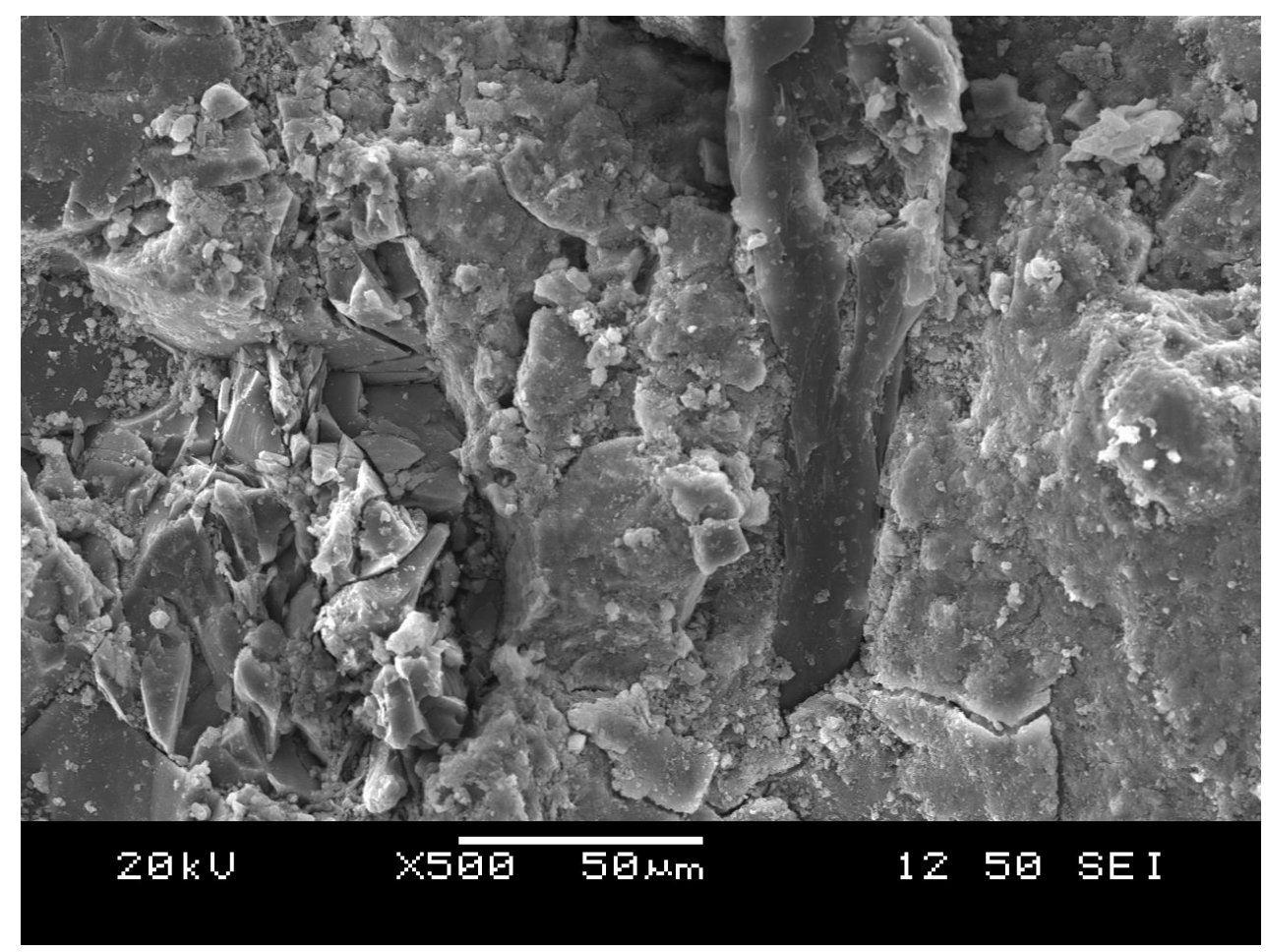

Figure 12: SEM P10 S26-5 


\section{APPENDIX-B: SEM ANALYSIS WITH MINERAL PROPERTIES}

Analysis-1: P 19 S 26-1
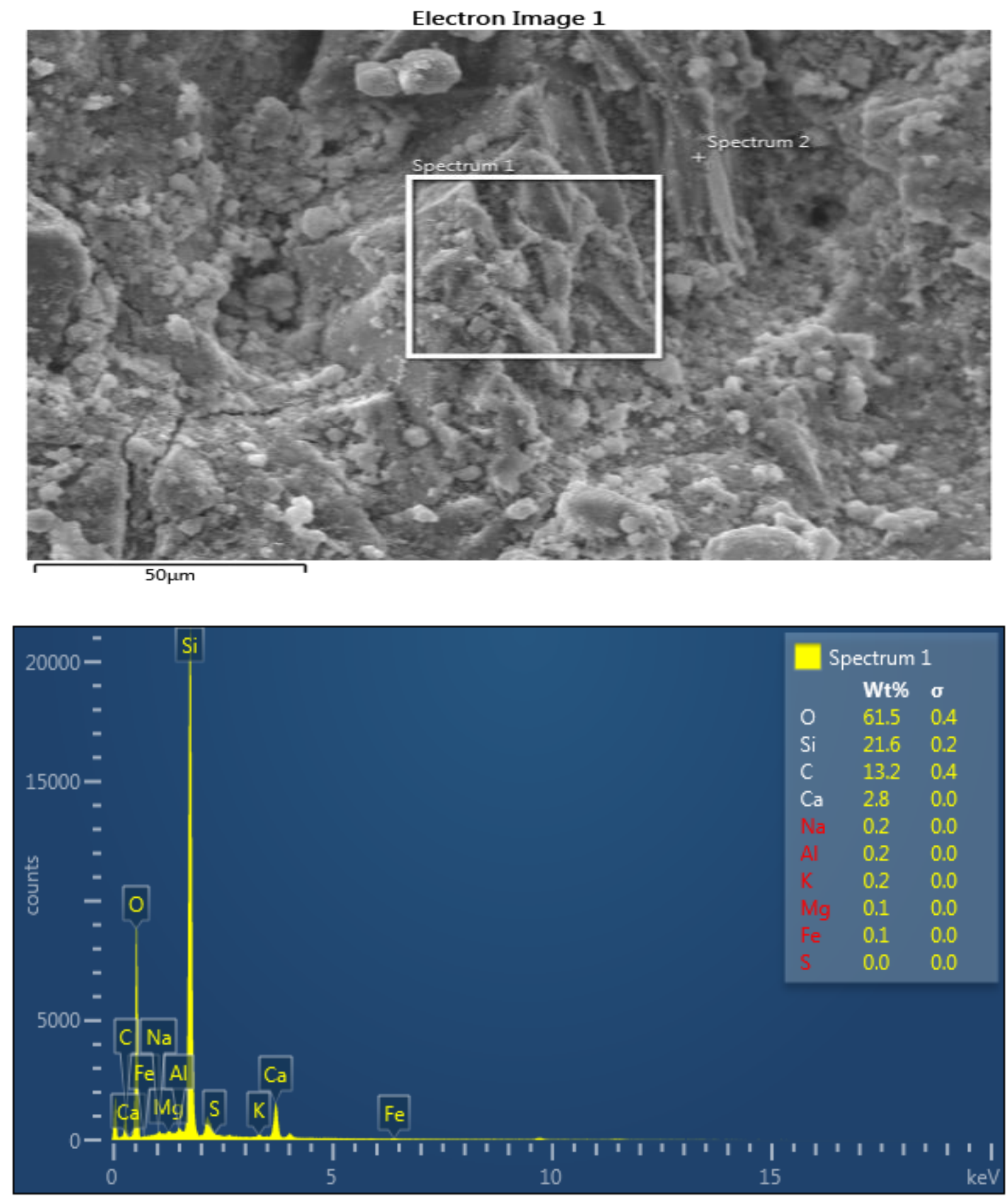
Analysis -2: P 19 S 26-2

Electron Image 2
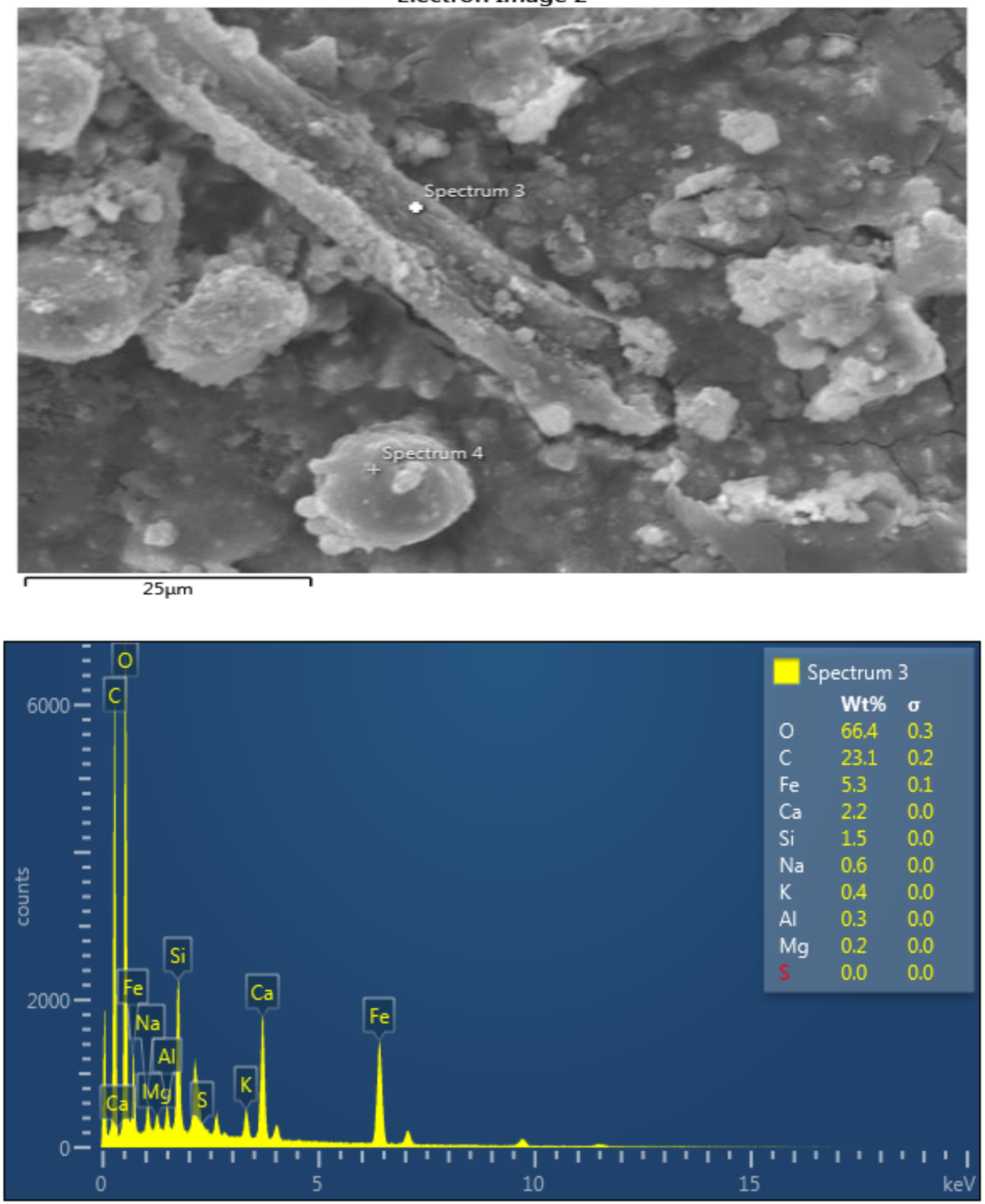


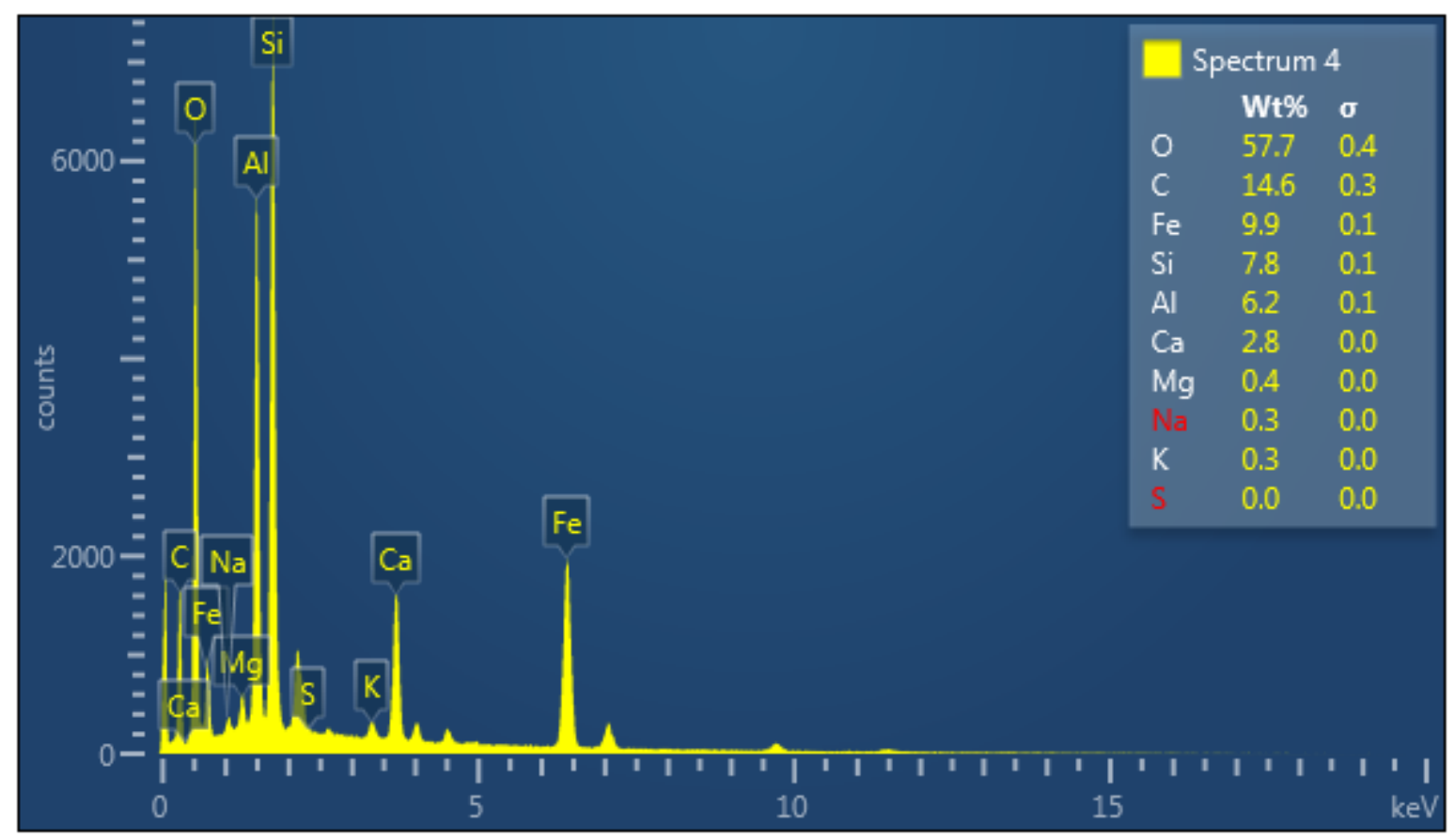


Analysis- 3: P19 S26-3

\section{Electron Image 3}
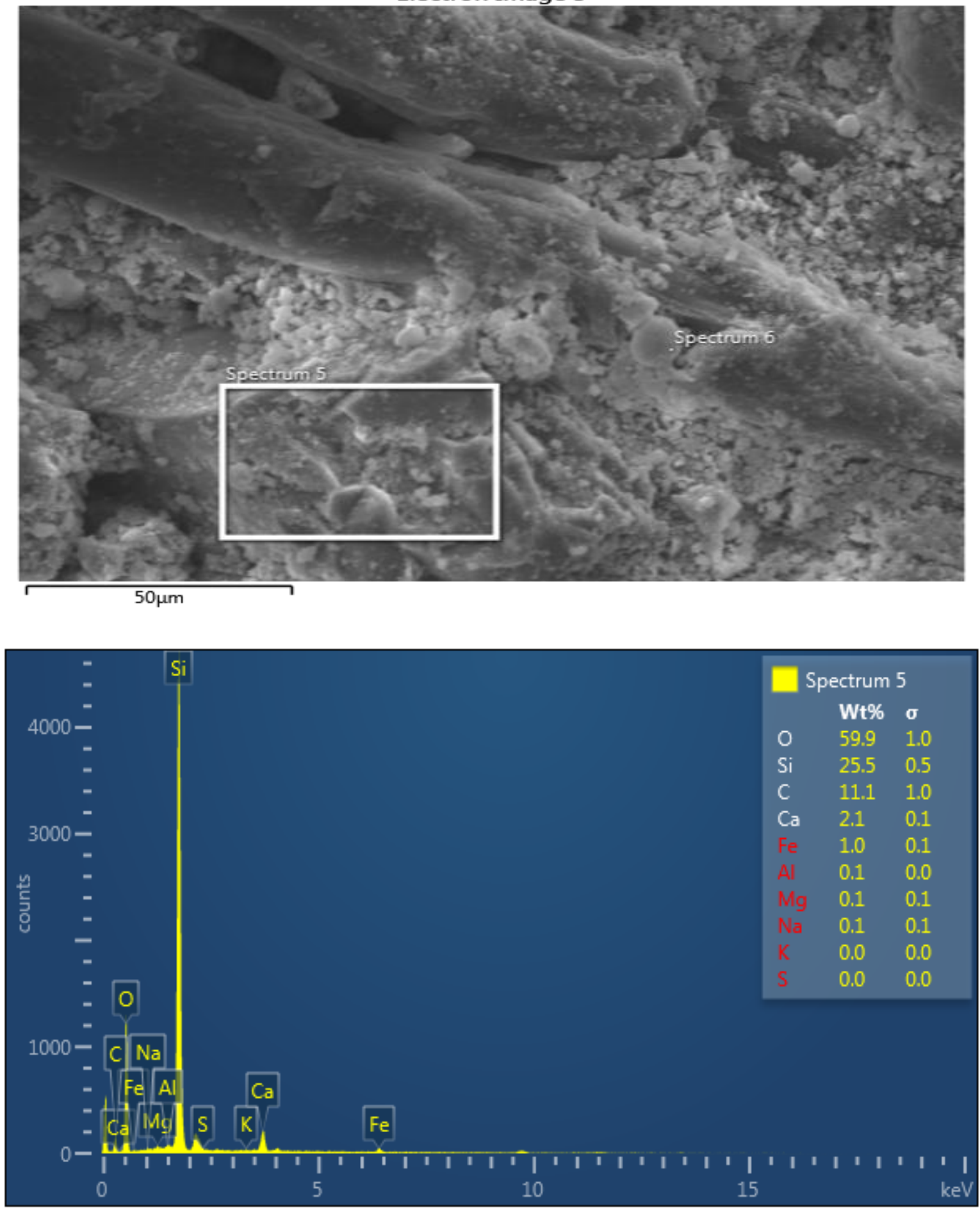


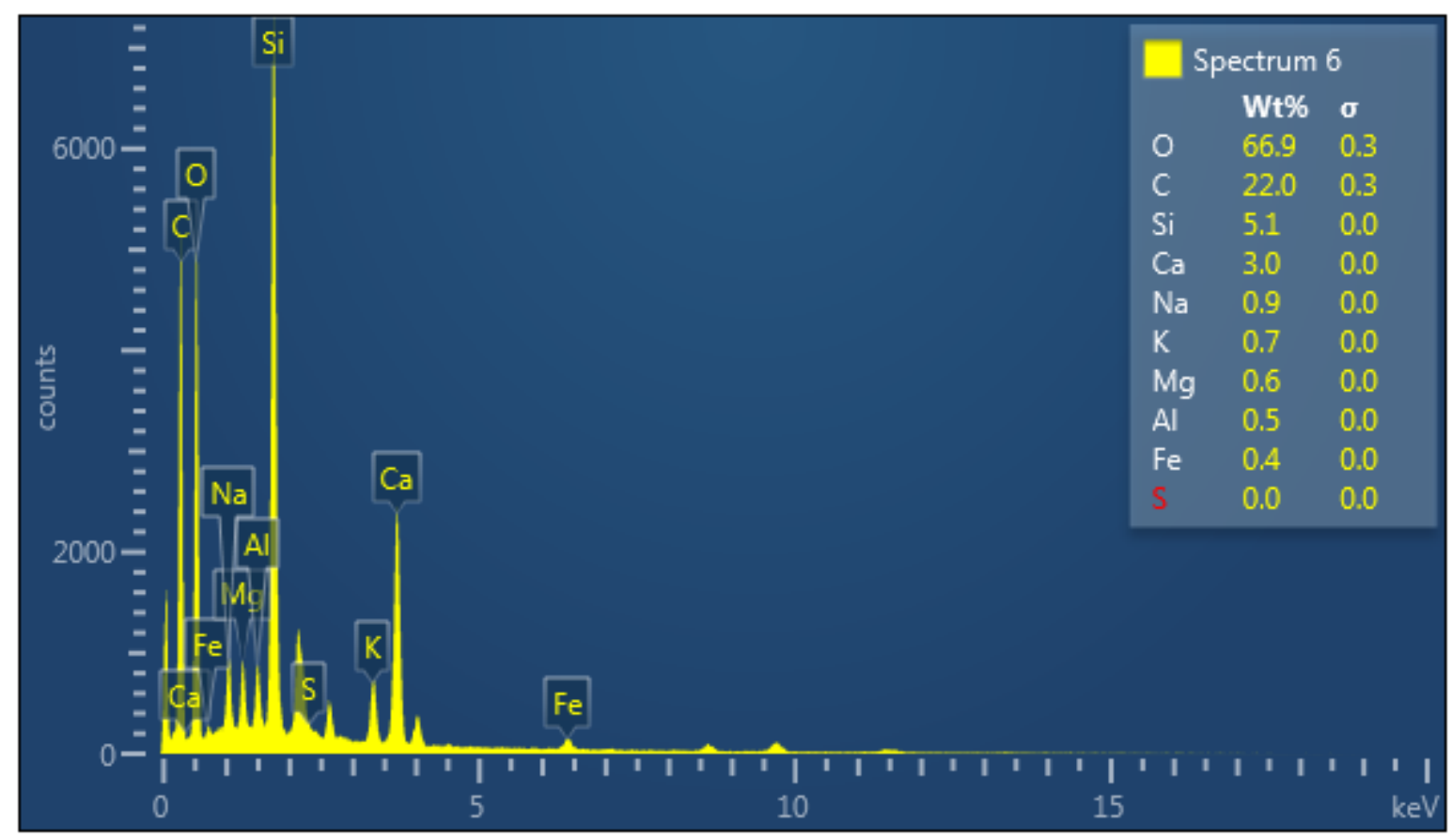

Analysis -4: P19 S26-4

Electron Image 4

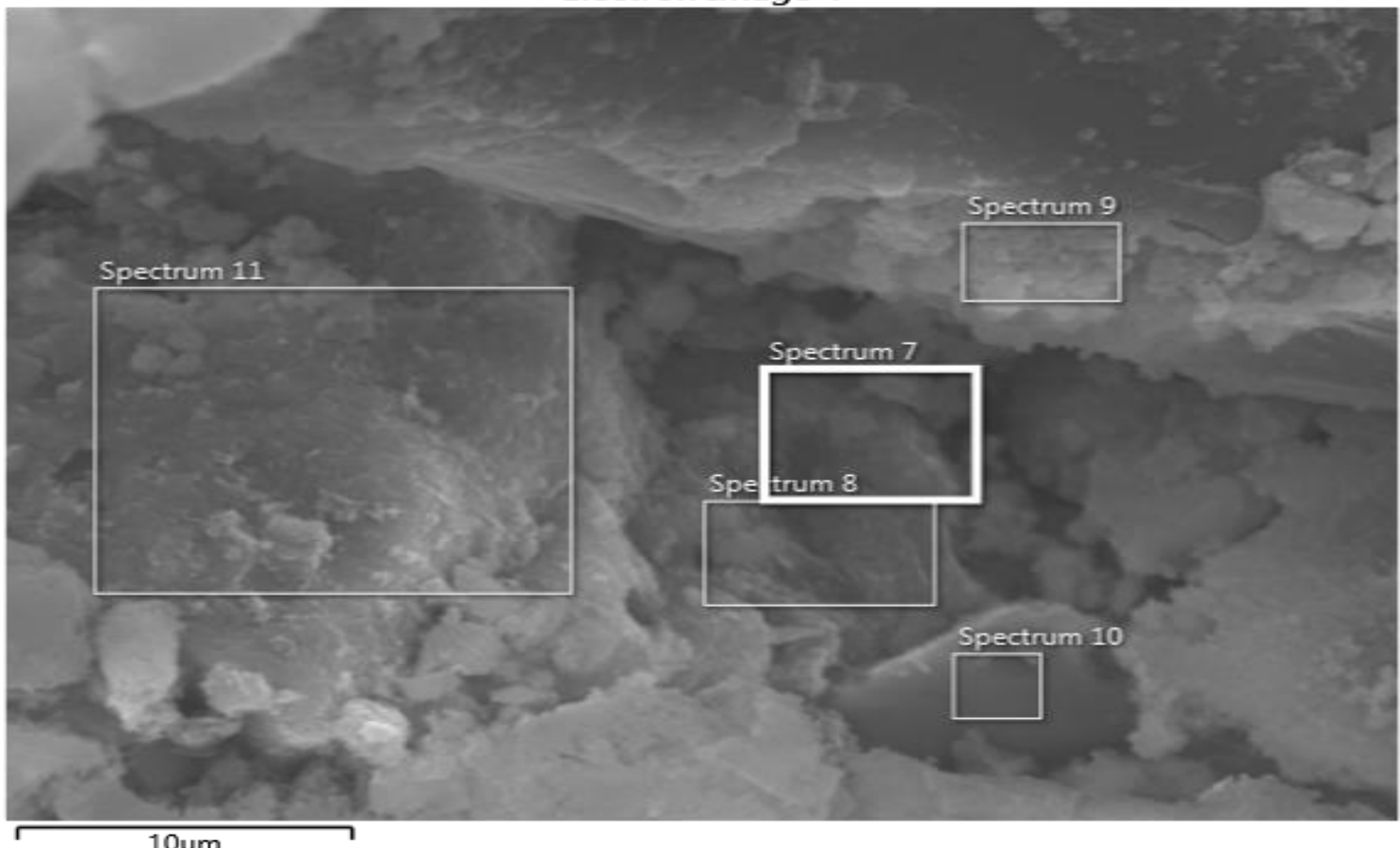

$10 \mu \mathrm{m}$ 

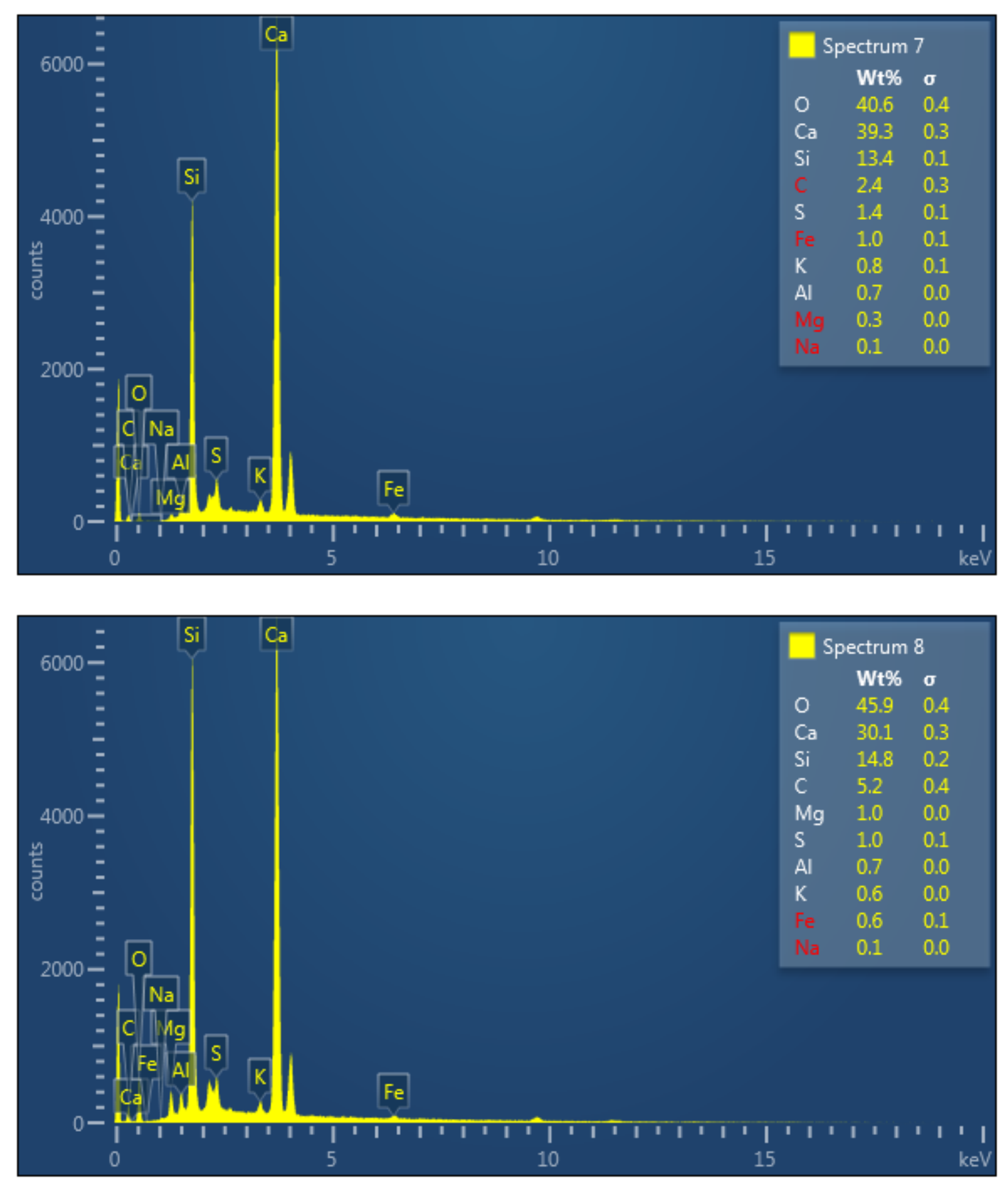

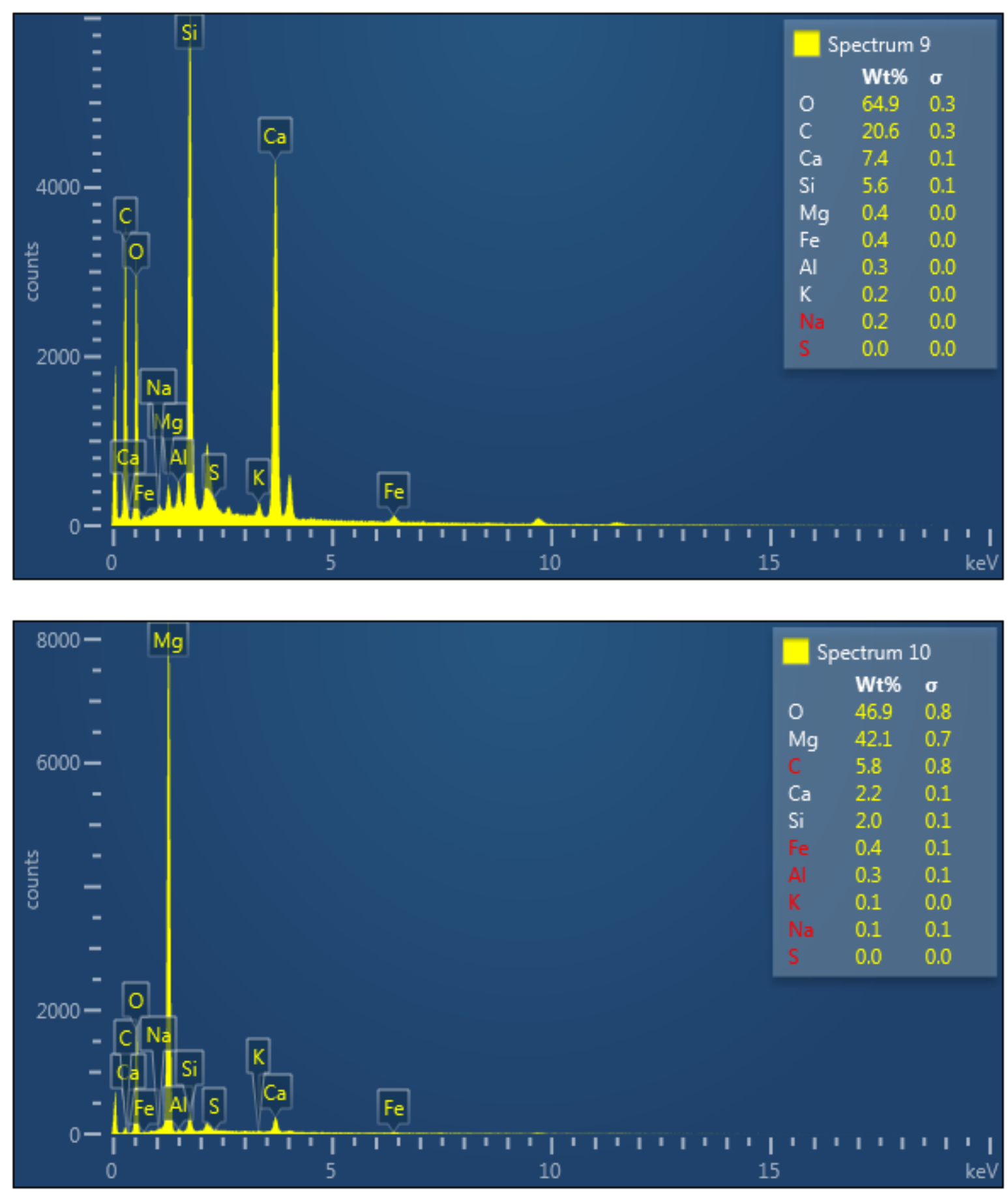


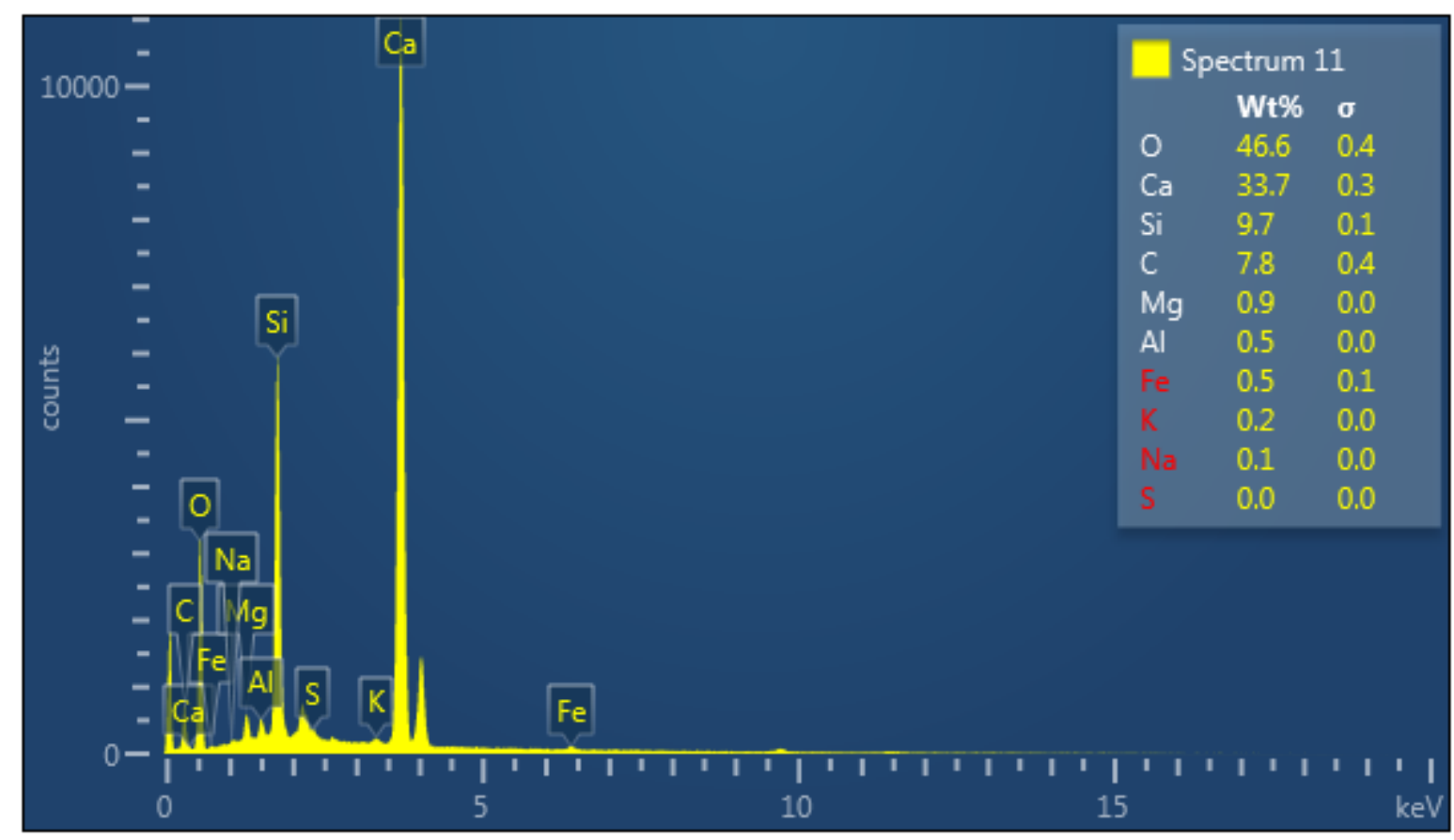

Analysis- 5: P19 S26-5

Electron Image 5

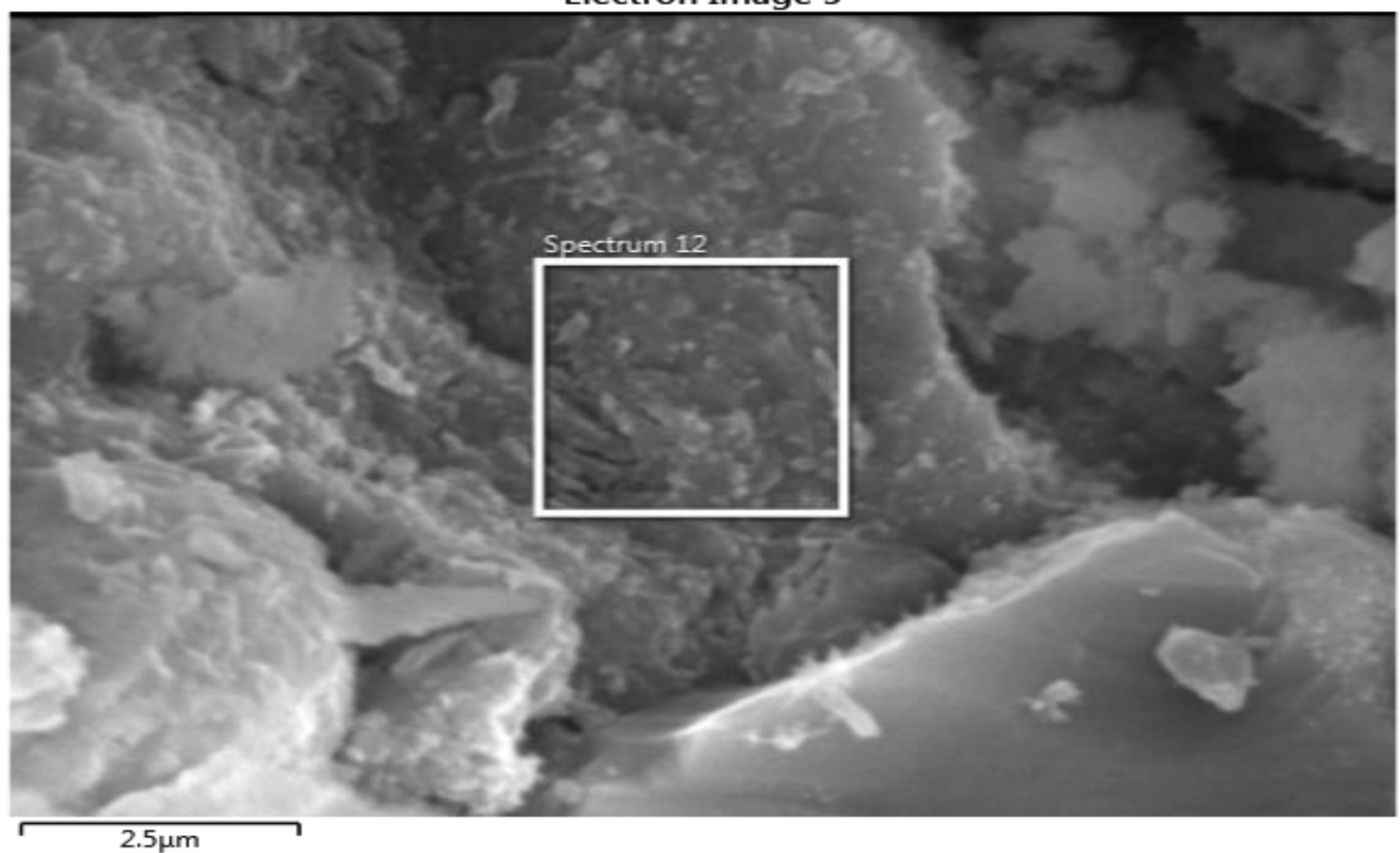

$2.5 \mu \mathrm{m}$ 


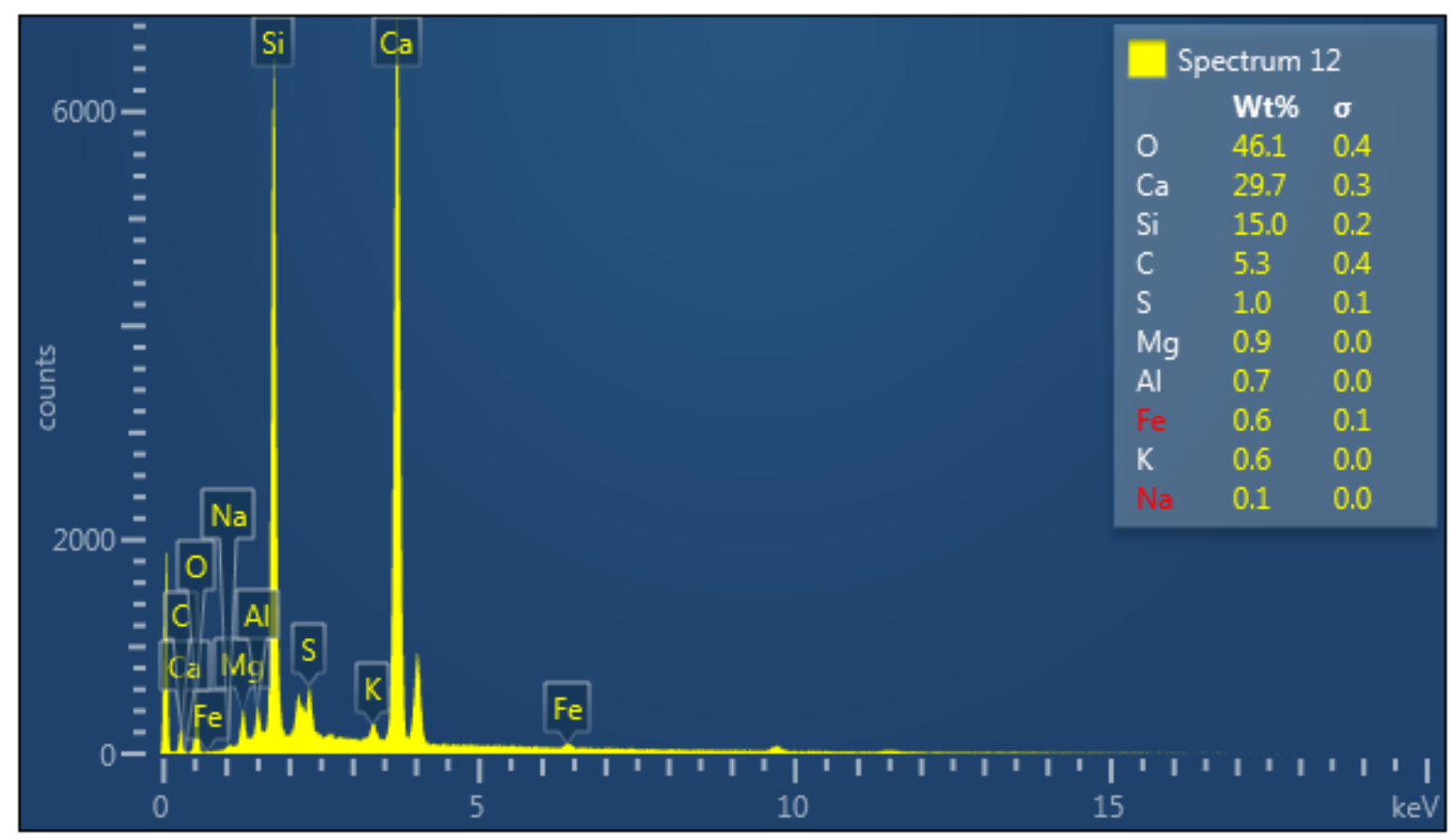

Analysis- 6: P19 S26- 6

Electron Image 6

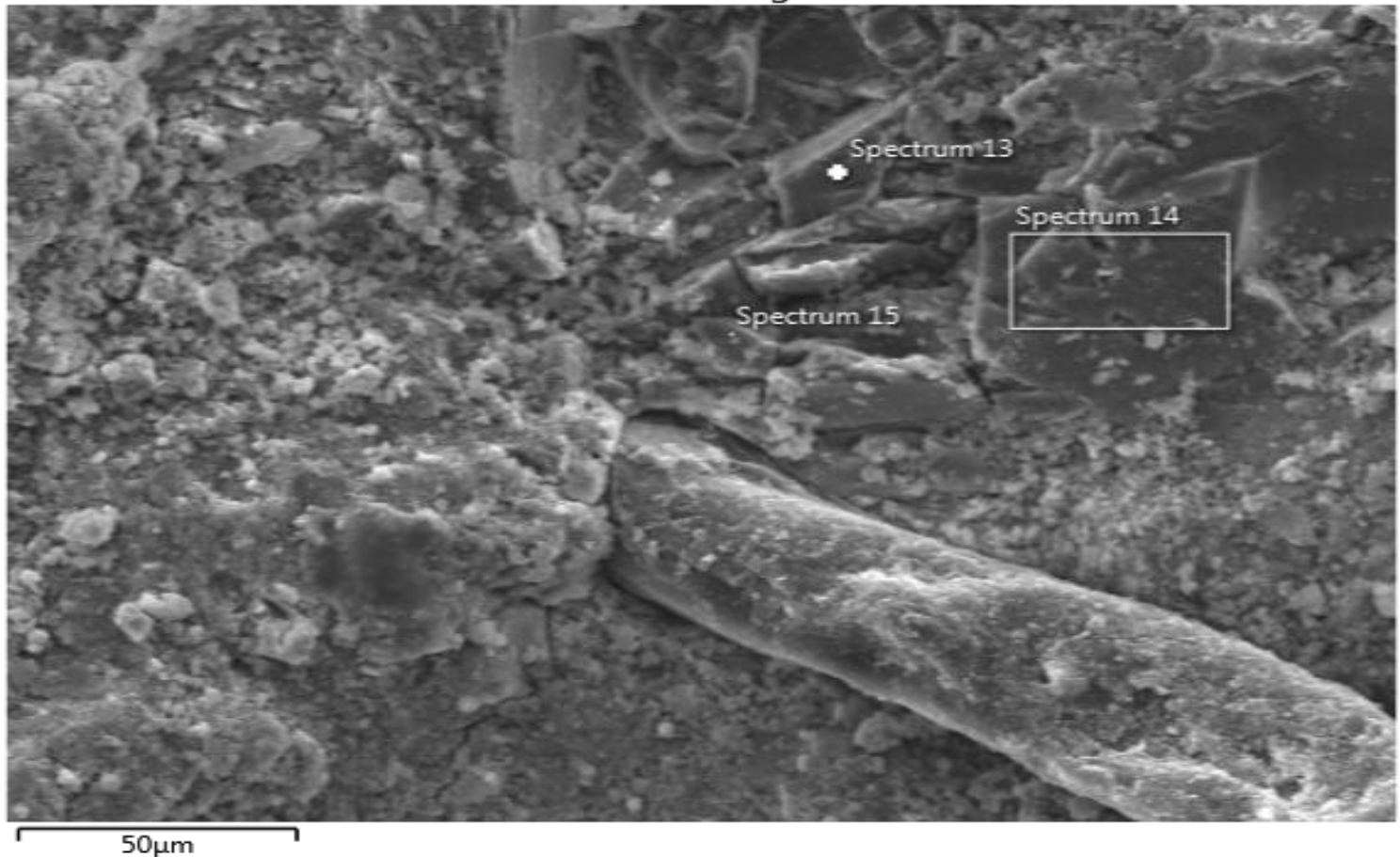



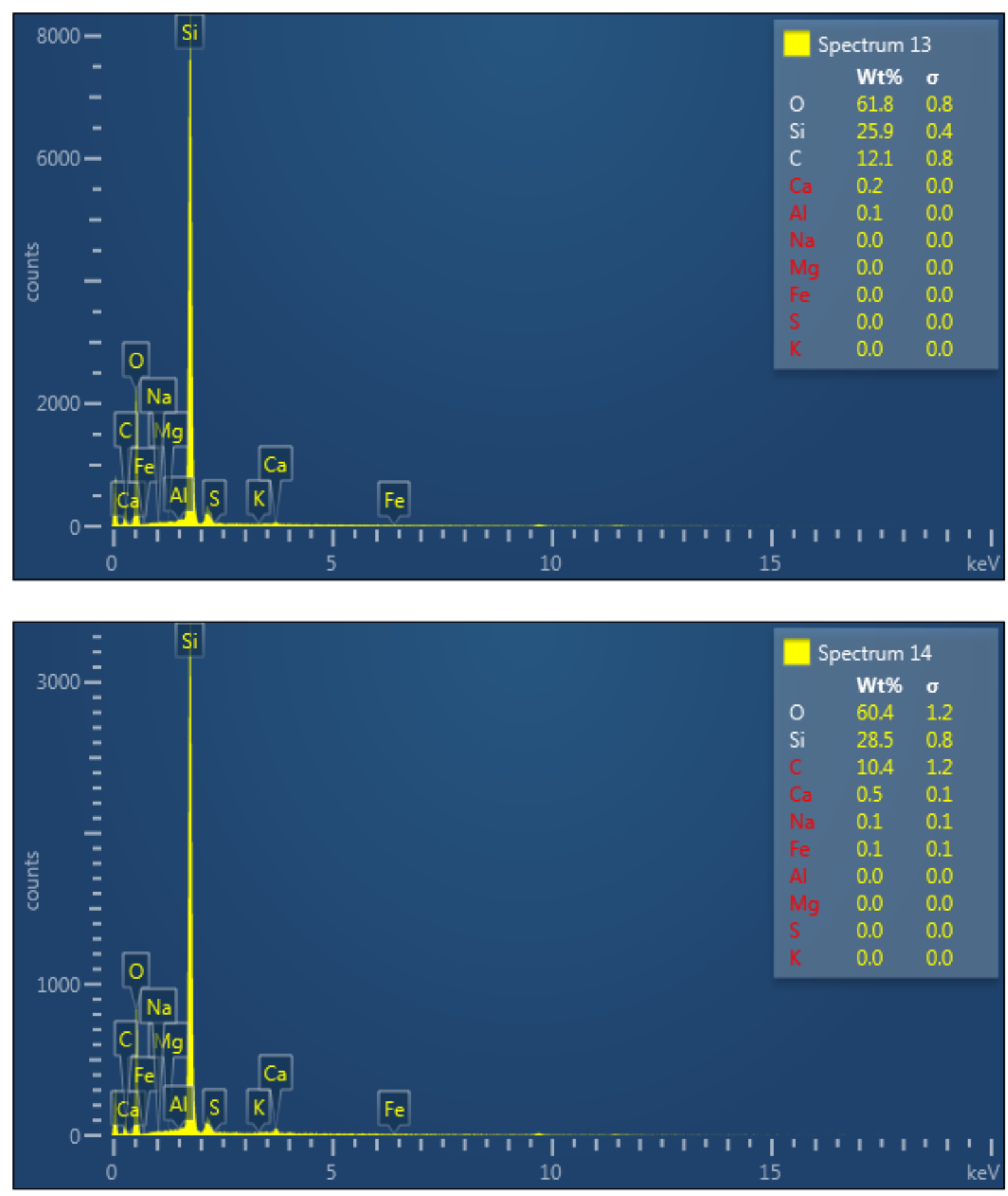


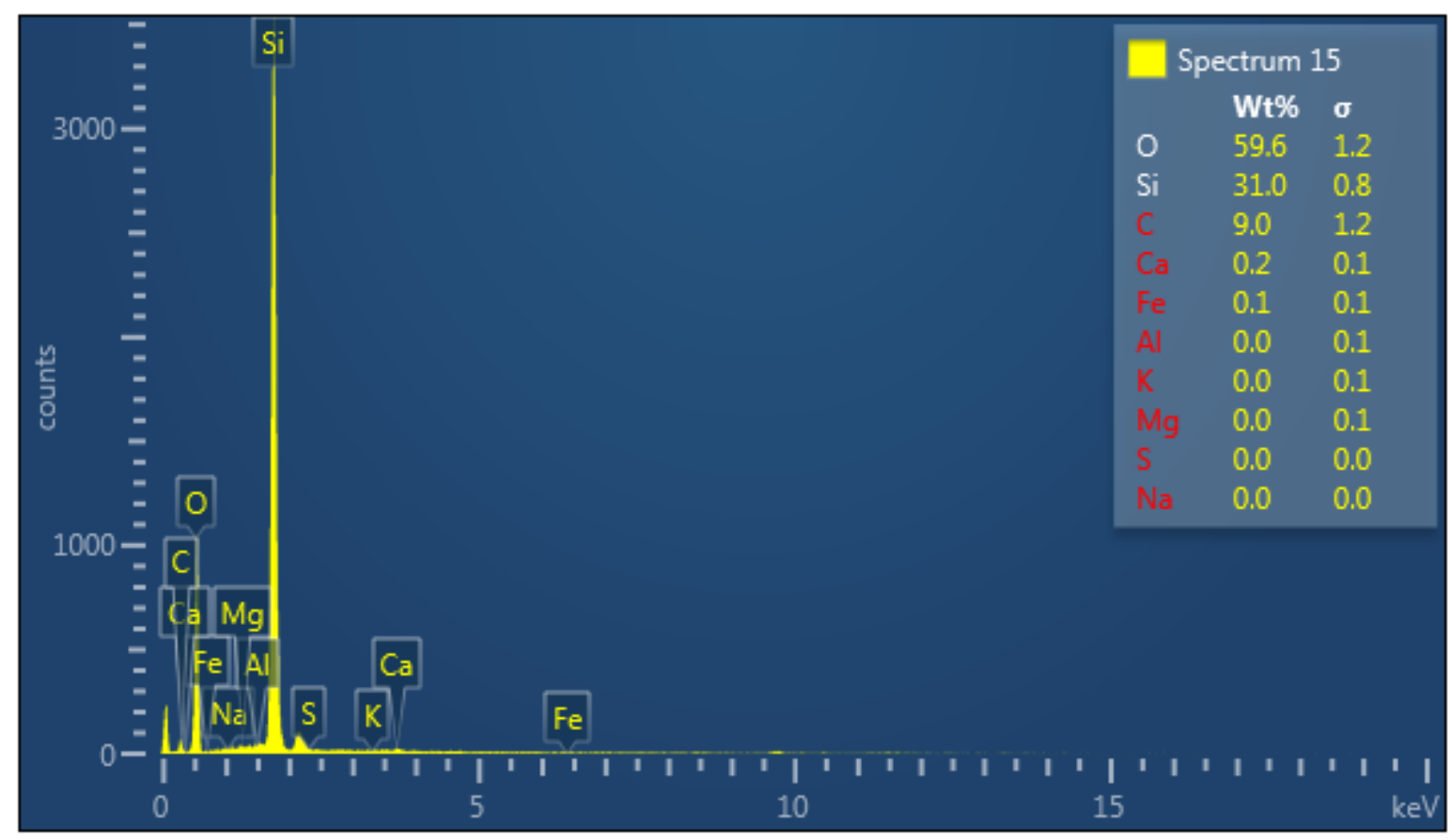

Analysis- 7: P19 S26-7

Electron Image 7

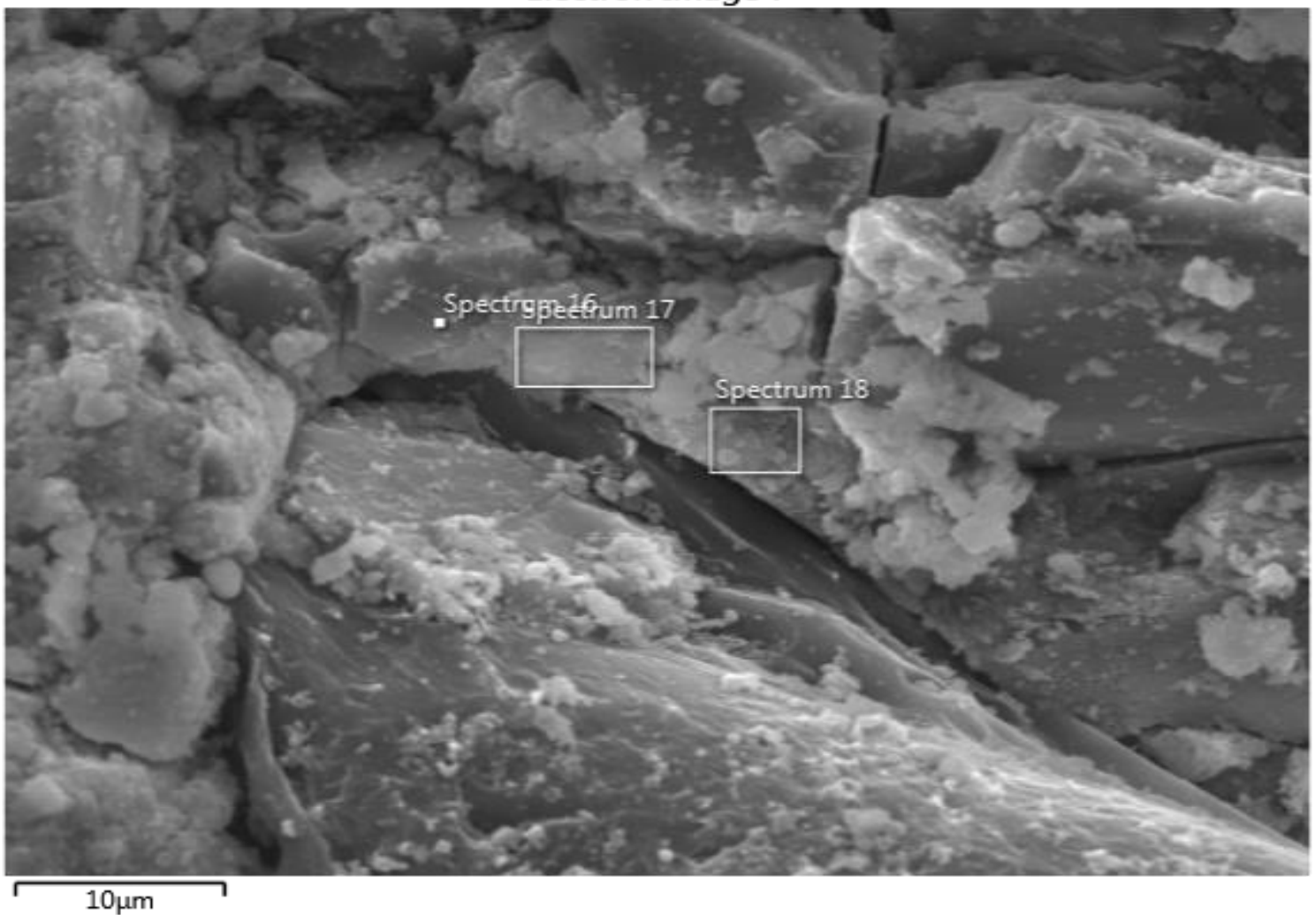



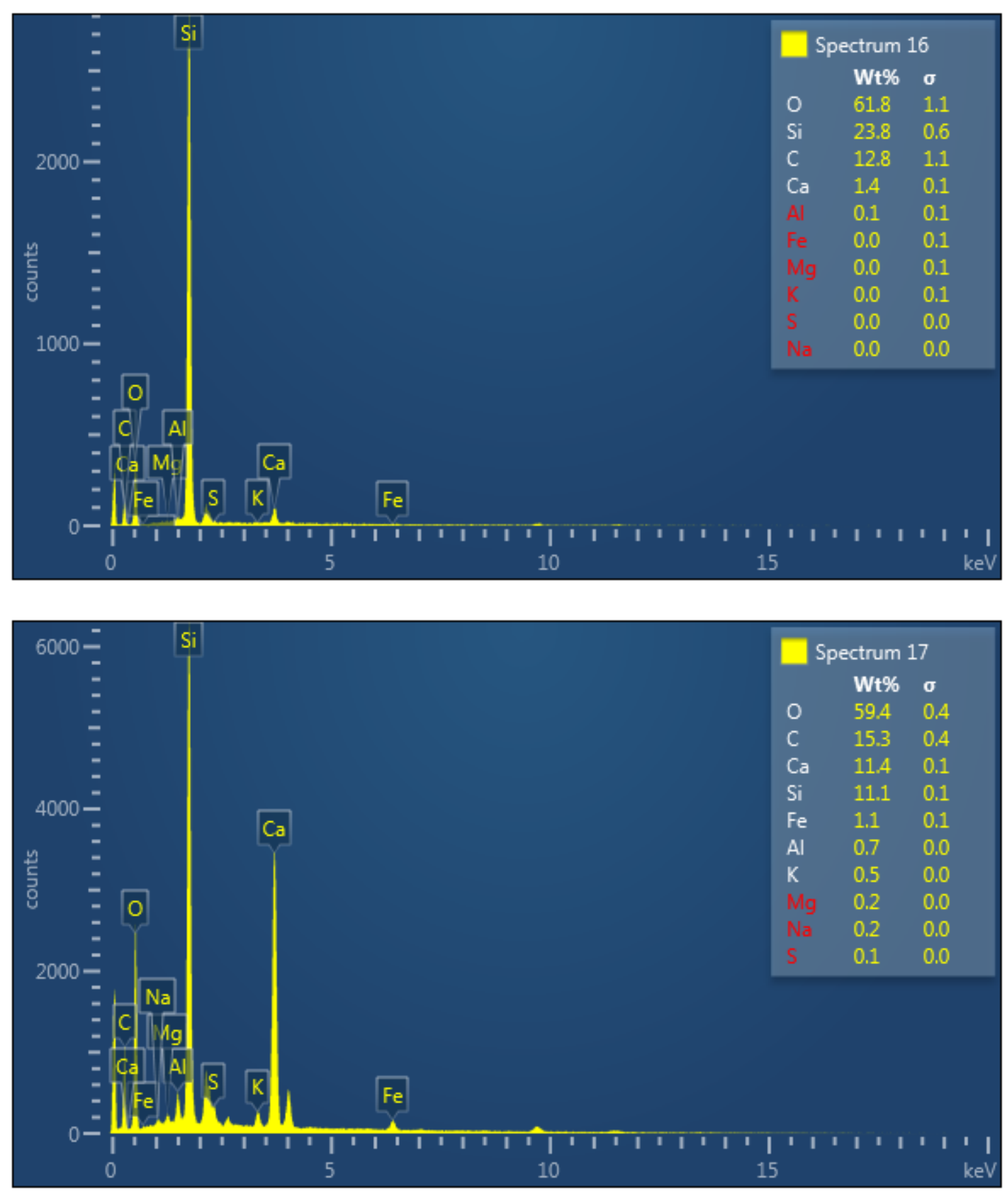


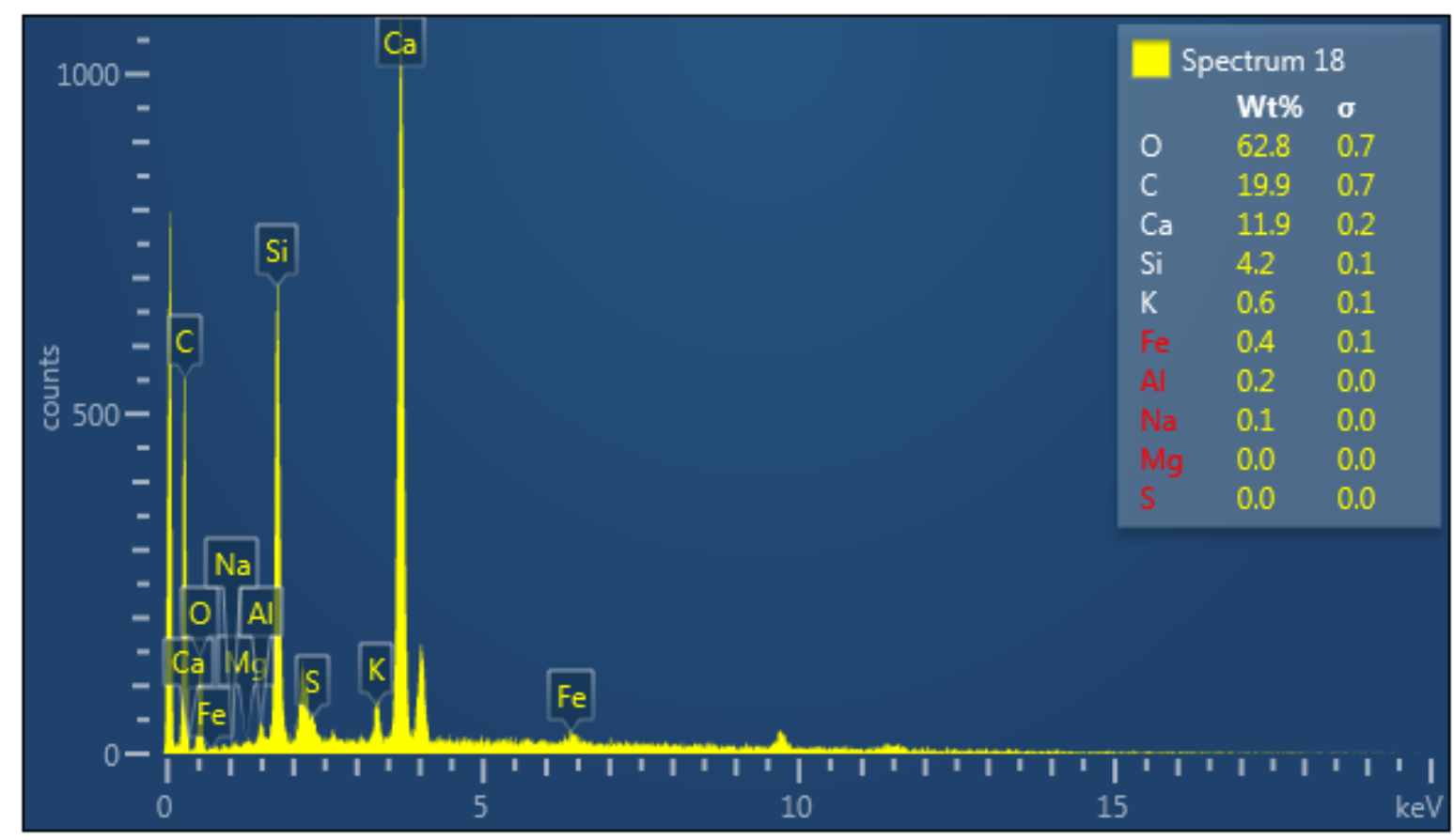

Analysis-1: P 10 S 26 -1

Electron Image 2

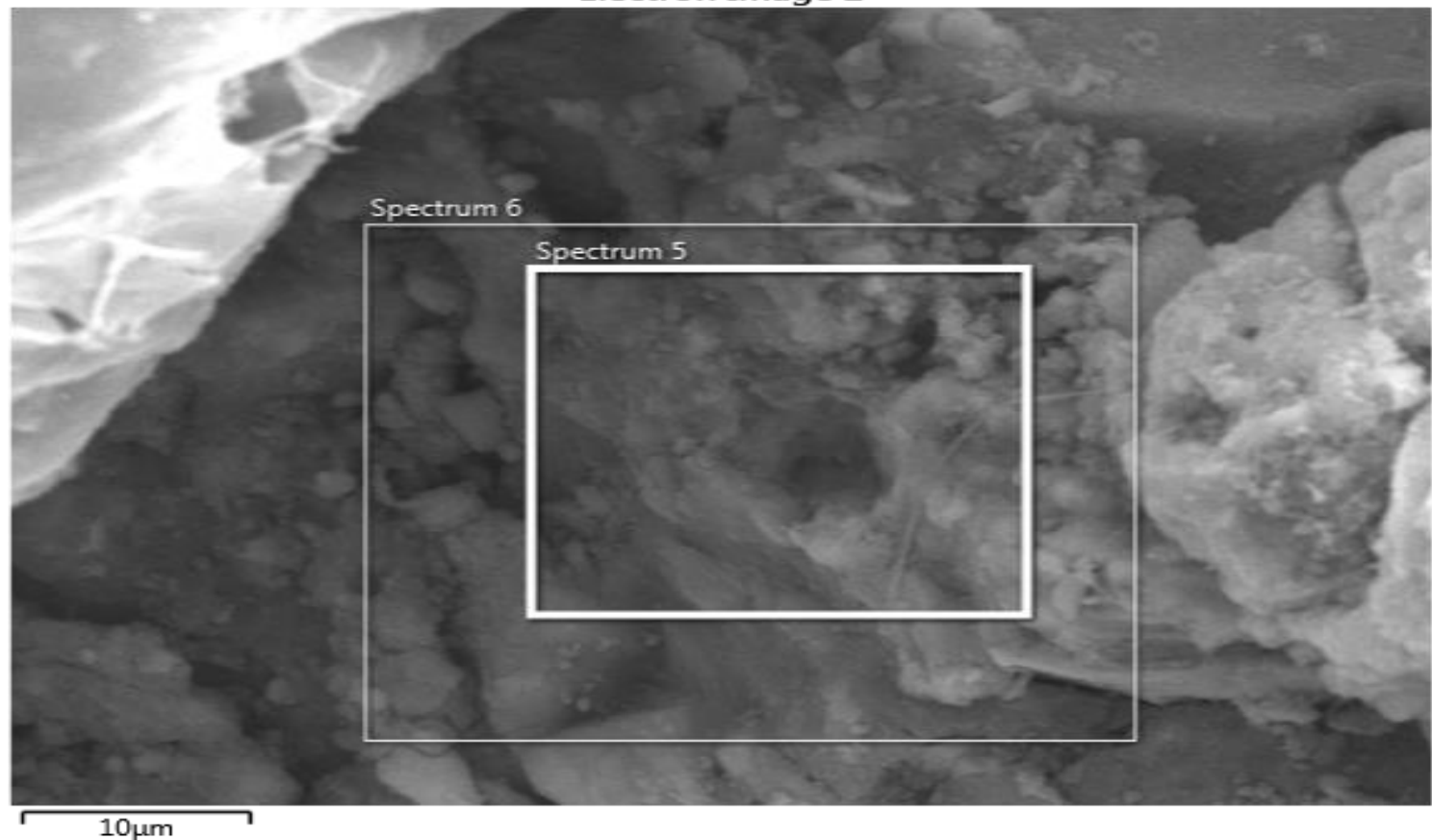



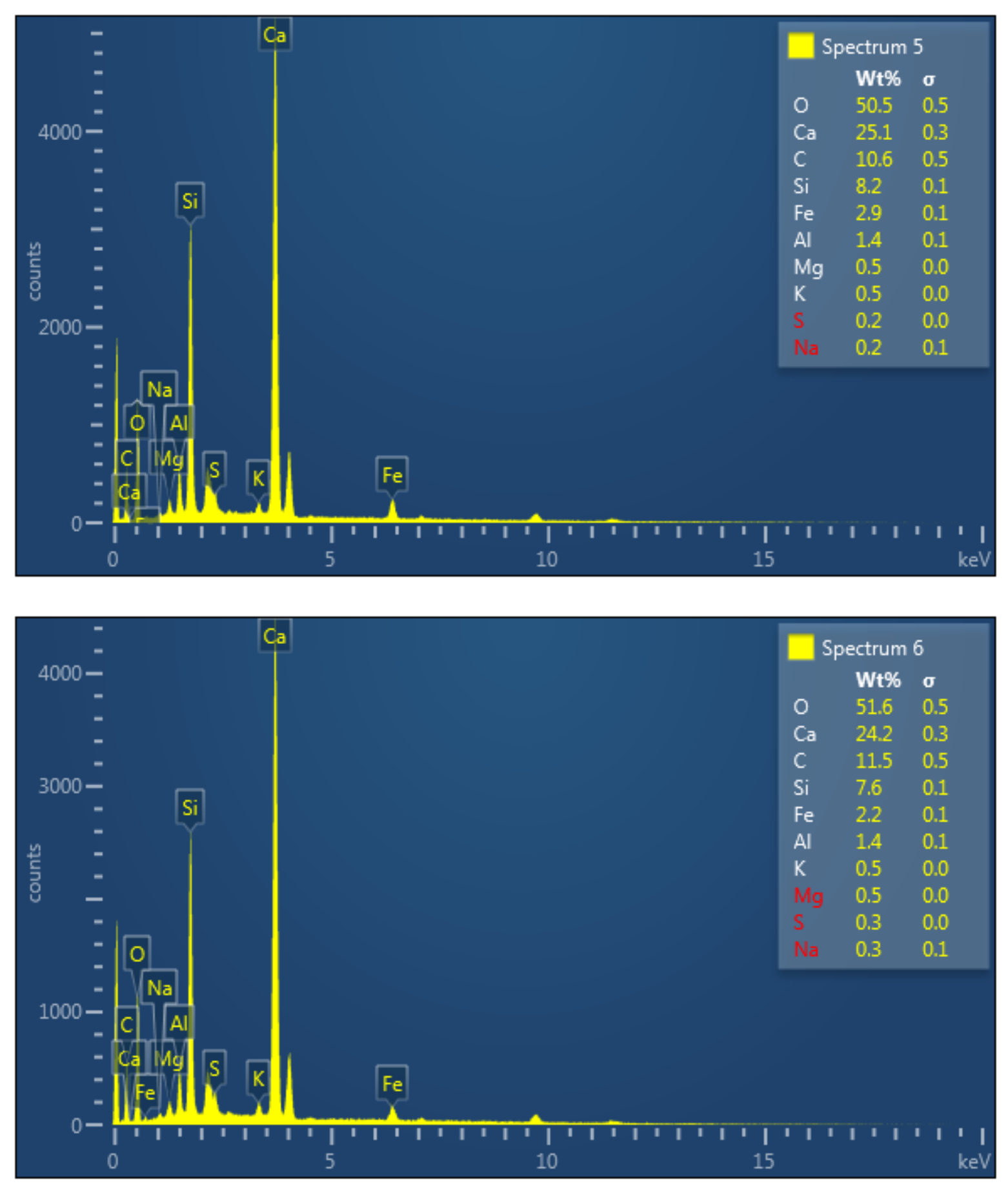
Analysis-2: P10 S26 -2

Electron Image 3
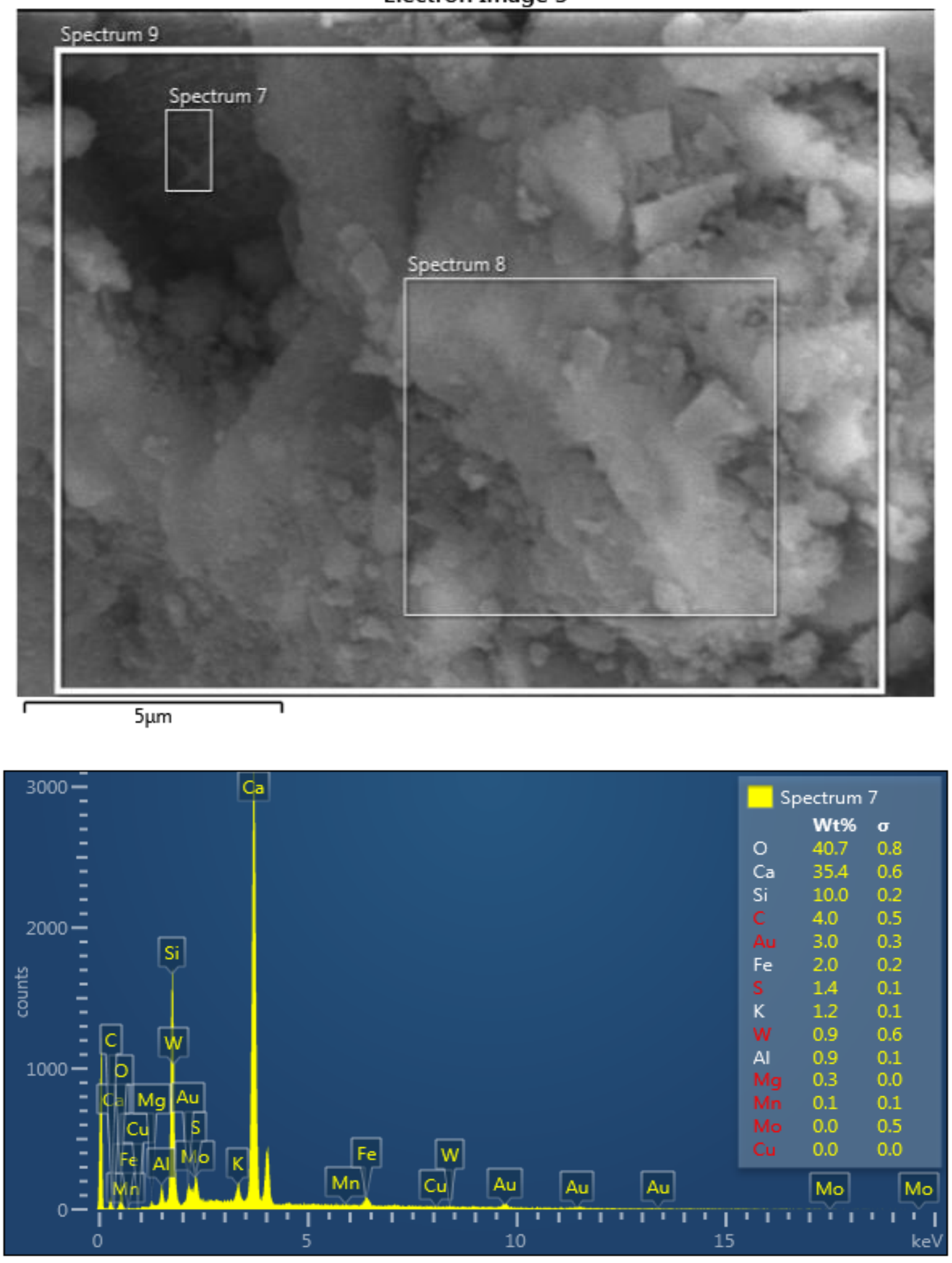

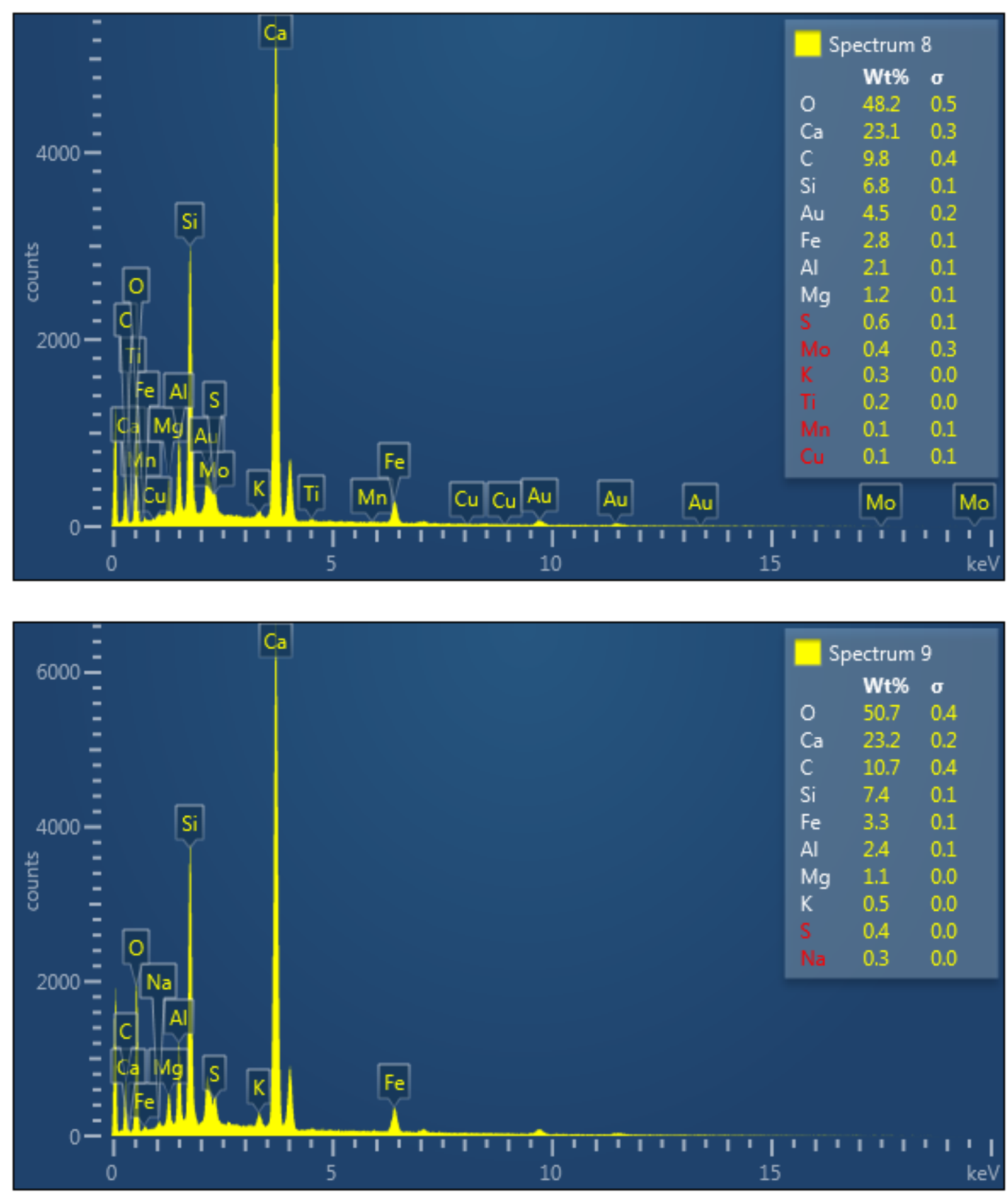


\section{Analysis-3: P10 S26 -3}

\section{Electron Image 4}
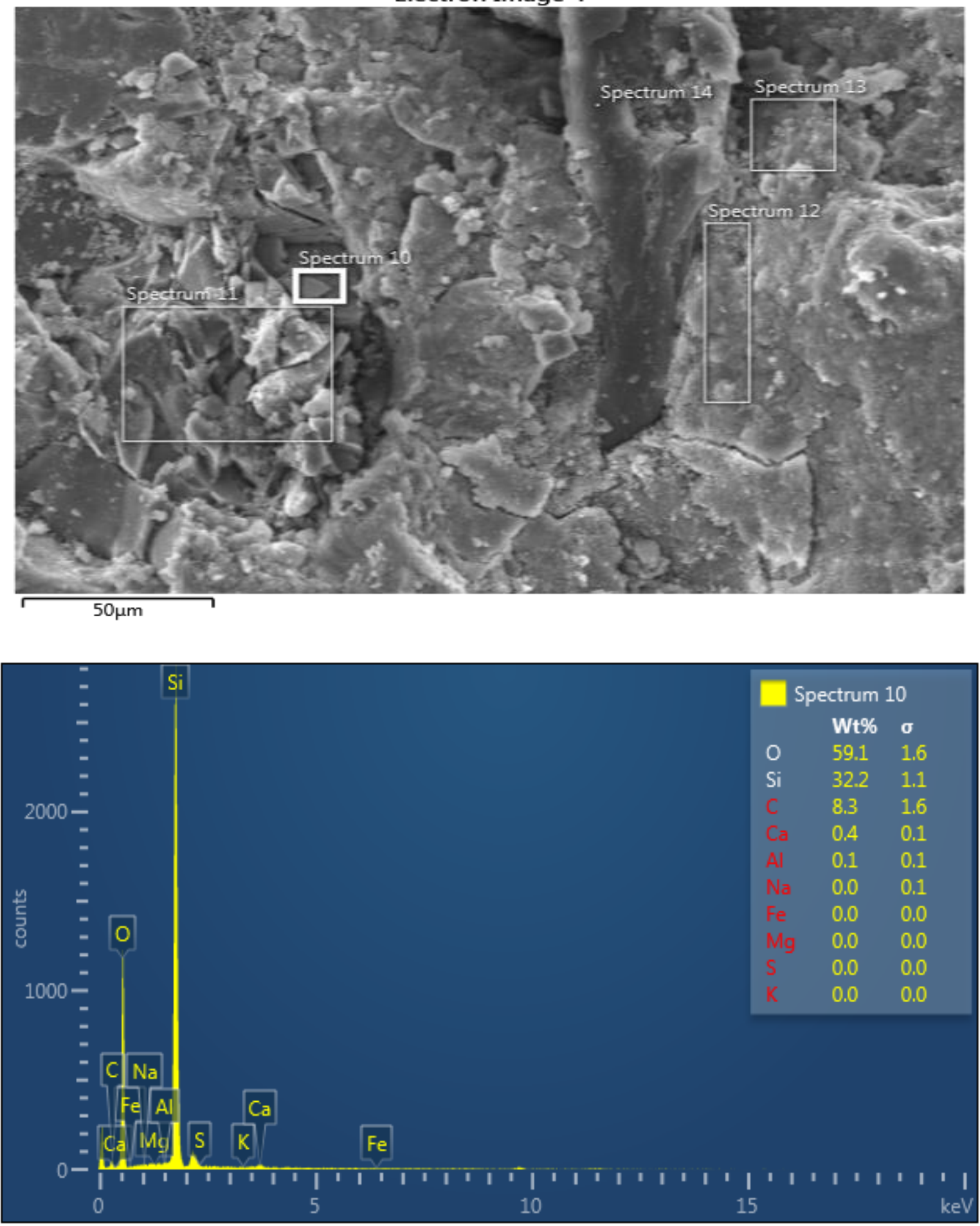

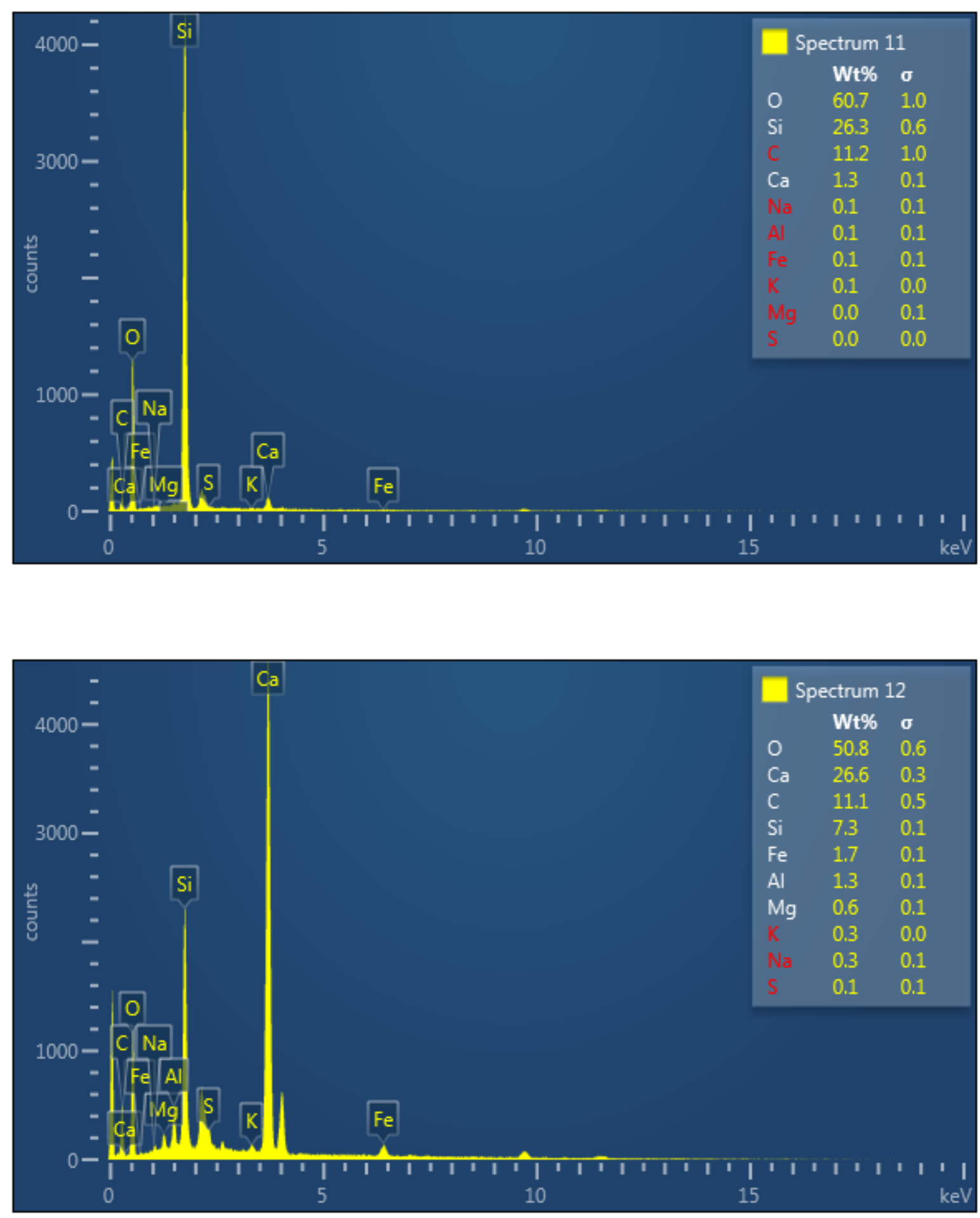

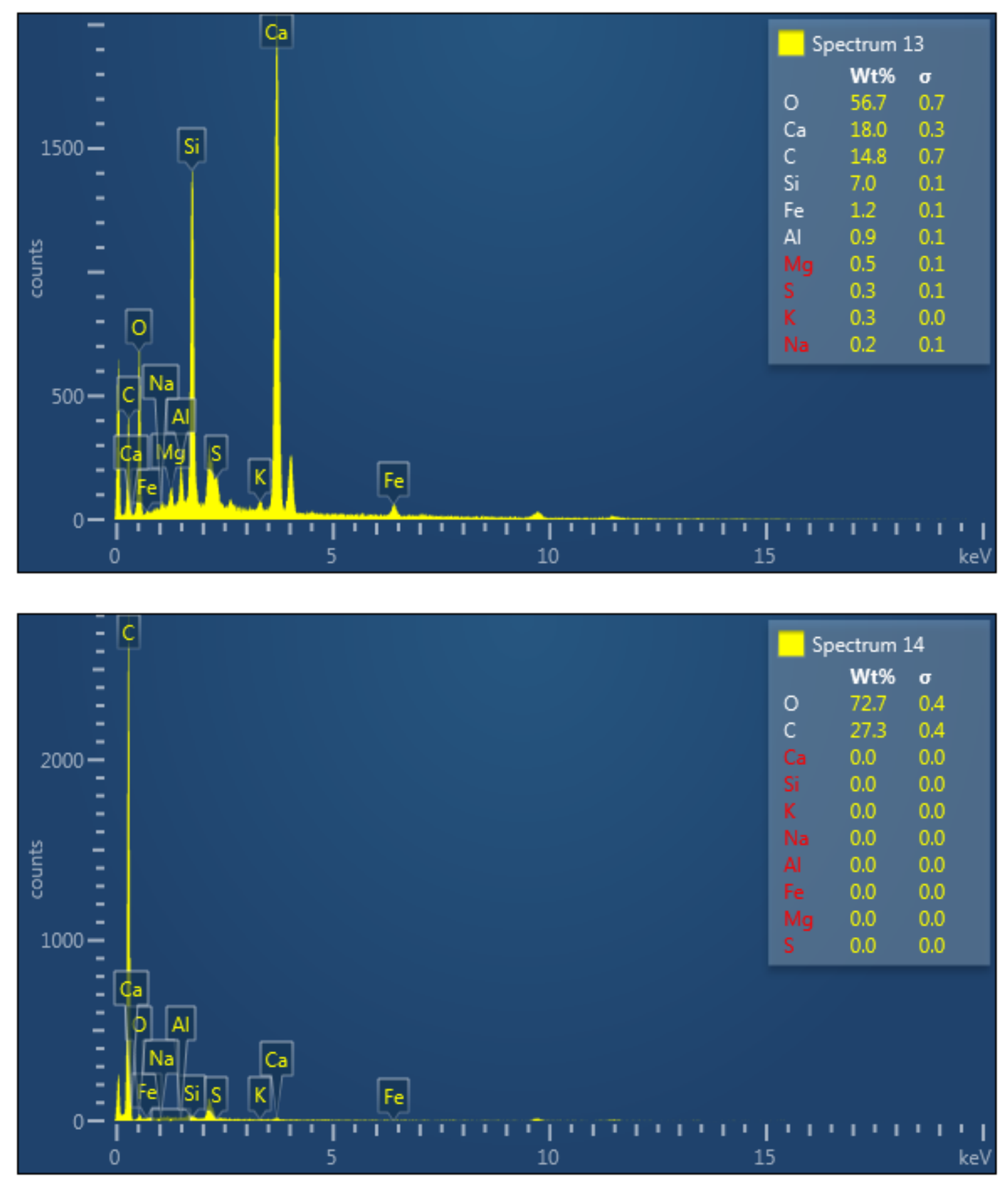


\section{REFERENCES}

Abhishek, K. M., Anshul, J. and Sanjay J. (2010), Rapid Chloride Permeability Test of Polypropylene and Glass Fiber Reinforced Concrete, International Journal of Engineering Research \& Technology, Vol. 2 Issue 5, pp. 780-818.

Afefy, M.H., Mahmoud, M. H., Nesreen , M. K. and Tarek ,M. F. (2014), Strengthening of Defected Beam-column Joints using CFRP, Journal of Advanced Research, Egypt, Vol.5,pp. $67-77$.

Ahmed, S.F.U., Maalej, M. and Paramasivam ,P. (2007), Flexural Response of Hybrid SteelPolyethylene Fiber Reinforced Cement Composites Containing High volume Fly Ash, Construction and Building Materials Vol.21, Issue 7, pp. 1088-1097.

ASTM Standard C150 /C150M-15-(2007), Standard Test Method for Standard Specification for Portland cement, ASTM International, West Conshohocken, PA, USA.

ASTM Standard C 942 (2007), Standard Test Method for Standard for Compressive Strength of Grouts for Preplaced-Aggregate Concrete in the Laboratory, ASTM International, West Conshohocken, PA, USA.

ASTM C39 / C39M (2007), Standard Test Method for Standard Compressive Strength of Cylindrical Concrete Specimens, ASTM International, West Conshohocken, PA, USA.

ASTM Standard C 1202 (2007), Standard Test Method for Electrical Indication of Concrete Ability to Resist Chloride Ion Penetration, ASTM International, West Conshohocken, PA, USA.

ASTM C1362 (2007), Standard Test Method for Flow of Freshly mixed Hydraulic Cement Concrete, ASTM International, West Conshohocken, PA, and USA.

ASTM Standard C 1609/C1609 (2007), Standard Test Method for Flexural Performance of FiberReinforced Concrete (Using Beam With Third-Point Loading) in the Laboratory, ASTM International, West Conshohocken, PA, USA.

ASTM Standard C1611/C161 (2007), Standard Test Method for Slump Flow of Self-Consolidating Concrete in the Laboratory, ASTM International, West Conshohocken, PA, USA. 
Aveston,J., Cooper,G.A., and Kelly, A. (1971), Single and Multiple Fractures in the Properties of Fiber Composites, IPC Science and Technology Press Ltd, Conf. Proc., USA, pp.15-24.

Backer, S. and Li, C.V. (1990), Tensile Properties of Synthetic Fiber Reinforced Mortar, ASCE Journal of Structural Engineering, Vom. 112, Issue 6, pp. 566-586.

ChandramouliK., Srinivasa Rao P., SeshadriSekhar T., PannirselvamN.and Sravana P. (2010), Rapid Chloride Permeability Test for Durability Studies on Glass Fiber Reinforced Concrete ,ARPN Journal of Engineering and Applied Sciences, India ,Vol. 5, Issue 3, pp. 1819-1877.

Chanvillard, G. and Rigaud, S. (2003), Complete Characterization of Tensile Properties of Ductal UHPFRC according to the French Recommendations and in Proc. of High Performance Fiber Reinforced Cement Composites, RILEM Publications SARL, Vol.3, pp. 21-34.

Chu, K. (2014), Behaviour of Composite Columns with High Performance Concrete, MASc Thesis, Dept. of Civil Engineering, Ryerson University.

Chu, K. and Hossain,K.M.A. (2014), Axial Load Behaviour of ECC-filled Steel Tube Columns, Katie Chu and Khandaker M.A. Hossain, CSCE 2014 4th International Structural Specialty Conférence, Halifax, NS, May 28 to 31.

Chu. K. and Hossain, K.M.A. (2015), Axial Load Behaviour of Engineered Cementitious Composite Concrete-filled Steel Tube Columns, Journal Constructional Steel Research, (in press).

Esnaola, A., Tena, I., Aurrekoetxea, I., Gallego, I. and Ulacia, I. (2016), Effect of Fiber Volume Fraction on Energy Absorption Capabilities of E-glass/polyester Automotive Crash Structures, Composites Part B, Vol.85, pp. 1-7.

Ferguson Chemical Innovation. (2015), http://www.fergusonchemical.com, (Accessed 21-Nov2015).

Fischer, G., Wang, S. and Li, V.C. (2003), Design of Engineered Cementitious Composites for Processing and Workability Requirements, Seventh International Symposium on Brittle Matrix Composites, Warsaw, Poland, pp. 29-36. 
Fischer, G. and Li, V.C. (2006), Proceedings of International RILEM Workshop on High Performance Fiber Reinforced Cementitious Composites in Structural Application, RILEM Publications SARL, pp. 580.

Galal, F., Khan, I., Shehab, M. and Abbas, W. (2015), Evaluation of PVA and PBI-based Engineered-Cementitious Composites Under Different Environments, Construction and Building Materials, Vol. 85 ,Issue 3 ,pp. 109-118.

Grace Construction Products. (2015), https://grace.com/Construction/Pages/LocationLanguage.aspx. (Accessed date: 20-Nov-2015).

Hillerborg, A. (1983), Analysis of One Single Crack in Fracture Mechanics of Concrete, edited by F.H. Wittmann, Elsevier Science Publishers, ,Amsterdam, pp. 223-249.

Hossain, K. M. A. (2014), Behaviour of ECC Link Slab for Joint-free Bridge Construction, Proc. Structural Faults and Repair, Imperial College, London, UK.

Hossain, K.M.A., Lachemi, M. and Sabouni, A.R. (2008), Application of Maturity Method to Slipforming Operations: Performance Validation; Cement and Concrete Composite, Volume 29, Issue 2, pp. 290-299.

Hossain, K.M.A., Lachemi, M., Sahmaran, M., Lotfy, A. and Shehata, M. (2010), Properties of Controlled Low-strength Materials Incorporating Cement Kiln Dust and Slag, Volume32, Issued September, pp. 623-629.

Hossain, K.M.A., Lachemi, M., Sammour, M. and Sonebi, M. (2013), Strength and Fracture Energy Characteristics of Self -consolidating Concrete Incorporating Polyvinyl alcohol, Steel and Hybrid fibers, Construction and Building Materials, Vol. 45 ,Issue August , pp. 20-29.

Hossain, K. M. A., and N. Vinay, N. (2012), Shear Bond Resistance of Composite Slabs with High Performance Concrete, The 6th International Conference on Advanced Composite Materials in Bridges and Structures, ACMBS-VI, May 22 to 25, Kingston, Ontario, Canada,.

Hossain, K.M. A., Samani, S.G., and Ehsani, Y.A. (2015), Prediction of Strength Properties of Engineered Cementitious Composites using Artificial Neural Network, CSCE conference, Building on Our Growth Opportunities, May 27 to 30, Regina, SK, Canada. 
Hossain, K.M.A. (2014), Structural performance of Ultra-High Performance Concrete Beams, Research Report, Department of Civil Engineering, Ryerson University, pp. 89.

Hossain, K.M.A. and Anwar, M.S. (2014), Properties of Green Engineered Cementitious Composites Incorporating Volcanic Materials, Structural Faults + Repair, 2014, July 8 to 10, Imperial College, London, UK.

Hossain, K.M.A., Ametrano D., Mak C., and Lachemi M. (2011), Bond strength and Development Length of GFRP bars in Ultra-high Performance Concrete, Ministry of Transport Ontario (MTO) Technical Report (HIIFP Research Project), May, pp. 89.

Hossain, K.M.A., Ametrano, D. and Lachemi, M. (2014), Bond Strength of GFRP bars in High Strength Concrete, ASCE Journal of Materials in Civil Engineering, Vol.26, Issue 3, pp. 449456.

Hossain, K.M.A., Ametrano, D., Mak, C. and Lachemi, M. (2011), Bond Strength and Development Length of GFRP Bars in Ultra-High Performance Concrete, Ministry of Transport Ontario (MTO) Technical Report (HIIFP Research Project), May 2011, pp. 89.

Hossain, K.M.A., and Anwar, M.S. (2014), Strength and Deformation Characteristic of ECC Link Slab in Joint-Free Bridge Decks, Istanbul Bridge Conference, August 11 to 13, Istanbul, Turkey.

Hossain, K.M.A. and Ghatrehsamani, S. (2015), Flexural Fatigue Performance of ECC Link Slabs for Bridge Deck Applications, 8th New York City Bridge Conference, and August 24 to 25, 2015.

Hossain, K.M.A. and Lachemi, M. (2010), Fresh, Mechanical, and Durability Characteristics of Self-Consolidating Concrete incorporating Volcanic Ash, ASCE Journal of Materials in Civil Engineering, Vol. 22, Issue 7 ,pp. 651-657.

Hossain, K.M.A. and Taormina, A. (2012), Axial Load Behaviour of Profiled Composite Walling System under Elevated Temperatures, CSCE 3rd Int. Structural Specialty Conference, June 6 to 9 , Edmonton, Canada. 
Hossain, K.M.A., Kayes, M.A., Mavani, M.B. and Lachemi M. (2013), Influence of ECC Mixture on the Structural Performance of Link Slabs in Bridge Decks, $3^{\text {rd }}$ CSCE Specialty Conference on Material Engineering \& Applied Mechanics, May 29 to June 1 Montréal, Québec.

Hossain, K.M.A., Mak, C. and Ametrano, D. (2012), GFRP reinforced UHPC Composites for Sustainable bridge construction, Canadian Civil Engineer, Vol. 29.1, Issue Spring, pp. 1215.

Hossain, K.M.A., Lachemi, M., Sammour, M. and Sonebi,M. (2013), Strength and Fracture Energy Characteristics of Self-consolidating Concrete Incorporating Polyvinyl Alcohol, Steel and Hybrid Fibers, Construction and Building Materials, Vol.45, Issue August ,pp. 20-29.

Hossain, K.M.A., Lachemi, M., Sammour, M. and Sonebi, M. (2012), Influence of Polyvinyl Alcohol, Steel and Hybrid Fibers on Fresh Properties of Self-consolidating Concrete, Construction and Building Materials, Vol. 3,Issue 6 ,pp 320-325.

Issani R. and Hossain K.M.A. (2013), High performance ECC floor Slabs in Coupled Shear Wall Structures, $3^{\text {rd }}$ CSCE Int. Spec. Conf. Material Eng. \& Applied Mech, May 29 to June 1, Montréal, Canada.

Issani. R. (2012), Flexural Behavior of ECC Coupling Slab in Coupled Shear Wall Structures, MASc Thesis, Civil Engineering, Ryerson University,Canada.

Jang, J.G., Kim, H.K., Kim, T.S., Min, B.J. and Lee, H.K. (2014), Improved Flexural Fatigue Resistance of PVA Fiber-reinforced concrete Subjected to Freezing and Thawing Cycles, Construction and Building Materials, Vol.59,Issue 5 ,pp. 129-135.

Jiang, G. and Yudong H. (2015), Interfacial Characterization, Control and Modification of Carbon Fiber Reinforced Polymer Composites, Composites Science and Technology, Vol. 121 ,Issue 2, pp. $56-72$.

Johnson, C.D. (2001), Fiber Reinforced Cements and Concretes, Advances in Concrete Technology, Vol. 3, Gordon and Breach Science Publishers.

Juarez, C.A., Fajardo, G., Monroy, S., Valdez, P. and Camille, M. (2015), Comparative Study Between Natural and PVA fibers to Reduce Plastic Shrinkage Cracking in Cement-based Composite, Construction and Building Materials, Vol. 91,Issue May, pp. 164-170. 
Kinayekari, V. D. and Kishor, K. (2014), The Effect of Addition of Carbon Fibers on Mechanical Properties of High Strength Concrete, International Journal of Innovative Research in Science, Engineering and Technology, Vol. 3, Issue 1, pp. 321-343.

Krenchel, H. and Stang, H. (1989), Stable Micro cracking in Cementitious Materials in Brittle Matrix Composites, .Elsevier Applied Science, Journal of Structural Division,ASCE, Vol. 102,Issue 5, pp. 899-917.

Kurtis, B.D. (2007), Natural Fiber Reinforced Concrete, University of Washington, Fall 2007, CEE 8813, pp. 24-30.

Lachemi, M., Hossain, K.M.A., Lambros, V.B., and Bouzoubaa, N. (2003), Development of CostEffective Self-Consolidating Concrete Incorporating Fly Ash, Slag Cement, or ViscosityModifying Admixtures, ACI Materials Journal, Vol.100,Issue 5 ,pp. 419-425.

Li, V.C. (1993), Micromechanics to Structural Engineering ,The Design of Cementitious Composites for Civil Engineering Applications,JSCE Journal of Structure, Mechanics and Earthquake Engineering ,Vol.10,Issue 2,pp. 37-48.

Li, V.C., Fischer, G., Kim, Y.Y., Lepech, M., Qian, S., Weimann, M. and Wang, S. (2003), Durable Link Slabs for Joint Less Bridge Decks Based on Strain-hardening Cementitious Composites, Report for Michigan Department of Transportation RC-1438, USA.

Li, V.C. and Leung, C.K.Y. (1992), Steady State and Multiple Cracking of Short Random Fiber Composites, ASCE Journal of Engineering Mechanic, Vol.118, issue 11, pp. 2246-2264.

Li, V.C. and Yang, E.H. (2007), Self-healing in Concrete Materials in Self-Healing Materials, Alternative Approach to 20 Centuries of Materials Science, pp. 161-193.

Li, V.C. and Wang, S. (2002), Failure Mode and Structural Ductility of GFRP Reinforced Engineered Cementitious Composite Beams, ACI Materials Journal, Vol.99 , Issue 1, pp. 11-21.

Li, V.C., Wang, S., Wu. C., Wang .S. Ogawa, A. and Saito, T. (2014), Interface Tailoring for StrainHardening PVA-ECC, ACI Materials Journal, Vol.99, Issue 5, pp.463-472. 
Li, V. C. (2012), Tailoring ECC for Special Attributes, International Journal Concrete Structural Materials Vol.6, Issue 3, pp. 135-44.

Li, V.C. (1993). The Design of Cementitious Composites for Civil Engineering Applications, JSCE Journal Structure Mechanical Earthquake Engineering, Vol.10, Issue 2, pp.37-48.

Li, V.C., Wang, S. and Wu, C. (2001), Tensile Strain-hardening Behavior of PVA-ECC, ACI Material Journal 2001, Vol. 98,issue 6, pp. 483-92.

Mak, C., Hossain, K.M.A. and Lachemi, M. (2011), Splice Length of GFRP Bars in UHPC, $2^{\text {nd }}$ CSCE Int. Engineering Mechanics and Materials Specialty Conf., June 14-17, Ottawa.

Naaman, A. E.,Wongtanakitcharoen, T. and Hauser, G.(2005), Influence of Different Fibers on Plastic Srinkage Cracking of Concrete,ACI Material Journal, Vol. 32,pp. 102-107.

Naaman, A.E. and Reinhardt, H.W. (2003), Setting the Stage Toward Performance-based Classification of FRC composites, In High Performance Fiber Reinforced Cement Composites (HPFRCC-4), Proc. Of the 4th Int'I RILEM Workshop, eds. Published by RILEM SARL.

Nemati, K. M. (2005), Progress in Concrete Technology, CM 425, Winter 2005-2015, University of Washington, pp. 102-111.

Noguchi,T., Tomosawa, F., Nemati, M.K., Chiaia, B.M. and Fantilli, A. P. A. (2009), Practical Equation for Elastic Modules of Concrete, ACl Structural Journal,Title no.106-S64,pp. 690-696.

Ozbay E., Karahan O., Lachemi M., and Hossain K.M.A. and Atis C.D. (2012), Investigation of Properties of ECC Incorporating High Volumes of Fly Ash and Metakaolin, ACI Materials Journal, Vol.109,Issue 5,pp. 565-571.

Ozbay, E. Karahan, O. Lachemi, M. Hossain, K. M. A. and Atis C. D. (2013), Dual Effectiveness of Freezing-Thawing and Sulphate Attack on High-Volume Slag-Incorporated ECC. Composites Part B: Engineering, Vol. 45, Issue 1, pp. 1384-1390.

Rafiei, S., Hossain, K.M.A. Lachemi, M., Behdinan, K. and Anwar, M. (2013), FE modeling of Double Skin Profiled Composite Shear Wall System under in-plane Loadings, Engineering Structures, Vol.56,Issue Nov, pp. 46-57. 
Rafiei, S. (2011), Behaviour of Double Skin Composite Shear Wall under in-plane Monotonic, Cyclic and Impact Loading, PhD Thesis, Dept. of Civil Engineering, Ryerson University, pp. 315.

Rafiei, S.,Hossain, K.M.A.Lachemi, M. and Behdinan, K. (2015), Profiled Sandwich Composite Wall with High Performance Concrete Subjected to Monotonic Shear, Journal of Constructional Steel Research, Vol. 107,Issue 5. pp. 124-136.

Ranade ,R., Victor, C. Li., Michael, D. S., Todd ,S. R., Jason R. and William, F. H (2011), Development of High strength High Ductility Concrete, $2^{\text {nd }}$ International RILEM Conference, Brazil , Vol. 98 ,Issue 60,pp. 483-492.

Ranade ,R., Victor, C. Li., Michael, D. S., Todd ,S. R., Jason R. and William, F. H (2013), Micromechanics of High-Strength, High-Ductility Concrete, $\mathrm{ACl}$ Materials Journal,Vol.110,Issue M33, pp. 375-384.

Ranade, R., Victor, C. Li. and William, F. H (2015), Tensile Rate Effects in High Strength-High Ductility Concrete, ELSEVIER, Cement and Concrete Research,Vol. 68 ,Issue 15, pp. 94104.

Roel, Marissen. (2011), Design with Ultra Strong Polyethylene Fibers, Materials Science and Applications, Vol. 2, Issue 5, pp. 319-330.

Romualdi, J.P. and Mandel, J.A. (1964), Tensile Strength of Concrete Affected by Uniformly Distributed Closely Spaced Short Lengths of Wire Reinforcement Proc., ACl Journal, Vol. 61, Issue 6 and pp. 657-671.

Sahmaran, M. and Ozgur I.Y. (2007), Hybrid Fiber Reinforced Self-compacting Concrete with a High-Volume Coarse Fly Ash, Construction and Building Materials, Vol. 21 ,pp. 150-156.

Şahmaran M.L., Lachemi M., Hossain K.M.A., and Li, V.C. (2009), Influence of Aggregate Type and Size on the Ductility and Mechanical Properties of ECC, ACl Materials Journal, Vol. 6, Issue 3, pp. 308-316.

Şahmaran M.L., Lachemi M., Hossain K.M.A., Ranade R. and Li, V.C. (2010), Internal Curing of ECCs for Prevention of Early Age Autogenous Shrinkage Cracking, Cement and Concrete Research, Vol.3, Issue 10, pp. 893-901. 
Samani, S.G. (2015), Structural Performance of Link Slabs Subjected to Monotonic and Fatigue Loading Incorporating Engineered Cementitious Composites, MASc Thesis, Dept, of Civil Engineering, Ryerson University.

Sherir, M.A.A. (2012), Fracture, Fatigue and Creep Performance of ECC Mixtures with Reference Bridge Deck Applications, MASc Thesis, Dept. of Civil Engineering, Ryerson University.

Sherir, M.A.A., Hossain, K.M.A., and Lachemi, M. (2013), Behaviour of Engineered Cementitious Composites Under Fatigue Loading, 3rd Specialty Conference on Material Engineering \& Applied Mechanics, May 29 to June 1, Montréal, Québe.

Sherir, M.A.A., Hossain, K.M.A., and Lachemi, M. (2014), Fracture Energy Characteristics of Engineered Cementitious Composites Incorporating Different Aggregates, CSCE 2014 4th International Structural Specialty Conference, May 29 to June 1, Halifax, NS.

Sato, Y., Walgreen, J.C. (2000), Mechanical Characteristics of the Multi-model Fiber Reinforced Cement based Composites, Proceedings of the $5^{\text {th }}$ International RILEM Symposium, BEFIB, and pp. 791-800.

Sherir, M. A. A., Hossain, K.M.A. and Lachemi, M. (2014), Fracture Energy Characteristics of Engineered Cementitious Composites Incorporating Different Aggregates, 4th International Structural Specialty Conference, May 29 to June 1, CSCE, Halifax, NS.

Sherir, M. A. A., Hossain, K.M.A., and Lachemi, M. (2015), Structural Performance of Polymer Fiber Reinforced Engineered Cementitious Composites Subjected to Static and Fatigue Flexural Loading, Polymers, Vol. 7, Issue 2015, pp. 1299-1330.

Soulioti, D. V., Barkoula, N. M., Paipetis, A. and Matikas, T. E. (2011), Effects of Fiber Geometry and Volume Fraction on the Flexural Behavior of Steel-Fiber Reinforced Concrete, Blackwell Publishing Ltd Strain, Greece, pp. 535-541.

Stanley, B., Li, V.C. and Wang, Youjiang. (1988), Modeling of the Fiber Pull-out from a Cement Matrix, The international Journal of Cement Composites and Lightweight Concrete, Vol. 10 ,Issue 3 ,pp. 143-149. 
Taormina, A. (2012), Axial Load Behaviour of Double Skin Composite Walls Subjected to Elevated Temperatures, MASc Thesis, Dept. of Civil Engineering, and Ryerson University.

Taormina, A., and Hossain, K.M.A.(2013), Post-Fire Axial Load Behaviour of Double Skin Composite Walls Incorporating Ultra-High Performance Concrete, 3rd Specialty Conference on Material Engineering \& Applied Mechanics, May 29 to June 1.Montréal, Québec.

Wang, S. and Victor, Coli. (2003), Polyvinyl Alcohol Fiber Reinforced Engineered Cementitious Composite, Department of Civil and Environmental Engineering, University of Michigan, USA.

Wang, S. Backer and Li, V.C., (1983), An Experimental Study of Synthetic Fiber Reinforced Cementitious Composite, Journal of Materials Science, Vol, 22, pp. 4281-4291.

Wile, K. and Naaman, A.E. (2010), Bond-Slip Mechanisms of Steel Fibers in Concrete, in ACI Materials Journal, Vol. 88, No. 2, pp. 135-145.

Wong, D.W.S., Camirand, W.M., Pavlath, A.E.,Krochta, J.M., Baldwin, E.A. andNisperos-Carriedo, M.O.(1994), Development of Edible Coatings for Minimally Processed Fruits and Vegetables in Edible Coatings and Films to improve Food Quality, Techonomic Publishing Company, Lancaster, pp. 65-88.

Wu,R.W.,Chen,B., Yao,D. and Zhang,D. (2001), Effect of Coarse Aggregate Type on Mechanical Properties of High-performance Concrere,Cement and Concrete Research, Vol. 31,Issue 2001,China, pp. 1421-1425.

Yu, R., Onna, D.V. and Spiesz, P. (2016), Development of Ultra-Lightweight Fiber Reinforced Concrete Applying Expanded Waste glass, Journal of Cleaner Production, Vol.112, pp. 691-700.

Yun, H. (2013), Effect of Accelerated Freeze-Thaw Cycling on Mechanical Properties of Hybrid PVA and PE Fiber-Reinforced Strain-Hardening cement-based Composites (SHCCS), Composites: Part B (52), pp. 11-20. 